NBER WORKING PAPER SERIES

\title{
MANUFACTURING RISK-FREE GOVERNMENT DEBT
}

\author{
Zhengyang Jiang \\ Hanno Lustig \\ Stijn Van Nieuwerburgh \\ Mindy Z. Xiaolan \\ Working Paper 27786 \\ http://www.nber.org/papers/w27786 \\ NATIONAL BUREAU OF ECONOMIC RESEARCH \\ 1050 Massachusetts Avenue \\ Cambridge, MA 02138 \\ September 2020, Revised February 2022
}

First version: 07/08/2020. We are grateful to David Andalfatto, Cristina Arellano, Adrien Auclert, Aydogan Alti, David Beckworth, Jonathan Berk, Saki Bigio, Luigi Boccola, Lorenzo Bretscher, Mike Chernov (discussant), Hal Cole, Pierre Collin-Dufresne, Alexandre Corhay (discussant), Pierre-Olivier Gourinchas, Peter DeMarzo, Sebastian DiTella, Francois Gourio, Lars Hansen, Patrick Kehoe, Ralph Koijen, Arvind Krishnamurthy, Matteo Maggiori, Ellen McGrattan, Carolin Pflueger, Victor Rios-Rull, Clemens Sialm, Alp Simsek (discussant), Adi Sunderam (discussant), Alan Taylor, Sheridan Titman and seminar participants at Stanford University (macro and finance), Columbia University (macro and finance), the University of Pennsylvania, Duke-UNC University research triangle seminar, Imperial College London, UT Austin, University of Lausanne, University of Rochester, University of Maryland, the University of Wisconsin, NBER IFM, 2021 JHU Carey Finance Conference, 2021 FIRS, 2021 WFA, the AEA 2022, and the European Winter Meetings of the Econometric Society for helpful comments. Yuan Tian and Jeremias Huber provided outstanding research assistance. We gratefully acknowledge financial support from NSF award 2049260. The views expressed herein are those of the authors and do not necessarily reflect the views of the National Bureau of Economic Research.

NBER working papers are circulated for discussion and comment purposes. They have not been peer-reviewed or been subject to the review by the NBER Board of Directors that accompanies official NBER publications.

(C) 2020 by Zhengyang Jiang, Hanno Lustig, Stijn Van Nieuwerburgh, and Mindy Z. Xiaolan. All rights reserved. Short sections of text, not to exceed two paragraphs, may be quoted without explicit permission provided that full credit, including $\odot$ notice, is given to the source. 
Manufacturing Risk-free Government Debt

Zhengyang Jiang, Hanno Lustig, Stijn Van Nieuwerburgh, and Mindy Z. Xiaolan

NBER Working Paper No. 27786

September 2020, Revised February 2022

JEL No. F34,G12,H62,H63

\section{ABSTRACT}

Governments face a trade-off between insuring bondholders and insuring taxpayers against output risk. If they insure bondholders by manufacturing risk-free zero-beta debt, then their capacity to insure taxpayers by lowering tax rates or raising government spending during recessions is limited. Using asset pricing tools, we develop a sufficient statistic for taxpayer insurance possibilities over different horizons, and characterize it analytically as a function of the debt/ output, spending/output, and pricing kernel dynamics. With permanent shocks, taxpayers can only be insured over short horizons through counter-cyclical debt issuance. The horizon shrinks as the debt/output ratio reverts faster to its mean. The trade-off worsens if the output shocks are transitory instead of permanent. As the world's safe asset supplier, the U.S. relies on strongly counter-cyclical debt issuance to provide more short-run insurance to its taxpayers.

Zhengyang Jiang

Kellogg School of Management

Northwestern University

2211 Campus Drive

Evanston, IL 60610

zhengyang.jiang@kellogg.northwestern.edu

Hanno Lustig

Stanford Graduate School of Business

655 Knight Way

Stanford, CA 94305

and NBER

hlustig@stanford.edu
Stijn Van Nieuwerburgh

Columbia University

Graduate school of Business

Uris Hall, office 809

3022 Broadway

New York, NY 10027

and NBER

svnieuwe@gsb.columbia.edu

Mindy Z. Xiaolan

University of Texas at Austin

2110 Speedway B6600

Austin, TX 78703

mindy.xiaolan@mccombs.utexas.edu 
Safe assets play an important role in the financial system as collateral and store of value. As a result of their ability to tax households and corporations, governments are natural suppliers of such safe assets (see Gorton and Ordoñez, 2022). ${ }^{1}$ Governments have an incentive to manufacture safe debt, because safe debt earns sizeable convenience yields, lowering the interest they must pay on their debt.

Manufacturing a safe, zero-beta debt portfolio is not a free lunch for the government. Rather, it comes at the expense of protecting taxpayers from aggregate output risk, by spending more and taxing less in the wake of adverse macroeconomic shocks. Insuring bondholders limits taxpayer insurance. In this paper, we analytically characterize this trade-off at different horizons. The analysis of this trade-off requires a dynamic asset pricing model with priced aggregate risk, because, the question of insuring bondholders and taxpayers is a valuation question at its core.

The government bond portfolio is backed by a long position in a claim to tax revenue and a short position in a claim to government spending. The Treasury's long position in the tax claim exceeds the short position in the spending claim by the value of outstanding debt. To ensure riskfree debt, defined as a zero beta on government debt $\beta^{D}=0$ in the language of asset pricing, the claim to tax revenues needs to be less risky than the spending claim, i.e., a lower beta than the spending claim: $\beta^{T}<\beta^{G}$. Recast in the language of Modigliani-Miller, the claim to tax revenue can be regarded as the government's unlevered asset, which is divided into the government debt and the claim to government spending. To manufacture risk-free debt, the spending claim has to be a levered version of the tax claim. Therefore, just as the equity of a firm has to be riskier than its assets in order to generate risk-free debt, the government's spending beta has to be higher than its tax beta to ensure a zero-beta debt. The tax beta has to be low.

The tax claim has a low beta if the present discounted value (PDV) of future tax revenues increases in bad times, times in which the investor's marginal utility is high. Since the taxpayers pay the taxes, they have a short position on the tax revenue claim. From their perspective, a low-beta tax claim is a risky tax liability. The larger the amount of outstanding debt, the more levered the government becomes, and the larger the gap between the tax beta and the spending beta needs to be to keep the debt risk-free. As the debt grows, the beta of the tax claim has to go to zero, holding fixed the spending beta. The trade-off between insuring taxpayers and bondholders steepens.

To characterize this trade-off analytically over different horizons, we establish two key results. First, the riskiness of the surplus process over any finite horizon $h$ is a sufficient statistic for the marginal insurance benefits enjoyed by taxpayers. The more risk there is in the surpluses, the more insurance is provided to taxpayers. We measure taxpayer insurance possibilities over each $h$ by the cash-flow beta of the cumulative surpluses generated over the next $h$ periods, $\beta_{t}^{S, C F}(h)$. Second,

\footnotetext{
${ }^{1}$ There are private suppliers of safe assets (Gorton, Lewellen, and Metrick, 2012), but, because of the issuer's size, government bonds are likely to be more liquid and less subject to information asymmetries.
} 
when the government insures bondholders by keeping debt risk-free $\left(\beta_{t}^{D}=0\right)$, this sufficient statistic $\beta_{t}^{S, C F}(h)$ is pinned down by the risk properties of the debt issuance process at time $t+h$, an asset with stochastic payoffs equal to the debt at time $t+h$ (debt strip).

To characterize this trade-off analytically and quantify it, we consider both models with permanent and with transitory output risk. The permanent risk case is our leading model since financial markets strongly indicate the presence of priced permanent risk. We specify a stochastic discount factor (SDF) model in the spirit of Lucas (1978) where i.i.d. shocks to output growth receive a high price of risk. Other than the SDF and output dynamics, the debt issuance process is the only input in the computations. We consider three cases.

First, when the government keeps the debt/output ratio constant, there is no scope for insurance of taxpayers at any horizon. The tax process has to be safer than the spending process at short, intermediate, and long horizons. The risk premium of the debt issuance process (the debt strip at time $t+h)$, is given by the risk premium on a claim to output at all horizons $h$. The latter equals $\gamma \sigma$, where $\sigma$ is the volatility of output growth and $\gamma$ is the market price of risk, i.e., the maximum Sharpe ratio in the economy. When output shocks are permanent, the debt strip inherits the long-run risk in output because the debt/output ratio is constant. This long-run output risk in future debt needs to be born by the taxpayer so as to keep the debt safe today. This requires making the surplus process safe from the government's perspective (risky from the taxpayer's perspective), at every horizon. There is no scope for taxpayer insurance at any horizon. For example, at business-cycle frequencies surpluses must rise in response to an adverse macro-economic shock. When government spending is a- or counter-cyclical, the same is true for tax rates. This lack of insurance is costly to taxpayers because the welfare benefits of insurance are largest when shocks to output and consumption are permanent (Alvarez and Jermann, 2004).

Second, when the government can issue more debt in response to a negative GDP growth shock, it can provide insurance to taxpayers for a limited time by lowering surpluses. The cashflow beta of cumulative surpluses $\beta_{t}^{S, C F}(h)$ is positive for small $h$. Put differently, the tax claim can be riskier than the spending claim over short horizons $\left(\beta_{t}^{T, C F}(h)>\beta_{t}^{G, C F}(h)\right)$. The risk premium on the debt strip at horizon $h$ is given by $\gamma\left(\sigma-\phi^{h-1} \lambda\right)$, where $\lambda$ measures how countercyclical the debt/output ratio is, and $\phi$ measures the autocorrelation of the debt/output ratio. If $\lambda$ exceeds $\sigma$, the risk premium on the debt issuance process is negative over short horizons. This allows for risky surpluses while keeping the debt risk-free. Strongly counter-cyclical debt issuance more than offsets the output risk and renders the debt process a hedge over short horizons. Over intermediate and longer horizons, the surplus and tax revenue claims have to become sufficiently safe for investors (risky for taxpayers) to exactly offset the long-run output risk $(\gamma \sigma)$ priced into the debt issuance process. Taxpayer insurance provision is limited in magnitude and duration.

The features of the debt issuance process plays a central role. By increasing the persistence of the debt/output ratio $\phi$ and its counter-cyclicality $\lambda$, the government can increase the horizon 
over which surpluses are risky and taxpayers are insured. In the U.S., the counter-cyclicality parameter $\lambda$ is close to two times $\sigma$, large enough for the government to insure taxpayers over short horizons. As the world's supplier of safe assets, the U.S. manages to implement a stronger counter-cyclicality of debt issuance than the U.K. It's value for $\lambda$ is $55 \%$ larger than that in the U.K. in the post-war period. Judged by the value of our sufficient statistic at one-year horizon $\beta_{t}^{S, C F}(1)$, this difference provides the U.S. taxpayer with roughly four times more insurance than her U.K. counterpart. Consistent with the model's prediction, the GDP growth beta of tax revenue growth is about four times larger in the U.S. than in the U.K. Seen through the lens of our trade-off, the main quantitative benefit of the U.S.' special status as a safe asset provider is its ability to issue a lot of debt in bad times.

As the world's safe asset supplier, the U.S. government also earns large and counter-cyclical convenience yields. Krishnamurthy and Vissing-Jorgensen (2012) estimate average convenience yields on U.S. Treasuries of $0.75 \%$ per year. Convenience yields lower the debt service, an extra source of revenue we refer to as seigniorage. We find that counter-cyclical seigniorage revenue only relaxes the trade-off in the short run. In the long-run, the seigniorage revenue stream is exposed to long-run output risk which hurts taxpayer insurance possibilities. Convenience yields are no panacea.

Third, the government can save instead of borrow, in which case the debt/output process is negative. We show that this is the only way out of the trade-off at all horizons. While theoretically interesting, very few if any governments are net savers.

Finally, we analyze a model with only transitory output shocks. In traditional neoclassical and New-Keynesian business cycle models, shocks to output are transitory, as output fluctuates around potential output. The models typically studied in the literature on optimal fiscal policy similarly imply that equilibrium output and consumption do not have a unit root component. ${ }^{2}$ Surprisingly, the trade-off between insuring taxpayers and bondholders worsens in models with transitory output shocks compared to models with permanent output risk.

The key observation is that environments with transitory shocks feature substantial interest rate risk. When output is below potential, the representative investor wants to borrow, pushing up interest rates when her marginal utility is high. The long-term government bond is the riskiest asset in such economies (Alvarez and Jermann, 2005). To keep the debt risk-free, the government has to offset the interest rate risk in long-run debt strips by producing safer surpluses in the near future. This dramatically shortens the horizon over which governments can insure taxpayers.

The trade-off is steeper in the model with transitory shocks than in the model with permanent shocks because the interest rate risk premium on the debt, $\gamma^{2}$, exceeds the output risk premium,

\footnotetext{
${ }^{2}$ Instead, these models have mean-reverting processes for productivity and government spending. See Chari, Christiano, and Kehoe (1994); Debortoli, Nunes, and Yared (2017); Bhandari, Evans, Golosov, and Sargent (2017) for examples of calibrated economies with transitory spending and productivity processes.
} 
$\gamma \sigma$, in any model with a reasonable maximum Sharpe ratio $\gamma$. This is a direct implication of the Hansen and Jagannathan (1991) bound: $\gamma \gg \sigma$.

We study the implications for taxpayer insurance of keeping the debt risk-free $\left(\beta^{D}=0\right)$. Over the last two decades, the beta of U.S. government debt has turned negative (Baele, Bekaert, and Inghelbrecht, 2010; Campbell, Pflueger, and Viceira, 2020). We show that when $\beta^{D}<0$, the scope for insuring taxpayers shrinks further. The zero-beta debt case is conservative in terms of the restrictions it implies on surpluses and taxes.

Related Literature There is a growing literature on dynamic inefficiencies $(r<g)$ and its implications for debt sustainability (Blanchard, 2019; Furman and Summers, 2020; Andolfatto, 2020; Mehrotra and Sergeyev, 2021; Aguiar, Amador, and Arellano, 2021; Mian, Straub, and Sufi, 2021a). We show that when the government commits to a stationary debt/output policy, the transversality condition (TVC) for debt is naturally satisfied in a world with priced permanent output shocks. In that world, the TVC is satisfied if and only if $r+\gamma \sigma-\frac{1}{2} \sigma^{2}>g$. The key new term is the output risk premium $\gamma \sigma$. When the debt/output ratio is stationary, future debt inherits the permanent risk in future output. The output risk premium $\gamma \sigma$ can be thought of as the unlevered equity risk premium. Asset pricing research indicates that the output risk premium is substantial, around 5\% per year. With a sizeable output risk premium, the TVC is easy to satisfy even when $r<g$. The condition $r>g$, analyzed in models without aggregate risk, is neither necessary nor sufficient for the TVC to be satisfied in economies with priced permanent output risk. Indeed, in our calibration, $r<g$ but $r+\gamma \sigma-\frac{1}{2} \sigma^{2}>g \cdot{ }^{3}$ In models with priced aggregate risk, violations of the TVC for government debt may also result in violations of the TVC for the GDP claim and other long-lived assets such as stocks.

Even when the TVC is satisfied, the government can sustain permanent primary deficits when $r<g$. This is not a free lunch, rather it is the trade-off at work. When taxpayers insure bondholders by suffering high taxation in high marginal-utility states, bondholders earn an insurance premium on the debt. This premium exactly offsets the primary deficit. The negative covariance of marginal utility and surpluses is what creates fiscal capacity.

In our economy, the government provides insurance to taxpayers against aggregate shocks. In models developed by Bassetto and Cui (2018); Brunnermeier, Merkel, and Sannikov (2020); Angeletos, Collard, and Dellas (2020); Reis (2021); Chien and Wen (2019, 2020); Kocherlakota (2021); Mian et al. (2021a), government debt plays a key role in allowing agents to self-insure against idiosyncratic risk and by providing liquidity services. These features give rise to a convenience yield, which contributes a bubble component to the valuation of public debt. Liu, Schmid, and

\footnotetext{
${ }^{3}$ Contemporaneous work by van Wijnbergen, Olijslagers, and de Vette (2020) highlights this point in a general equilibrium asset pricing model. In later work, Barro (2020) makes this point in a model with production and disaster risk.
} 
Yaron (2019) develop a structural model of the convenience yields earned on government debt and fiscal policy. In this paper, we analyze how convenience yields change the trade-off, while Jiang, Lustig, Van Nieuwerburgh, and Xiaolan (2019b); Reis (2021); Mian et al. (2021a) analyze the impact of convenience yields on fiscal capacity.

Our analysis contributes to a growing branch of the international economics literature that emphasizes the unique U.S. role as the world's safe asset supplier in explaining low U.S. interest rates. ${ }^{4}$ As the world's supplier of safe assets, we find that the U.S. can choose a debt issuance process that is more counter-cyclical than other countries, thereby extending the horizon over which it insures its taxpayers. This is a new dimension of the U.S.' exorbitant privilege.

There is a growing literature at the intersection of asset pricing and macro which focuses mostly on the asset pricing effects of fiscal uncertainty (Gomes, Michaelides, and Polkovnichenko, 2012; Croce, Kung, Nguyen, and Schmid, 2012; Pástor and Veronesi, 2013).

Recently, Mian, Straub, and Sufi $(2021 b, 2020)$ examine the distributional implications of government debt issuance, pointing out that the wealthy buy a large share of government (and private) debt. To the extent that the Gini coefficient of government debt holdings exceeds that of taxes, the government is trading off insuring the rich versus insuring the middle class.

Bhandari et al. (2017) and Bigio, Nuno, and Passadore (2019) study optimal debt maturity management, while Bianchi, Ottonello, and Presno (2019) study a version of the trade-off we analyze in environments with sovereign default risk.

Finally, there is a large normative literature on optimal taxation which focuses on representative agent economies with distortionary taxes, following Barro (1979)'s seminal work on tax smoothing. Aiyagari, Marcet, Sargent, and Seppälä (2002) were the first to derive the optimal tax and debt policy when the government issues zero-beta debt. We answer a different, narrower question: Given a government's actual debt policy, how much insurance can be provided to taxpayers while keeping the debt risk-free? Our alternative approach analyzes the trade-off conditional on empirically plausible debt policies without needing to commit to a fully-specified equilibrium model. By adopting Alvarez and Jermann (2004)'s preference-free approach of relying on asset prices to measure marginal welfare benefits, we can use standard asset pricing tools to characterize the trade-off.

The quantitative risk-return trade-off we highlight cannot be fruitfully analyzed in the current class of optimal taxation models, because these models are not equipped to match the equity premium. The maximum Sharpe ratio $\gamma$ is too small, and the risk is mostly composed of transitory shocks to the pricing kernel. Modern asset pricing has consistently found that permanent

\footnotetext{
${ }^{4}$ See Gourinchas and Rey (2007); Caballero, Farhi, and Gourinchas (2008); Caballero and Krishnamurthy (2009); Maggiori (2017); He, Krishnamurthy, and Milbradt (2018); Gopinath and Stein (2018); Krishnamurthy and Lustig (2019); Jiang, Krishnamurthy, and Lustig (2021, 2019a); Liu et al. (2019); Koijen and Yogo (2019). In related work, Farhi and Gourio (2018); Eggertsson, Robbins, and Wold (2018); Ball and Mankiw (2021) emphasize the role of increased market power in reconciling higher economic growth rates with low observed rates of return.
} 
shocks to output and consumption account for most of the variance of the pricing kernel, and receive a high price of risk in securities market (Bansal and Lehmann, 1997; Alvarez and Jermann, 2005; Hansen and Scheinkman, 2009; Bansal and Yaron, 2004; Backus, Chernov, and Zin, 2014; Borovička, Hansen, and Scheinkman, 2016; Backus, Boyarchenko, and Chernov, 2018). Models without large permanent shocks counterfactually produce bond risk premia that exceed equity risk premia. We show that permanent risk has important implications for the fiscal policy literature. Furthermore, the normative optimal taxation analysis implies that the government should accumulate zero-beta assets (save rather than borrow) to escape the trade-off (Bhandari et al., 2017).

The paper is organized as follows. Section 1 derives the general trade-off between insuring bondholders and taxpayers. We show that the riskiness of the surpluses is a sufficient statistic for marginal welfare calculations. With risk-free debt, only the debt/output dynamics are needed to compute this statistic. Section 2 characterizes the trade-off analytically in a model with permanent shocks to output and marginal utility. Section 3 investigates whether convenience yields can relax the trade-off. Section 4 revisits the trade-off in a model with transitory shocks to output and marginal utility. The appendix contains the proofs and auxiliary results.

\section{The General Trade-off between Insuring Bondholders and Taxpayers}

We use $T_{t}$ to denote government revenue, and $G_{t}$ to denote government spending. $M_{t}$ denotes the stochastic discount factor (SDF). We assume that debt is fairly priced and does not earn any convenience yields. Let $B_{t}$ denote the market value of outstanding government debt at the beginning of period $t$, before expiring debt is paid off and new debt is issued. The debt can be long-term or short-term, and it can be nominal or real. In fact, it can be any contingent claim. The value of government debt equals the sum of the expected risk-adjusted present discounted values of future tax revenues minus future government spending:

$$
B_{t}=\mathbb{E}_{t}\left[\sum_{j=0}^{\infty} M_{t, t+j}\left(T_{t+j}-G_{t+j}\right)\right] \text {, }
$$

provided that there are no arbitrage opportunities in the bond market and a transversality condition holds $\lim _{k \rightarrow \infty} \mathbb{E}_{t} M_{t, t+k} B_{t+k}=0$. See Jiang et al. (2019b) for a proof. This result does not rely on complete markets, and still applies even when the government can default on the debt. Let $P_{t}^{T}=\mathbb{E}_{t}\left[\sum_{j=0}^{\infty} M_{t, t+j} T_{t+j}\right]$ and $P_{t}^{G}=\mathbb{E}_{t}\left[\sum_{j=0}^{\infty} M_{t, t+j} G_{t+j}\right]$ denote the present values of the "cum-dividend" tax claim and spending claim. Value additivity then implies that $B_{t}=P_{t}^{T}-P_{t}^{G}$. For notational convenience, let $D_{t}=B_{t}-S_{t}$ denote the difference between the market value of outstanding government debt and the government surplus. By the government budget condition, 
$D_{t}$ is the market value of outstanding government debt at the end of period $t$, after expiring debt is paid off and new debt is issued. The TVC assumption is not a stringent one. Below, we will show that the TVC is satisfied in plausibly calibrated asset pricing models.

\subsection{Marginal Benefit of Fiscal Stabilization Policy for Taxpayers}

In an infinite horizon, closed, complete markets economy, with a representative agent, the bondholder is also the net transfer (transfers minus taxes) recipient. If the transfers are lump-sum, Ricardian equivalence holds, and net transfers are irrelevant. There is no trade-off between insuring bondholders and taxpayers. Any consideration that breaks Ricardian equivalence resuscitates the trade-off: finite horizons, foreign bond holders, incomplete markets with heterogeneous agents.

We consider a generic incomplete markets environment in which households are finitely lived. The government borrows at the margin from investors who are distinct from the taxpayers and the transfer recipients. For simplicity, we can think of the marginal bondholders as foreign investors. The analysis in this section connects fiscal stabilization policy and debt valuations to household welfare through the marginal benefit of fiscal stabilization policy.

We use $U^{h}$ to denote the expected utility of an investor with horizon $h$. In the background, households face idiosyncratic income risk that cannot be perfectly insured away. This risk manifests itself as the idiosyncratic component in the (post-trade) equilibrium consumption process $\left\{C^{i}\right\}=\left\{C+\epsilon^{i}\right\}$, where $\epsilon^{i}$ denotes the idiosyncratic component of consumption.

Let $\{T\}$ denote the tax process and $\{G\}$ denote the spending process; $\{T, G\}$ can only depend on the history of aggregate shocks. We assume that the government balances the budget in expectation: $\mathbb{E}_{0}[G-T]=0$. We focus on fiscal insurance against aggregate risk. We do not consider transfers that are contingent on idiosyncratic shocks. ${ }^{5}$

We consider the set of all taxpayer households who participate in asset markets and who are unconstrained. We can infer their marginal benefit from fiscal policy from the market valuation of tax revenues and spending outlays, even though these households do not equalize their intertemporal marginal rates of substitution in incomplete markets.

In the spirit of the cost of business cycles measures (Lucas, 1987), we define the benefit of government net transfers, $\Omega_{\text {net }}^{h}(\alpha)$, to agent $i$ with horizon $h$ as follows:

$$
U^{h}\left(\left(1+\Omega_{\text {net }}^{h, i}(\alpha)\right) C+\epsilon^{i}\right)=U^{h}\left((1-\alpha)\{C\}+(\alpha)\{C+G-T\}+\epsilon^{i}\right)
$$

where $\Omega^{h, i}(\alpha)$ denotes the fraction of systematic consumption this agent is willing to give up in exchange for a new systematic consumption profile that is a weighted average of the old one (with probability $1-\alpha$ ) and a new one that adds net government transfers $G-T$ (with probability $\alpha$ ).

\footnotetext{
${ }^{5}$ We analyze that case in Appendix B. We consider the optimal taxation approach in Appendix C.
} 
The total benefit of fiscal stabilization obtains for $\alpha=1$. We study the marginal benefit of fiscal stabilization at $\alpha=0, \Omega_{\text {net }}^{h^{\prime}}(0){ }^{6}$

Proposition 1.1. For households who participate in asset markets and who receive net transfers $\{G-T\}$, the marginal insurance benefit over horizon $h$ is given by:

$$
\Omega_{n e t}^{h^{\prime}}(0)=\frac{\mathbb{E}_{0}\left[\sum_{t=1}^{h} M_{0, t}\left(G_{t}-T_{t}\right)\right]}{\mathbb{E}_{0}\left[\sum_{t=1}^{h} M_{0, t} C_{t}\right]}=\frac{\mathbb{E}_{0}\left[\sum_{t=1}^{h} M_{0, t} C_{t}\right]+\mathbb{E}_{0}\left[\sum_{t=0}^{h} M_{0, t}\left(G_{t}-T_{t}\right)\right]}{\mathbb{E}_{0}\left[\sum_{t=1}^{h} M_{0, t} C_{t}\right]}-1
$$

To compute the marginal benefit of government fiscal intervention from the perspective of this household, we can compare the market valuations of net transfers and the household's consumption stream. $\mathbb{E}_{0}\left[\sum_{t=1}^{h} M_{0, t}\left(G_{t}-T_{t}\right)\right]$ measures how much this household would be willing to pay for these net transfers as an insurance policy. The safer the net transfers compared to her actual consumption, the higher the marginal benefit of the net transfers to the household. A larger marginal benefit of fiscal stabilization policy to households implies a larger risk premium paid by the government:

$$
\mathbb{E}_{0}\left[\sum_{t=1}^{h} M_{0, t}\left(G_{t}-T_{t}\right)\right]=\sum_{t=1}^{h} \operatorname{Cov}_{0}\left(-M_{0, t}, T_{t}-G_{t}\right),
$$

where we used $\mathbb{E}_{0}[G-T]=0$. There is a one-to-one mapping between the riskiness of the surplus $S_{t}=T_{t}-G_{t}$, and the marginal (and total) welfare benefit to the taxpayer. The riskier the surplus, the larger the welfare benefit. The riskiness of the surplus is a sufficient statistic. If the government provides a marginal insurance benefit to taxpayers at horizon $h, \Omega_{\text {net }}^{h^{\prime}}(0)>0$, and runs zero primary surpluses on average, the transfer policy has a positive cost: $\mathbb{E}_{0}\left[\sum_{t=1}^{h} M_{0, t}\left(G_{t}-T_{t}\right)\right]>0$.

Importantly, we do not need a representative agent for this marginal benefit approach to be valid. All we need is a SDF for the marginal investors. The cash flows $\left\{T_{t}-G_{t}\right\}$ and $\left\{C_{t}\right\}$ have to be in the span of traded assets. ${ }^{7}$ Since we are computing the marginal benefit, we are not changing the equilibrium consumption allocation.

The marginal benefit is a first-order approximation of the total benefit. When utility is increasing, homothetic, and concave, and the new allocation $\{C+G-T\}$ is preferred to the old one $\{C\}$, then the marginal benefit is an upper bound on the total benefit $\Omega_{\text {net }}^{h^{\prime}}(0) \geq \Omega_{\text {net }}^{h}(1)$ (see Alvarez and Jermann, 2004). Hence, to get a positive total benefit, we need a positive marginal benefit. Fiscal policies with a positive total welfare benefit have a positive cost. But a positive marginal benefit does not guarantee a positive total benefit. The trade-off between insuring taxpayers and bondholders is more stringent when considering the total benefit. This makes our marginal approach conservative. ${ }^{8}$

\footnotetext{
${ }^{6}$ In section D of the Appendix, we connect this measure to the marginal cost of the business cycle measure developed by Alvarez and Jermann (2004).

${ }^{7}$ The entire government debt portfolio is a claim to $\left\{T_{t}-G_{t}\right\}$. Unlevered equity is akin to a claim to aggregate consumption.

${ }^{8}$ Under this approach, it is straightforward to compute the marginal cost of taxation for a household who pays taxes
} 
Infinite Horizon Case We now let the horizon over which the government provides insurance go to $\infty$. The marginal benefit of net transfers to taxpayers becomes:

$$
\Omega_{\text {net }}^{\infty^{\prime}}(0)=\frac{\mathbb{E}_{0}\left[\sum_{t=1}^{\infty} M_{0, t}\left(G_{t}-T_{t}\right)\right]}{\mathbb{E}_{0}\left[\sum_{t=1}^{\infty} M_{0, t} C_{t}\right]}=\frac{\left(P_{0}^{G}-G_{0}\right)-\left(P_{0}^{T}-T_{0}\right)}{P_{0}^{C}-C_{0}}=\frac{-D_{0}}{P_{0}^{C}-C_{0}},
$$

where we used that the market value of debt equals the expected present-discounted value of future surpluses, assuming the TVC is satisfied. If the government provides a positive marginal insurance benefit to taxpayers at horizon $\infty, \Omega_{\text {net }}^{\infty^{\prime}}(0)>0$, then the government needs to endow a sovereign wealth fund of size $-D_{0}=\mathbb{E}_{0}\left[\sum_{t=1}^{\infty} M_{0, t}\left(G_{t}-T_{t}\right)\right]>0$. Providing insurance to risk averse taxpayers through a zero-average net transfer policy has a positive cost to the government of $P_{0}^{G}-P_{0}^{T}>0$. Conversely, if debt $D_{0} \geq 0$, the government can only provide a negative marginal insurance benefit $\Omega_{\text {net }}^{h^{\prime}}(0)<0$ to taxpayers at horizon $\infty$ with average zero primary surpluses. The government offloads aggregate risk onto its taxpayers to keep its debt safe.

The more valuable the debt, i.e., the safer the cash flows to bondholders, the smaller the insurance benefit to taxpayers, i.e. the smaller the marginal benefit of fiscal stabilization to taxpayers. Taxpayers always prefer riskier debt. This defines the trade-off between insuring bondholders and taxpayers.

Gordon Growth Intuition Let $r^{i}$ denote the expected log return on an asset $i$ and $g$ the average growth rate of output. To develop more intuition, we use Gordon's growth formula:

$$
\Omega_{n e t}^{\infty^{\prime}}(0) \approx \frac{\frac{G_{0}}{r^{G}-g}-\frac{T_{0}}{r^{T}-g}}{\frac{C_{0}}{r^{c}-g}}=\frac{G_{0} / C_{0}}{\left(r^{G}-g\right) /\left(r^{C}-g\right)}-\frac{T_{0} / C_{0}}{\left(r^{T}-g\right) /\left(r^{C}-g\right)}=\frac{G_{0}}{C_{0}} \frac{\left(r^{C}-g\right)\left(r^{T}-r^{G}\right)}{\left(r^{G}-g\right)\left(r^{T}-g\right)}
$$

The second equality says that the safer the spending process (lower $r^{G}$ ) and the riskier the tax process (higher $r^{T}$ ) relative to the consumption process $\left(r^{C}\right)$, the higher the marginal benefit of fiscal stabilization to the taxpayer. The last equality considers the case in which the government runs a zero surplus $\left(G_{0}=T_{0}\right)$. Even when the government provides zero net transfers, the household benefits when the net transfers arrive in bad states of the world, i.e., when fiscal policy provides insurance against business cycle risk. This is the case if the tax process is riskier than the spending process $\left(r^{T}>r^{G}\right)$. The larger the gap between the discount rate of the tax and the spending claim, but does not receive transfers:

$$
\Omega_{\text {tax }}^{h^{\prime}}(0)=-\frac{\mathbb{E}_{0}\left[\sum_{t=1}^{h} M_{0, t} T_{t}\right]}{\mathbb{E}_{0}\left[\sum_{t=1}^{h} M_{0, t} C_{t}\right]}=\frac{\mathbb{E}_{0}\left[\sum_{t=1}^{h} M_{0, t}\left(C_{t}-T_{t}\right)\right]}{\mathbb{E}_{0}\left[\sum_{t=1}^{\infty} M_{0, t} C_{t}\right]}-1
$$

Similarly, we can take the perspective of a transfer recipient who does not pay taxes, and compute the marginal benefit of transfers as:

$$
\Omega_{\text {trans }}^{h^{\prime}}(0)=\frac{\mathbb{E}_{0}\left[\sum_{t=1}^{h} M_{0, t} G_{t}\right]}{\mathbb{E}_{0}\left[\sum_{t=1}^{h} M_{0, t} C_{t}\right]}=\frac{\mathbb{E}_{0}\left[\sum_{t=1}^{h} M_{0, t}\left(C_{t}+G_{t}\right)\right]}{\mathbb{E}_{0}\left[\sum_{t=1}^{h} M_{0, t} C_{t}\right]}-1
$$


the larger the welfare benefit for the transfer recipient. However, the government needs savings in the amount of:

$$
-D_{0}=\frac{G_{0}}{r^{g}-g}-\frac{T_{0}}{r^{T}-g} \approx G_{0} \frac{\left(r^{T}-r^{G}\right)}{\left(r^{G}-g\right)\left(r^{T}-g\right)}>0
$$

to fund this zero-transfer insurance. Alternatively, to start this insurance scheme without initial assets, the government needs to run primary surpluses. The higher the benefits from the perspective of the net transfer recipients, the higher the cost of funding for the government.

Corollary 1.1. Assume that the TVC is satisfied. If $D_{0} \geq 0$, the government runs surpluses on average, and the government provides insurance to its taxpayers, then the debt is risky.

\subsection{Characterizing the Trade-Off with Return Betas over Long Horizons}

The results in the previous section motivate why we use the risk properties of the entire discounted surplus claim as a sufficient statistic for the marginal benefit of taxpayer insurance over infinite horizons. To examine the risk property of this claim, we define the return to this claim and its return beta. Let $R_{t+1}^{D}, R_{t+1}^{T}$ and $R_{t+1}^{G}$ denote the holding period returns on the bond portfolio, the tax claim, and the spending claim, respectively:

$$
R_{t+1}^{D}=\frac{B_{t+1}}{B_{t}-S_{t}}, \quad R_{t+1}^{T}=\frac{P_{t+1}^{T}}{P_{t}^{T}-T_{t}}, \quad R_{t+1}^{G}=\frac{P_{t+1}^{G}}{P_{t}^{G}-G_{t}} .
$$

Jiang et al. (2019b) show that the government debt portfolio return is the return on a portfolio that goes long in the tax claim and short in the spending claim:

$$
\mathbb{E}_{t}\left[R_{t+1}^{D}-R_{t}^{f}\right]=\frac{P_{t}^{T}-T_{t}}{D_{t}} \mathbb{E}_{t}\left[R_{t+1}^{T}-R_{t}^{f}\right]-\frac{P_{t}^{G}-G_{t}}{D_{t}} \mathbb{E}_{t}\left[R_{t+1}^{G}-R_{t}^{f}\right]
$$

This result only relies on equation (1) and additivity. By rearranging equation (2), we derive the following expression for the risk premium on the tax claim:

$$
\mathbb{E}_{t}\left[R_{t+1}^{T}-R_{t}^{f}\right]=\frac{P_{t}^{G}-G_{t}}{D_{t}+\left(P_{t}^{G}-G_{t}\right)} \mathbb{E}_{t}\left[R_{t+1}^{G}-R_{t}^{f}\right]+\frac{D_{t}}{D_{t}+\left(P_{t}^{G}-G_{t}\right)} \mathbb{E}_{t}\left[R_{t+1}^{D}-R_{t}^{f}\right] .
$$

Governments typically want a counter-cyclical spending claim, i.e. they want to spend more in recessions. On the other hand, they also want a risky tax claim, because they want to reduce the tax burden in recessions. As a result, the tax claim's risk premium $\mathbb{E}_{t}\left[R_{t+1}^{T}-R_{t}^{f}\right]$ is high and the spending claim's risk premium $\mathbb{E}_{t}\left[R_{t+1}^{G}-R_{t}^{f}\right]$ is low. When the debt value $D_{t}$ is positive, the fraction $\frac{P_{t}^{G}-G_{t}}{D_{t}+\left(P_{t}^{G}-G_{t}\right)}$ is between 0 and 1 . Then, for equation (3) to hold, it requires a high risk premium $\mathbb{E}_{t}\left[R_{t+1}^{D}-R_{t}^{f}\right]$ on the government debt portfolio. As the debt risk premium is a measure of the risk premium charged by bondholders, the government's debt portfolio has to be risky. 
According to equation (3), the tax revenue claim is the unlevered version of the spending claim, or, equivalently, the spending claim is the levered version of the tax claim. This result is analogous to the Miller-Modigliani relation between the unlevered return on equity (the return on the tax claim) and the levered return on equity (the return on the spending claim).

We define the return beta of an asset $i$ as: $\beta_{t}^{i}=\frac{-\operatorname{cov}_{t}\left(M_{t+1}, R_{t+1}^{i}\right)}{\operatorname{var}_{t}\left(M_{t+1}\right)}$. By the investor's Euler equation, $\beta_{t}^{i} \lambda_{t}$ determines the conditional risk premium of this asset $\mathbb{E}_{t}\left[R_{t+1}^{i}-R_{t}^{f}\right]=\beta_{t}^{i} \cdot \gamma_{t}$, where the market price of risk is $\gamma_{t}=\operatorname{var}_{t}\left[M_{t+1}\right] / E_{t}\left[M_{t+1}\right]$. Let $\beta_{t}^{D}, \beta_{t}^{T}, \beta_{t}^{G}$, and $\beta_{t}^{Y}$ denote the beta of the bond portfolio, the tax claim, the spending claim, and the output claim respectively. We assume $\beta_{t}^{Y}>0$, so that the output claim has a positive risk premium. The following proposition characterizes the relationship of these risk exposures.

Proposition 1.2. The beta on the tax claim is a weighted average of the beta of the spending claim and the beta of the debt:

$$
\beta_{t}^{T}=\frac{P_{t}^{G}-G_{t}}{D_{t}+\left(P_{t}^{G}-G_{t}\right)} \beta_{t}^{G}+\frac{D_{t}}{D_{t}+\left(P_{t}^{G}-G_{t}\right)} \beta_{t}^{D} .
$$

Governments want to provide insurance to transfer recipients by choosing $\beta_{t}^{G}<\beta_{t}^{Y}$, but they also want to provide insurance to taxpayers by choosing $\beta_{t}^{T}>\beta_{t}^{Y}$. However, the following corollary states that $\beta_{t}^{G}<\beta_{t}^{Y}<\beta_{t}^{T}$ is impossible if the government debt is risk-free.

Corollary 1.2. In order for debt to be risk-free $\left(\beta_{t}^{D}=0\right)$, the beta of the tax claim needs to equal the unlevered beta of the spending claim: $\beta_{t}^{T}=\frac{P_{t}^{G}-G_{t}}{D_{t}+\left(P_{t}^{G}-G_{t}\right)} \beta_{t}^{G}$. With $D_{t}>0, \beta_{t}^{T}<\beta_{t}^{G}$.

If the government has a positive amount of risk-free debt $D_{t}>0$, there is no scope to insure taxpayers. Instead, the taxpayers provide insurance to the rest of the economy.

First, consider the case in which the spending claim has a positive beta $\left(\beta_{t}^{G}>0\right)$. Then, the government engineers risk-free debt by lowering the beta of the tax claim relative to that of the spending claim: $\beta_{t}^{T}<\beta_{t}^{G}$. A low beta for the tax claim means that tax revenue must fall by less than GDP in a recession. Tax rates must rise in recessions. The more debt there is outstanding (higher $D_{t}$ ), the lower the beta of the tax claim needs to be relative to that of the spending claim. With more debt, the trade-off between insuring bondholders and taxpayers becomes steeper. The restriction on the betas holds true regardless of the specific dynamics of the tax and spending process. In the next sections, we will derive restrictions on the underlying cash flows by committing to particular processes for debt/output and spending/output. The only way the government can provide insurance to debt holders, while keeping the debt risk-free, is by saving-choosing $D_{t}<0$. In other words, the government can only insure taxpayers at the expense of bondholders. 
Second, consider the case in which the spending claim has a negative beta $\left(\beta_{t}^{G}<0\right)$. To ensure risk-free debt, the tax claim must also have a negative beta when $D_{t}>0\left(\beta_{t}^{T}<0\right)$. Tax payments increase during recessions. Taxpayers are insuring the bondholders.

\subsection{Characterizing the Trade-Off with Cash Flow Betas over Short Horizons}

Thus far, we have characterized the return betas of the tax and spending claims. These measure the riskiness of the cash flow and the marginal welfare implications claims over infinite horizons. We can get further insight on the trade-off over short horizons by studying cash-flow betas for the surplus claim. A key result is that the properties of these finite-horizon cash-flow betas of the surplus process are fully determined by the properties of the debt issuance process at the end of that horizon, when the debt is risk-free.

Proposition 1.3. When the TVC is satisfied, the debt return innovation reflects news about the present discounted value of future government surpluses: $D_{t}\left(\mathbb{E}_{t+1}-\mathbb{E}_{t}\right)\left[R_{t+1}^{D}\right]=\left(\mathbb{E}_{t+1}-\mathbb{E}_{t}\right)\left[\sum_{j=1}^{\infty} M_{t+1, t+j} S_{t+j}\right]$. When the debt is risk-free, there is no news about future surpluses: $\left(\mathbb{E}_{t+1}-\mathbb{E}_{t}\right)\left[\sum_{j=1}^{\infty} M_{t+1, t+j} S_{t+j}\right]=0$.

This proposition implies a restriction on the dynamics of future surpluses in response to any shock that arrives at time $t+1$. If a shock raises surpluses in the near-term future, then either the surpluses in the long-term or the discount rates have to adjust for debt to remain risk-free.

Define the cash flow beta of cumulative future discounted surpluses as:

$$
\beta_{t}^{S, C F}(h) \equiv-\frac{\operatorname{cov}_{t}\left(M_{t+1},\left(\mathbb{E}_{t+1}-\mathbb{E}_{t}\right) \sum_{j=1}^{h} M_{t+1, t+j} S_{t+j}\right)}{D_{t} \operatorname{var}_{t}\left(M_{t+1}\right)} .
$$

It follows immediately from the definition of return beta of debt and the intertemporal budget constraint, that if debt is risk-free, $\beta_{t}^{S, C F}(\infty)=\beta_{t}^{D}=0$. That is, for the government debt to be risk-free, the cash flow beta of the entire discounted surplus stream must be zero. The following proposition connects the return beta on the debt to the cash-flow beta of cumulative surpluses over finite horizons.

Proposition 1.4. The return beta of debt equals the cash-flow beta of the discounted surpluses over h periods minus the return beta of debt outstanding $h$ periods from now:

$$
\beta_{t}^{D}=\beta_{t}^{S, C F}(h)-\frac{\operatorname{cov}_{t}\left(M_{t+1},\left(\mathbb{E}_{t+1}-\mathbb{E}_{t}\right) M_{t+1, t+h} D_{t+h}\right)}{D_{t} \operatorname{var}_{t}\left(M_{t+1}\right)}
$$

When debt is risk-free $\left(\beta_{t}^{D}=0\right)$, then the cash flow beta of surpluses is determined by minus the return beta of debt outstanding $h$ periods from now:

$$
\beta_{t}^{S, C F}(h)=-\frac{\operatorname{cov}_{t}\left(-M_{t+1},\left(\mathbb{E}_{t+1}-\mathbb{E}_{t}\right) M_{t+1, t+h} D_{t+h}\right)}{D_{t} \operatorname{var}_{t}\left(M_{t+1}\right)} .
$$


When debt has negative risk premium $\left(\beta_{t}^{D}<0\right)$, then the cash flow beta is smaller than minus the return beta of debt outstanding $h$ periods from now:

$$
\beta_{t}^{S, C F}(h) \leq-\frac{\operatorname{cov}_{t}\left(-M_{t+1},\left(\mathbb{E}_{t+1}-\mathbb{E}_{t}\right) M_{t+1, t+h} D_{t+h}\right)}{D_{t} \operatorname{var}_{t}\left(M_{t+1}\right)}
$$

As the horizon tends to $\infty$, the debt issuance covariance tends to zero, and $\beta_{t}^{D} \rightarrow \beta_{t}^{S, C F}(\infty)$. As long as the debt is risk-free, the riskiness of the surpluses over a finite horizon $h$ are completely determined by the riskiness of the debt issuance process at time $t+h$, i.e., the debt strip that pays the cash flow $D_{t+h}$ at time $t+h$.

The proposition implies that, when debt is risk-free, the cash-flow beta of the surplus process does not depend on the spending and tax revenue dynamics during those $h$ periods. The only source of state-contingency is the debt issuance process itself. When hit by a bad shock, the government can respond by issuing more debt $h$ period from now. As we shall see, this places tight restrictions on how much surpluses can respond to adverse aggregate shocks.

$\beta_{t}^{S, C F}(h)$ is our summary statistic for how much insurance the government provides to taxpayers with at horizon $h$. Over short horizons, it can insure taxpayers and produce a risky surplus process with high $\beta_{t}^{S, C F}(h)$, by choosing a counter-cyclical debt issuance process with $\operatorname{cov}_{t}\left(-M_{t+1},\left(\mathbb{E}_{t+1}-\mathbb{E}_{t}\right) M_{t+1, t+h} D_{t+h}\right)<0$. When the debt is risk-free, there can be no insurance over long horizons: $\beta_{t}^{D}=\beta_{t}^{S, C F}(\infty)=0$.

The last part of the proposition shows that, when government debt has a negative risk premium $\left(\beta_{t}^{D}<0\right)$, this constraints the government even more: the debt issuance beta puts an upper bound on the cash-flow beta of the surplus.

We now turn to evaluating these general results quantitatively by letting the government adopt specific debt policies. We first do so in an environment where macroeconomic shocks are permanent, and then in a model where shocks are transitory.

\section{The Trade-off in a Benchmark Economy with Permanent Risk}

We characterize the trade-off between insuring debtholders and taxpayers in a canonical macrofinance model in the tradition of Lucas (1978). We solve for the revenue process $T$ that keeps the debt risk-free. We do so under simple spending and debt policies at first and more complex policies in the next step.

\subsection{Setup}

To derive closed form-solutions, we adopt an exogenous stochastic discount factor (SDF) with plausible asset pricing implications. This SDF prices payoffs from the perspective of domestic and 
foreign investors buying government debt. Output is subject to permanent shocks.

Assumption 1. (a) Let $Y_{t}$ and $y_{t}=\log Y_{t}$ denote output and its $\log$. All output shocks are i.i.d. and permanent: $y_{t+1}=\mu+y_{t}+\sigma \varepsilon_{t+1}$, where $\varepsilon_{t+1}$ denotes the innovation to output growth that is i.i.d. normally distributed with mean zero and standard deviation one. (b) The log SDF is given by: $m_{t, t+1}=$ $-\rho-\frac{1}{2} \gamma^{2}-\gamma \varepsilon_{t+1}$. (c) The government only issues one-period real risk-free debt.

The one-period risk-free rate in this simple model is constant and equal to $\rho$. The market price of risk, or equivalently the maximum Sharpe ratio, is also constant and equal to $\sigma_{t}\left(m_{t+1}\right)=\gamma$. We choose this SDF because it delivers tractable expressions.

\subsection{Characterizing the Trade-off with Constant Debt-Output}

To build intuition for the general trade-off between insurance of bondholders and taxpayers, we start by considering the simplest case of constant spending/output and debt/output ratio policies.

Assumption 2. (a) The government commits to a constant spending/output ratio $x=G_{t} / Y_{t}$.

(b) The government commits to a constant debt/output ratio $d=D_{t} / Y_{t}$.

Under Assumption 2, the government budget constraint implies a counter-cyclical process for tax revenue-to-GDP (the tax rate):

$$
\frac{T_{t}}{Y_{t}}=\frac{G_{t}}{Y_{t}}-\frac{D_{t}}{Y_{t}}+R_{t-1}^{f} \frac{D_{t-1}}{Y_{t}}=x-d\left(1-\exp \left\{-\left(\mu-\rho+\sigma \varepsilon_{t}\right)\right\}\right) .
$$

To perfectly insure the bondholders by keeping the debt risk-free, the government must make the tax revenue claim counter-cyclical: $\partial(T / Y) \partial \varepsilon<0$. When the growth rate of output is low $(\varepsilon<0)$, tax revenue needs to increase as a fraction of GDP. Tax rates must rise in recessions. The magnitude of the counter-cyclical exposure is increasing in the debt-to-GDP ratio $d$.

Similarly, the primary surplus/output ratio is counter-cyclical:

$$
s_{t}=\frac{S_{t}}{Y_{t}}=\frac{T_{t}-G_{t}}{Y_{t}}=-d\left(1-\exp \left\{-\left(\mu-\rho+\sigma \varepsilon_{t}\right)\right\}\right) .
$$

We have that $\partial s_{t} / \partial \varepsilon_{t}<0$. When the unconditional growth rate of output exceeds the risk-free rate $(\mu>\rho)$, the government runs a primary deficit on average. But when shocks are negative enough $(\mu-\rho<-\sigma \varepsilon)$, the government must run a primary surplus.

This simple model places tight restrictions on the persistence of surpluses. The conditional auto-covariance of the surplus/output ratio is zero: $\operatorname{cov}_{t}\left(s_{t}, s_{t-1}\right)=0$. The government cannot run persistent deficits. ${ }^{9}$ This result is more general. With risk-free debt, the autocorrelation of surpluses tends to zero as the persistence of the debt/output ratio tends to one.

\footnotetext{
${ }^{9}$ When $\sigma \rightarrow 0$, the government always runs deficits. But $\mu>\rho$ now implies a violation of the TVC, as we show below.
} 
The restrictions on the surplus and tax processes described above were independent of the SDF model. Next, we turn to valuing the debt as the expected present-discounted value of future surpluses using the SDF.

Proposition 2.1. Under Assumptions 1 and 2, if the transversality condition holds and the primary surplus satisfies (4), the government debt value is the sum of the values of the surplus strips:

$$
D_{t}=\mathbb{E}_{t}\left[\sum_{k=1}^{\infty} M_{t, t+k} S_{t+k}\right]=d Y_{t}
$$

This proposition confirms that the (ex-dividend) value of outstanding debt in period $t$ is indeed a constant fraction of output. The proof solves for the price of a claim to a single future surplus realization (a surplus strip), and adding up the surplus strip prices at all horizons. The result implies that there is no news about the present discounted value of future surpluses since output is already known at time $t$.

Transversality Condition The government surpluses are not discounted at the risk-free rate even though the debt is risk-free. To see why, consider the valuation equation for debt as a function of surplus/output ratios:

$$
D_{t}=\mathbb{E}_{t}\left[\sum_{j=0}^{T} M_{t, t+j} Y_{t+j} s_{t+j}\right]+\mathbb{E}_{t}\left[M_{t, t+T} Y_{t+T} \frac{D_{t+T}}{Y_{t+T}}\right]
$$

Under Assumption 2, the debt/output ratio $\frac{D_{t+T}}{Y_{t+T}}=d$ in the second term is constant. The correct TVC for government debt in this model is given by:

$$
\lim _{T \rightarrow \infty} \mathbb{E}_{t}\left[M_{t, t+T} D_{t+T}\right]=\lim _{T \rightarrow \infty} \exp \left\{T\left(\mu-\rho+\frac{1}{2} \sigma^{2}-\gamma \sigma\right)\right\} d Y_{t}
$$

This TVC is satisfied if and only if $\mu-\rho+\frac{1}{2} \sigma^{2}-\gamma \sigma<0$. The textbook condition $\rho<\mu$ is neither necessary nor sufficient for a TVC violation. A necessary and sufficient condition for the TVC to be satisfied is that there is enough permanent, priced risk in output: $\gamma \sigma>\mu-\rho+\frac{1}{2} \sigma^{2}$. The output risk premium $\gamma \sigma$ must be high enough. This ensures that this term $\mathbb{E}_{t}\left[M_{t, t+T} Y_{t+T}\right] \rightarrow 0$ as $T \rightarrow \infty$. Since the output risk premium is akin to the unlevered equity risk premium, and since the asset pricing literature suggests that the equity risk premium is large, the TVC is likely to be satisfied. In an economy with permanent GDP risk, comparing the risk-free rate to the average growth rate of the economy, as in Blanchard (2019), sheds no light on the fiscal cost of deficits. ${ }^{10}$

The TVC highlights the importance of modeling the dynamics of future outstanding debt. While the debt at $t, D_{t}$, is risk-free under Assumption 1, meaning that its value does not change

\footnotetext{
${ }^{10}$ See Bohn (1995) for an early reference on why discounting at the risk-free may fail.
} 
in response to news revealed between $t$ and $t+1$, the value of debt outstanding at some future date $t+T$, debt strip $D_{t+T}$, is a stochastic variable, even when the debt-to-output ratio is a constant, since $Y_{t+T}$ is random. More generally, as long as the debt quantity and the output are cointegrated, future debt inherits the permanent risk in output. As evident in (5), the risk premium associated with the debt strip at time $t+T$ is crucial in determining whether the TVC is satisfied.

When GDP growth has a permanent component, then the surplus process in levels $S_{t}$ inherits that permanent component from $Y_{t}$. Therefore, even when the entire debt portfolio is risk-free, the risk-free rate is not the right discount rate for surpluses in the presence of permanent output risk.

Tax Beta Next, we turn to the baseline result characterizing the expected return and the return beta of the tax claim.

Proposition 2.2. (a) The ex-dividend values of the spending and revenue claims are given by:

$$
P_{t}^{G}-G_{t}=x \frac{\xi_{1}}{1-\xi_{1}} Y_{t}, \quad P_{t}^{T}-T_{t}=\left(d+x \frac{\xi_{1}}{1-\xi_{1}}\right) Y_{t},
$$

with $\xi_{1}=\exp \left\{-\rho-\gamma \sigma+\mu+\frac{1}{2} \sigma^{2}\right\}$.

(b) The risk premia and betas on the tax claim and the spending claim satisfy:

$$
\mathbb{E}_{t}\left[R_{t+1}^{T}-R_{t}^{f}\right]=\frac{x \frac{\xi_{1}}{1-\xi_{1}}}{d+x \frac{\xi_{1}}{1-\xi_{1}}} \mathbb{E}_{t}\left[R_{t+1}^{G}-R_{t}^{f}\right], \quad \beta^{T}=\frac{x \frac{\xi_{1}}{1-\xi_{1}}}{d+x \frac{\xi_{1}}{1-\xi_{1}}} \beta^{G}<\beta^{G}
$$

The constant $\xi_{1}$ is the price/dividend ratio of a one-period output strip, a claim to GDP next year. The expected return on this output strip is given by $\mathbb{E}_{t}\left[R_{t+1}^{Y}\right]=\frac{\exp \left(\mu+0.5 \sigma^{2}\right)}{\exp \left(-\rho-\gamma \sigma+\mu+0.5 \sigma^{2}\right)}=$ $\exp (\rho+\gamma \sigma)$. Hence, the (log of the multiplicative) output risk premium is constant and equal to $\gamma \sigma$. Since spending is a constant fraction of output, the risk premium on the spending claim equals that of the output claim: $\mathbb{E}\left[R^{G}-R^{f}\right]=\mathbb{E}\left[R^{Y}-R^{f}\right]$. The beta of the spending claim equals the beta of the output claim: $\beta^{G}=\beta^{Y}>0$. In section $\mathrm{E}$ of the Appendix, we explicitly solve for these risk premia.

The investor in government debt is long in a tax revenue claim and short in a spending claim. To make the debt risk-free, as long as the debt/output ratio $d$ is positive, we need to render the government tax revenue process safer than the spending process. A positive $d$ implies the fraction $\frac{x \frac{\xi_{1}}{1-\xi_{1}}}{d+x \frac{\xi_{1}}{1-\tilde{\xi}_{1}}}$ is between 0 and 1 , which requires the return on the tax claim to be less risky than the return on the output claim: $0<\beta^{T}<\beta^{Y}$. When output falls, tax revenues must fall by less. The tax rate increases. In other words, there is no scope to insure taxpayers. As the debt/output ratio $d$ increases, the government needs to make the tax revenue increasingly safe. The tax claim is really a portfolio of a claim to government spending and risk-free debt. The larger the debt/output ratio $d$, the safer the tax claim needs to be. 


\subsection{The Case of $r<g$}

A particularly interesting case in this model is when the risk-free rate is lower than the average output growth rate. In our notation, $\rho<\mu$. To guarantee finite valuation, the TVC condition in Eq. (5) may be satisfied when the risk premium $\gamma \sigma$ on the output claim is large enough: $\rho+\gamma \sigma-$ $\frac{1}{2} \sigma^{2}>\mu$. In this case, if the Jensen's term $\frac{1}{2} \sigma^{2}$ is small enough so that $\rho+\frac{1}{2} \sigma^{2}<\mu$, then, the government can sustain deficits on average:

$$
\mathbb{E}\left[s_{t}\right]=\mathbb{E}\left[\frac{S_{t}}{Y_{t}}\right]=-d\left(1-\exp \left\{-\mu+\rho+\frac{1}{2} \sigma^{2}\right\}\right)<0
$$

However, this is not a free lunch: the beta constraint characterized by Proposition 2.2 still has to be satisfied. In other words, the average deficits reflect an insurance premium that is earned by the government by providing risk-free debt at the cost of increasing taxes in bad times. It is precisely the positive covariance between the marginal utility and the government surpluses that creates fiscal capacity to manufacture risk-free debt. The $r<g$ condition is neither necessary nor sufficient to gauge this fiscal capacity.

\subsection{Quantifying the Trade-off with Constant Debt-Output}

Panel A of Table 1 proposes a calibration of the model that matches basic features of post-war U.S. data. We set $\gamma$ to 1 . This parameter measures the maximum Sharpe ratio in the economy. A long asset pricing literature suggests that this is a reasonable value given high average excess returns on a broad set of risky assets. The standard deviation of annual output growth is set to $\sigma=5 \%$. The growth rate of real GDP is set to its observed value: $\mu=3.1 \%$. The real risk-free rate $\rho$ is set to $2 \%$. Spending accounts for $10 \%$ of GDP in post-war data: $x=0.10$. This calibration features a risk-free rate below the growth rate of output. However, per our discussion above, the TVC is satisfied because $-\rho+\mu+\frac{1}{2} \sigma^{2}-\gamma \sigma=\log \left(\xi_{1}\right)=-0.0418<0$.

The left panel of Figure 1 plots the risk premia on the tax and the spending claim as we vary the debt/output ratio $d$. The risk premium on the spending claim is $5 \%$ per annum. This is also the output risk premium, which we can think of as an unlevered equity premium. By Prop. 2.2, the risk premium on the tax claim is given by Eq. (6). The risk premium on the tax claim is $5 \%$ when $d=0$. It falls to $4 \%$ when $d=1$, and close to $3 \%$ when $d=2$. As the government becomes more levered, the tax claims must become safer for debt to remain risk-free. The scope for taxpayer insurance disappears. This trade-off steepens when we increase the maximum Sharpe ratio $\gamma$ from 1 in the left panel to 2 in the right panel. When $\gamma=2$, the risk premium on the spending claim is $10 \%$ per annum. The risk premium on the tax claim falls to $6 \%$ when $d=1$ and to $4 \%$ when $d=2$. 
Table 1: Benchmark Calibration for U.S.

\begin{tabular}{lcl}
\hline \multicolumn{3}{c}{ Panel A: Preferences and Output Dynamics } \\
\hline$\gamma$ & 1 & maximum annual Sharpe ratio \\
$\rho$ & $2.0 \%$ & $\begin{array}{l}\text { real risk-free rate } \\
\mu\end{array}$ \\
$3.1 \%$ & mean of growth rate of output \\
5 & $5.0 \%$ & std. of growth rate of output \\
\multicolumn{4}{c}{ Panel B: Debt/Output Ratio Dynamics } \\
\hline$\lambda$ & $1.94 \times \sigma$ & sensitivity of debt/output to output innovations \\
$d=\exp \left\{\phi_{0} /\left(1-\phi_{1}-\phi_{2}\right)\right\}$ & 0.37 & mean of debt/output \\
$\phi_{1}$ & 1.40 & AR(1) coeff of debt/output \\
$\phi_{2}$ & -0.48 & AR(2) coeff of debt/output \\
\hline \multicolumn{4}{c}{} \\
\hline$\beta_{g}^{g}$ & Panel C: Government Spending/Output Ratio Dynamics \\
$\varphi_{1}^{g}$ & $1.53 \times \sigma$ & sensitivity of spending/output to output innovations \\
$x=\exp \left\{\varphi_{0}^{g} /\left(1-\varphi_{1}^{g}\right)\right\}$ & 0.88 & AR(1) coeff of spending/output \\
& 0.10 & mean of govt. spending/output \\
\hline
\end{tabular}

Figure 1: Risk Premium of T and G Claims with $\gamma=1$ or 2

The figure plots the implied risk premium of the $\mathrm{T}$ and $\mathrm{G}$ claims when the debt/output ratio and spending/output ratio are constant. The figure plots two values for the maximum Sharpe ratio $\gamma$ of 1 (left panel) and $\gamma$ of 2 (right panel). The other parameters are given in Table 1.
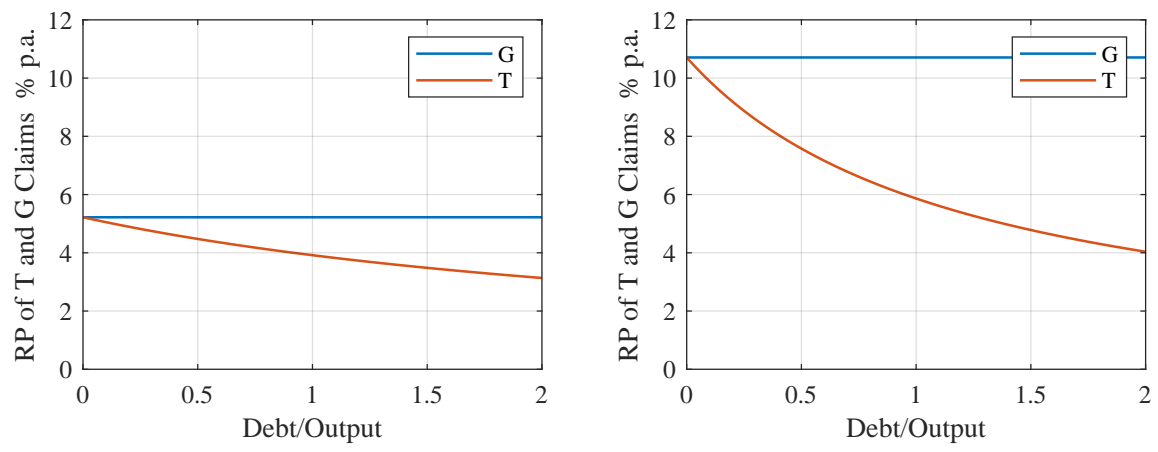

\subsection{Characterizing the Trade-off with Counter-cyclical Debt-Output}

The previous section showed that there is no scope for insuring taxpayers at any horizon in the presence of permanent output shocks when the debt/output ratio is constant. Next, we assume that the government commits to a state-contingent policy for the debt/output ratio which features persistence and counter-cyclicality. We show that this enables limited opportunities for the government to insure taxpayers over short horizons. The debt policies we analyze are fitted to the data and hence empirically plausible. We see this as a major advantage of our approach. ${ }^{11}$

\footnotetext{
${ }^{11}$ As Appendix C shows, a Ramsey planner in an incomplete markets environment would also choose a meanreverting and counter-cyclical process for debt. The Ramsey planner prefers tax rates that are smooth, and will resort
} 
We allow the government to vary the debt/output ratio counter-cyclically. We consider a flexible class of $A R(p)$ processes for the debt/output ratio.

Assumption 3. The government commits to a policy for the debt/output ratio $d_{t}=D_{t} / Y_{t}$ given by:

$$
\log d_{t}=\sum_{p=1}^{P} \phi_{p} \log d_{t-p}+\phi_{0}-\lambda \varepsilon_{t}-\frac{1}{2} \lambda^{2}
$$

where $\lambda>0$ so that the debt-output ratio increases in response to a negative output shock $\varepsilon_{t}$.

The results in Section 1 still apply and are a straightforward generalization of the results from the constant debt/output ratio case analyzed in Section 2.2. The value of the spending claim is unchanged. The value of the tax claim now depends on the time-varying debt/output ratio $d_{t}$ :

$$
P_{t}^{G}-G_{t}=x \frac{\xi_{1}}{1-\xi_{1}} Y_{t}, \quad P_{t}^{T}-T_{t}=\left(d_{t}+x \frac{\xi_{1}}{1-\xi_{1}}\right) Y_{t}
$$

The tax claim's conditional beta satisfies: $\beta_{t}^{T}=\frac{x \frac{\tilde{\xi}_{1}}{1-\tilde{\xi}_{1}}}{d_{t}+x \frac{\tilde{\xi}_{1}}{1-\xi_{1}}} \beta_{t}^{G}$.

Can the government systematically issue more risk-free debt, instead of raising taxes, when the economy is hit by a permanent, adverse shock, in order to break the restriction on insurance of taxpayers? We consider two empirically relevant cases for the debt/output dynamics.

Case 1: AR(1) Assume that the debt/output ratio evolves according to an $A R(1)$-process:

$$
\log d_{t}=\phi_{0}+\phi_{1} \log d_{t-1}-\lambda \varepsilon_{t}-\frac{1}{2} \lambda^{2}
$$

When $0<\phi_{1}<1$, the debt/output process is stationary. A positive $\lambda$ means that the debt/output ratio increases when the shock $\varepsilon_{t}$ is negative, implying a counter-cyclical debt policy. ${ }^{12}$ First, we need to make sure the transversality (TVC) is satisfied. How persistent can debt be without violating TVC?

Proposition 2.3. Under Assumptions 1 and 3 with lag $P=1$, when $0<\phi_{1}<1$, the TVC condition is satisfied if and only if $\log \left(\xi_{1}\right)=-\rho+\mu+\frac{1}{2} \sigma(\sigma-2 \gamma)<0$.

For the relevant case of $0<\phi_{1}<1$, the TVC is satisfied whenever the price-dividend ratio of a claim to next period's output, $\xi_{1}$, is less than one. That is, when investors are willing to pay less than $Y_{t}$ today for a claim to $Y_{t+1}$. This requires the discount rate to exceed the growth rate of GDP

to choosing counter-cyclical debt policy. Recall that tax rates are countercyclical if the debt/output ratio is constant and debt is risk-free. One difference with our setup is that the Ramsey planner chooses a negative debt target (saving rather than borrowing) in the long run. We discuss the case of government saving in Section 2.8.

${ }^{12}$ The Ramsey planner prefers tax rates that are smooth, and will resort to choosing counter-cyclical debt policy: $\lambda>0$. Recall that tax rates are countercyclical if the debt/output ratio is constant and debt is risk-free. 
(modulo a Jensen adjustment). This condition is satisfied even when $\rho<\mu$, as long as the output risk premium $\gamma \sigma$ is large enough. ${ }^{13}: \sigma \gamma>\mu-\rho+\frac{1}{2} \sigma^{2}$. In this case, the steady-state surplus is negative: $d=-\frac{s}{(1-\exp (\rho-\mu))}$. As we explained, the government can run steady-state deficits, even though the TVC is satisfied, because the government earns an insurance risk premium in exchange for insuring bondholders against aggregate risk by raising taxes in bad times. This is not a free lunch: the larger the steady-state deficits, the larger the increase in taxes required in bad times. ${ }^{14}$

Case 2: AR(2) As we show below, a better description of the debt/output ratio is the data is an $\mathrm{AR}(2)$ process:

$$
\log d_{t}=\phi_{0}+\phi_{1} \log d_{t-1}+\phi_{2} \log d_{t-2}-\lambda \varepsilon_{t}-\frac{1}{2} \lambda^{2}
$$

When the roots of the characteristic equation $1-\phi_{1} z-\phi_{2} z^{2}=0$ lie outside the unit circle, the debt/output process is mean-reverting. The result of Proposition 2.3 applies.

Response of the Surplus to Adverse Shock We can compute the impulse-response functions (IRF) of the surpluses with respect to an output shock in closed form when the government issues risk-free debt. These moments are particularly powerful because they do not depend on the properties of the SDF. We start from the expression for the surplus/output ratio in period $t+j$ for $j \geq 1$ : $s_{t+j}=\frac{s_{t+j}}{Y_{t+j}}=d_{t+j-1} \exp \left(\rho-\mu-\sigma \varepsilon_{t+j}\right)-d_{t+j}$, which follows directly from the government's static budget constraint. If we assume that the risk-free rate equals the growth rate of the economy $(\mu=\rho)$, we obtain closed-form expression for the IRF of the surplus with respect to an output shock. Specifically, the IRF is evaluated at $\varepsilon_{\tau}=0$ for all $\tau$, and hence $d_{t}=\exp \left(\frac{\phi_{0}-\frac{1}{2} \lambda^{2}}{1-\phi_{1}}\right)=\exp (\bar{d})$.

Proposition 2.4. If Assumptions 1 and 3 hold, the TVC is satisfied, and $\rho=\mu$, when the debt/output ratio follows an AR(2) process, the IRF of the surplus output ratio is given by:

$$
\begin{aligned}
\frac{\partial \frac{S_{t+j}}{\partial \varepsilon_{t+j}}}{\partial \varepsilon_{t+1}} & =-\sigma \exp (\bar{d})+\lambda \exp \left(\bar{d}-\frac{1}{2} \lambda^{2}\right), \text { for } j=1, \\
& =-\lambda \exp (\bar{d})+\lambda \phi_{1} \exp \left(\bar{d}-\frac{1}{2} \lambda^{2}\right), \text { for } j=2, \\
& =-\lambda \psi_{j-2} \exp (\bar{d})+\lambda \psi_{j-1} \exp \left(\bar{d}-\frac{1}{2} \lambda^{2}\right), \text { for } j>2 .
\end{aligned}
$$

where $\psi_{j}=\phi_{1} \psi_{j-1}+\phi_{2} \psi_{j-2}, j>2 ; \psi_{2}=\phi_{2}+\phi_{1} \psi_{1} ; \psi_{1}=\phi_{1} . \psi_{j}$ denotes the coefficients in the autocorrelation function.

\footnotetext{
${ }^{13}$ We formally derive the expression for the risk premium in section $\mathrm{E}$ of the Appendix.

${ }^{14}$ For the random walk case in which $\phi_{1}=1$, the TVC is only satisfied if: $\gamma \sigma-\lambda(\gamma-\sigma)>-\rho+\mu+\frac{1}{2} \sigma^{2} \Leftrightarrow \lambda<$ $\frac{\rho+\gamma \sigma-\mu-\frac{1}{2} \sigma^{2}}{\gamma-\sigma}$. Intuitively, when investors are risk averse enough, the insurance provided by the counter-cyclical debt issuance policy is so valuable that the price of a claim to the debt outstanding in the distant future $d_{t+T} Y_{t+T}$ fails to converge to zero. This result is derived in the Appendix. See section A.8.2.
} 
When the debt/output ratio follows an $\operatorname{AR}(1)\left(\phi_{2}=0\right)$, the initial response of the surplus is positive in the empirically relevant case where $\lambda>\sigma$. That is, a negative shock to output is countered with a large enough government debt issuance that the surplus in the initial period can be negative without jeopardizing the risk-free nature of the debt. However, the deficit must turn to a surplus starting in the second year since $\phi_{1}<1$. Surpluses remain in the years that follow. As the persistence of the debt/output process $\phi_{1}$ increases, the response of the surplus/output ratio converges to zero in year 2 and beyond.

For an $A R(2)$ process, by choosing $\phi_{1}>1$, the government can run a deficit in the year of the shock (year 1 ) as well as in the following year. In year three, the IRF equals $\lambda\left(\psi_{2}-\psi_{1}\right)=$ $\lambda\left(\phi_{2}+\phi_{1}\left(\phi_{1}-1\right)\right)$. This expression can be positive or negative depending on parameter values but is smaller than the response in year two. In other words, the government's ability to run a third year of deficits in response to the negative output shock is either limited or gone. The IRF flips sign in year three or four depending on parameters. The government must revert to running surpluses as the ACFs decline: $\psi_{j-1}<\psi_{j-2}$.

Prop. 2.4 can be generalized to any AR process. In Appendix, we also derive the case in which the debt/output ratio follows an $A R(3)$. Then, an additional year of deficits possible while keeping debt risk-free. These deficits must be made up by several years of surpluses afterwards. The surplus dynamics can display more pronounced hump-shaped IRFs. With higher-order $A R(P)$ models for debt/output, the government is able to run deficits for longer before a reversal. As shown below, there is no empirical support for higher-order $A R(P)$ dynamics (i.e., $P>2$ ) in the observed US debt/output process.

\subsection{Quantifying the Trade-Off with Counter-cyclical Debt/Output}

The calibration of the debt/output dynamics is reported in Panel B of Table 1. When we fit an $\operatorname{AR}(1)$, we estimate $\phi_{1}=0.985$. An AR(2) with the estimated coefficients $\phi_{1}=1.40$ and $\phi_{2}=-0.48$ provides the best fit. We compare the dynamics of the debt/output ratio in model and data in Appendix F. There is no empirical evidence supporting higher-order dynamics. We explore the implications of these debt/output dynamics for the surplus dynamics, provided that the debt be risk-free.

We choose $\phi_{0}$ to match the unconditional mean of the debt/output ratio of 0.37 . We set $\lambda=$ $1.953 \times \sigma$ equal to match the slope coefficient in a regression of the debt/output ratio innovations on GDP growth in the post-war U.S. sample. A one percentage point increase in GDP growth lowers the debt/output ratio by 1.95 percentage points. The parameter restriction in Proposition 2.3 is satisfied, despite the risk-free interest rate being below the growth rate of output, because the risk premium $\gamma \sigma$ is large enough.

Figure 2 plots the IRF of the surplus/output ratio (left panel) and the debt/output ratio (right 
Figure 2: IRF of Surplus/Output and Debt/Output in Model

The figure plots the IRF of $S / Y$ and $D / Y$ for an $A R(2)$. We vary $\phi_{1}$ and choose $\phi_{2}$ to match the first-order autocorrelation. The other parameters are given in Table 1.
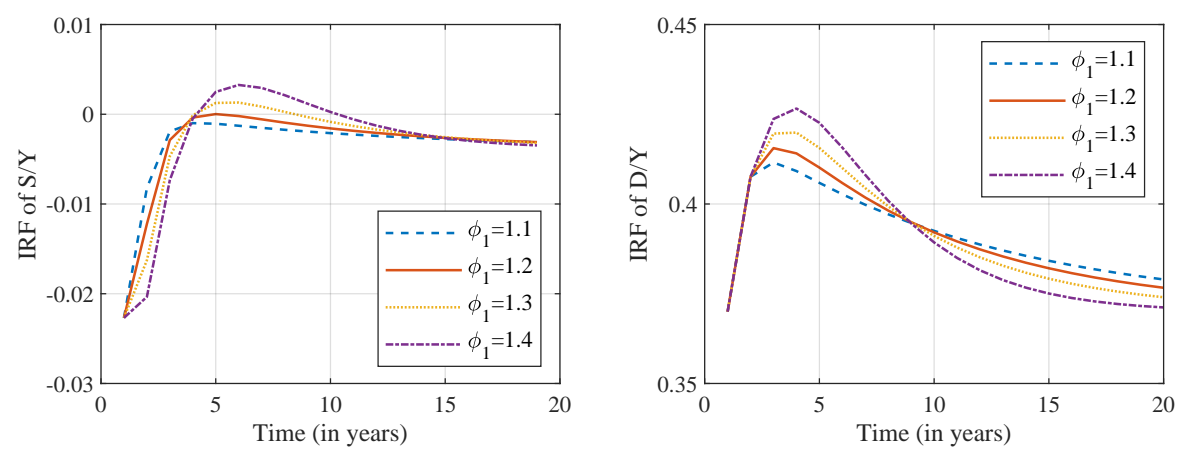

panel) when debt/output follows an AR(2), our preferred empirical specification. We vary $\phi_{1}$ from 1.1 to 1.4 and choose $\phi_{2}$ to match the first-order autocorrelation of debt/output. With $\phi_{1}=1.1$, the IRF looks similar to the $A R(1)$ case with $\phi_{1}$ close to 1 . However, with $\phi_{1}=1.4$ and $\phi_{2}=$ -0.48 , the point estimates from the data, the IRF for the surplus/output ratio displays a humpshaped pattern. Consistent with the results in Proposition 2.4, a state-contingent and persistent debt issuance policy enables the government to delay the fiscal adjustment. The deficit/output ratio in the year of the shock is followed by a second large deficit in year 2 . However, the deficit must shrink dramatically in year 3 and turn into a surplus starting in year 4 and beyond. The surplus eventually converges back to the steady-state surplus from above. Keeping debt risk-free still imposes severe restrictions on the size of the S-shaped surplus dynamics. Running sizeable deficits for more than two years is incompatible with risk-free debt.

To make the model's implications for tax revenues as comparable to the data as possible, we posit a more realistic process for spending/output than the one we have worked with hitherto. Specifically, we assume that the government commits to a policy for the spending/output ratio $x_{t}=G_{t} / Y_{t}$ given by:

$$
\log x_{t}=\varphi_{0}^{g}+\varphi_{1}^{g} \log x_{t-1}-b_{g} \varepsilon_{t}-\frac{1}{2} b_{g}^{2}
$$

When $b_{g}>0$, the spending/output ratio rises in response to a negative output shock. We estimate $\left(\varphi_{0}^{g}, \varphi_{0}^{g}, \beta^{g}\right)$ from the post-war U.S. data. The parameter estimates are reported in Panel C of Table 1. Spending/output is counter-cyclical in the data. A $1 \%$ point decline in output coincides with a $1.53 \%$ point increase in the spending/output ratio. The persistence of spending/output matches that in the data with an $\mathrm{AR}(1)$ coefficient of 0.88 . With this spending process in hand, we compute 
the model-implied tax revenue/output in the next section.

\subsection{The Insurance Trade-off over Short Horizons}

How much smoothing can the U.S. government achieve for taxpayers when debt is risk-free by issuing more debt in response to bad shocks? It depends on the horizon. Section 1.3 showed that we can gauge the welfare implications by examining the riskiness of the surplus process at different horizons. This section applies the general result to the asset pricing model and debt/output processes from the previous sections. In the presence of permanent shocks, the government can only insure taxpayers over a limited period of time.

\subsubsection{Cash-Flow Betas with Risk-free Debt}

We start by deriving closed-form expressions for the cash flow betas using the debt/output, output and pricing kernel dynamics. The general Proposition 1.4 specializes to the following result:

Proposition 2.5. Under Assumptions 1 and 3, when debt is risk-free and debt/output follows an autoregressive process as in (7), the cash-flow beta of the discounted surpluses over h periods is given by the beta of debt $h$ periods from now:

$$
\begin{aligned}
\beta_{t}^{S, C F}(h) & =\frac{\operatorname{cov}_{t}\left(M_{t+1},\left(\mathbb{E}_{t+1}-\mathbb{E}_{t}\right) M_{t+1, t+h} D_{t+h}\right)}{D_{t} \operatorname{var}_{t}\left(M_{t+1}\right)} \\
& =\frac{\mathbb{E}_{t}\left[M_{t+1}\right]}{D_{t} \operatorname{var}_{t}\left(M_{t+1}\right)} \mathbb{E}_{t}\left[M_{t+1, t+h} d_{t+h} Y_{t+h}\right]\left(\exp \left\{\gamma\left(\psi_{h-1} \lambda-\sigma\right)\right\}-1\right) .
\end{aligned}
$$

where $\psi_{j}=\phi_{1} \psi_{j-1}+\phi_{2} \psi_{j-2}, j>2 ; \psi_{2}=\phi_{2}+\phi_{1} \psi_{1} ; \psi_{1}=\phi_{1} ; \psi_{0}=1$, and $\operatorname{sign}\left(\beta_{t}^{S, C F}(h)\right)=$ $\operatorname{sign}\left(\gamma\left(\psi_{h-1} \lambda-\sigma\right)\right)$.

This result can easily be generalized to any AR process, with $\psi_{j}$ denoting the coefficients in the autocorrelation function. The risk properties of the government surpluses over a given horizon are completely determined by riskiness of the debt issuance process, as long as the debt is riskfree. The cash-flow beta of the surplus at various horizons does not depend on the spending and tax revenue dynamics. Analogously, we define the cash-flow beta of discounted government spending and of tax revenues.

Corollary 2.1. Under Assumptions 1 and 3, and when debt is risk-free and debt/output follows an AR(2) and the government commits to a policy of spending-to-output ratio following equation (8), the cash flow 
beta of spending and tax revenues have to satisfy the following restrictions:

$$
\begin{aligned}
\beta_{t}^{G, C F}(h) & =\sum_{j=1}^{h} \frac{\mathbb{E}_{t}\left[M_{t+1}\right]}{D_{t} v a r_{t}\left[M_{t+1}\right]} \mathbb{E}_{t}\left[M_{t+1, t+j} x_{t+j} Y_{t+j}\right]\left(\exp \left\{\gamma\left(\varphi_{g}^{j-1} b_{g}-\sigma\right)\right\}-1\right) . \\
\beta_{t}^{T, C F}(h) & =\frac{\mathbb{E}_{t}\left[M_{t+1}\right]}{D_{t} \operatorname{var}_{t}\left[M_{t+1}\right]} \mathbb{E}_{t}\left[M_{t+1, t+h} d_{t+h} Y_{t+h}\right]\left(\exp \left\{\gamma\left(\psi_{h-1} \lambda-\sigma\right)\right\}-1\right) \\
& +\sum_{j=1}^{h} \frac{\mathbb{E}_{t}\left[M_{t+1}\right]}{D_{t} v a r_{t}\left[M_{t+1}\right]} \mathbb{E}_{t}\left[M_{t+1, t+j} x_{t+j} Y_{t+j}\right]\left(\exp \left\{\gamma\left(\varphi_{g}^{j-1} b_{g}-\sigma\right)\right\}-1\right) .
\end{aligned}
$$

The properties of the $\beta_{t}^{G, C F}(h)$ depend on the persistence and cyclicality of the exogenous spending/GDP process in equation (8). The properties of $\beta_{t}^{T, C F}(h)$ depend on the risk properties of both the debt claim and the spending claim.

\subsubsection{The Trade-off over Short Horizons with Constant Debt-Output}

When debt/output is constant $(\lambda=0)$, Proposition 2.5 implies:

$$
\beta_{t}^{S, C F}(h)=\frac{\mathbb{E}_{t}\left[M_{t+1}\right]}{D_{t} \operatorname{var}_{t}\left[M_{t+1}\right]} \mathbb{E}_{t}\left[M_{t+1, t+h} d Y_{t+h}\right](\exp \{-\gamma \sigma\}-1) .
$$

The cash-flow beta of the surplus is negative at all horizons since $\gamma \sigma>0$. In bad times, the surplus/output ratio goes up. When spending/output is constant (or also goes up), tax revenues/output must go up. The government cannot insure taxpayers against adverse output shocks. Rather, the taxpayers insure the bondholders.

Panel A of Figure 3 plots the risk premium on a claim to cumulative surpluses over the next $h$ periods in the left panel. It is the spending beta multiplied by the market prices of risk, $\beta_{t}^{S, C F}(h) \times$ $\frac{\operatorname{var}_{t}\left[M_{t+1}\right]}{\mathbb{E}_{t}\left[M_{t+1}\right]}$. The cumulative risk premium at horizon $h$ is the sum of the individual strip risk premia up until horizon $h$. The negative risk premium over short horizons indicates that surpluses are a hedge. Since taxpayers are short the surplus claim, their tax-minus-transfer liability is risky. When debt/output is constant and there is no possibility to raise the debt in response to an adverse shock, the surplus/output ratio must rise on impact. This makes the one-period surplus claim a hedge. The year-2 surplus claim in contrast earns a small positive risk premium, reflecting the underlying output risk, so that the cumulative 2-period surplus risk premium is higher than the 1-period surplus risk premium. As $h \rightarrow \infty$, the sum of discounted surpluses converges to the current value of debt $D_{t}$. Insisting on risk-free debt $\left(\beta_{t}^{D}=0\right)$ implies that $\beta_{t}^{S, C F}(h) \rightarrow 0$. The red line in the left panel converges to zero from below for large $h$.

The solid black line in the left panel plots the risk premium on the claim to cumulative government spending over the next $h$ periods. It equals the cash-flow beta of the $h$-period spending claim multiplied by the market price of risk. Since the spending/output dynamics are exoge- 


\section{Figure 3: Risk Premia Across Horizons}

The figure plots the risk premium of cumulative discounted cash flows, $\beta_{t}^{i, C F}(h) \times \frac{v^{2} r_{t}\left[M_{t+1}\right]}{\mathbb{E}_{t}\left[M_{t+1}\right]}$, in the left panel against the horizon $h$. The right panel plots the risk premium on the debt strips: $1-\exp \left\{\gamma\left(\phi^{h-1} \lambda-\sigma\right)\right\}$. The parameters are given in Table 1, except for the debt dynamics in the first two panels.

Panel A: Constant Debt/Output $(\lambda=0)$
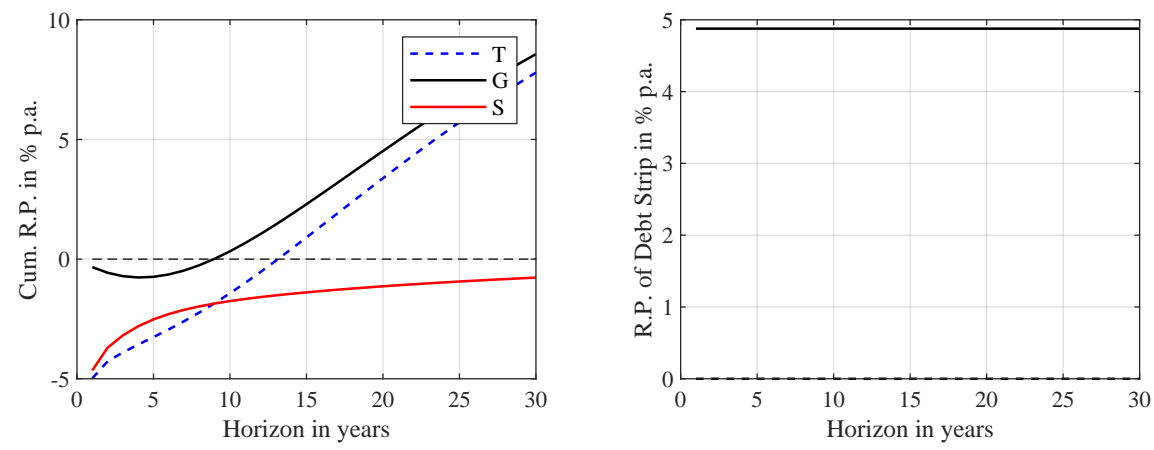

Panel B: AR(1) Debt/Output $\left(\phi_{1}=0.75\right)$
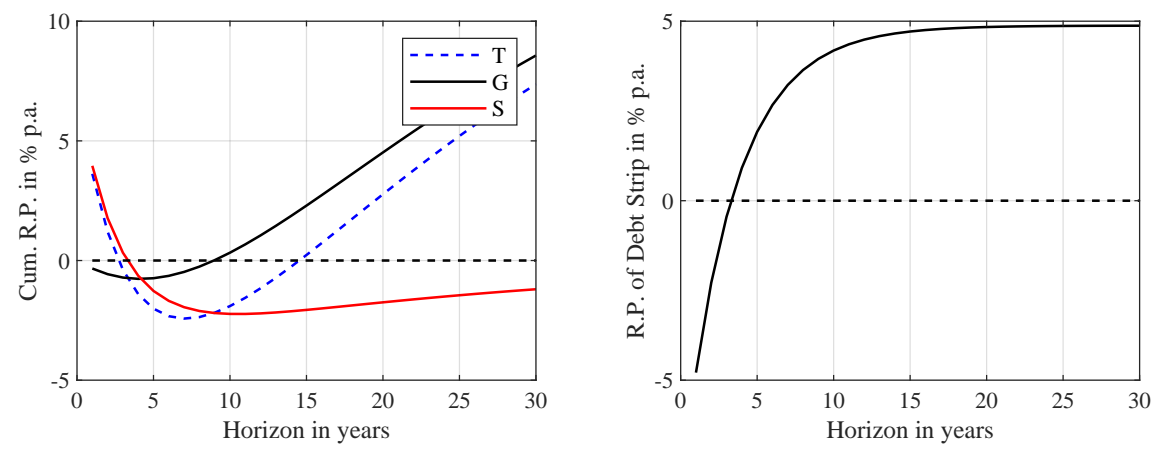

Panel C: $A R(2)$ Debt/Output ( $\left.\phi_{1}=1.40, \phi_{2}=-0.48\right)$
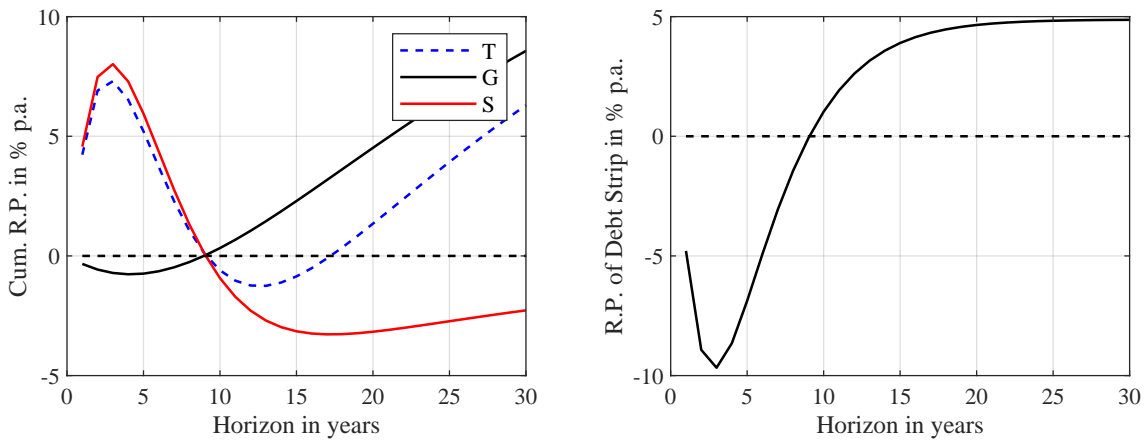

nously given, the spending beta does not depend on the debt policy. The countercyclical nature of spending/output makes the risk premium negative at short horizons. At longer horizons, the 
spending risk premium turns positive reflecting the long-run output risk in the spending claim, since the spending/output ratio is stationary.

The extent of taxpayer insurance is captured by $\beta_{t}^{T, C F}(h)$. The blue dashed line in the left panel plots $\beta_{t}^{T, C F}(h)$ multiplied by the market price of risk, the risk premium on a claim to the next $h$ periods of tax revenue. When this risk premium is negative, taxpayers are providing insurance to the government rather than receiving insurance. The risk premium is negative until year 13 for our parameters. It then turns positive. The positive risk premium on longer-dated tax strips reflects cointegration between tax revenues and output and a positive risk premium for output risk.

The tax beta $\beta_{t}^{T, C F}(h)$ in the left panel is below the spending beta $\beta_{t}^{G, C F}(h)$ at all horizons. As $h \rightarrow \infty$, these cash-flow betas converge to the return betas $\beta_{t}^{T}$ and $\beta_{t}^{G}$. As we discussed in Corollary $1.2, \beta_{t}^{T}<\beta_{t}^{G}$ was the condition to keep the debt risk-free.

On the right-hand side of Panel A, we report a scaled version of the risk premium on the debt strips. Specifically, it is the valuation of the debt strip scaled by its expectation at time $t$ and multiplied by the market price of risk $\frac{\operatorname{var}_{t}\left(M_{t+1}\right)}{\mathbb{E}_{t}\left[M_{t+1}\right]}$ :

$$
R P_{t}^{D \text { strip }}(h)=-\frac{\operatorname{cov}_{t}\left(M_{t+1}, \frac{\left(\mathbb{E}_{t+1}-\mathbb{E}_{t}\right) M_{t+1, t+h} D_{t+h}}{\mathbb{E}_{t}\left[M_{t+1, t+h} D_{t+h}\right]}\right)}{\operatorname{var}_{t}\left(M_{t+1}\right)} \frac{\operatorname{var}_{t}\left(M_{t+1}\right)}{\mathbb{E}_{t}\left[M_{t+1}\right]} .
$$

When the debt/output ratio is a constant, this risk premium on the debt strip is also a constant, given by $1-\exp \{-\gamma \sigma)\}$. We recall that the risk premium on the $h$-period debt strip is inversely related to the risk premium on the cumulative surpluses over the next $h$ periods. To offset the output risk in the debt strips, the risk premium on the surplus has to be negative.

\subsubsection{AR(1) for debt/output}

The sign and magnitude of the cash-flow beta of the surplus $\beta_{t}^{S, C F}(h)$ are now governed by $\gamma\left(\phi_{1}^{h-1} \lambda-\right.$ $\sigma)$, where $\phi_{1}$ is the autocorrelation coefficient of the debt/output ratio.

If debt/output is pro-cyclical $(\lambda \leq 0), \beta_{t}^{S, C F}(h)<0$ at all horizons. We are back in the previous case. In other words, when the government repays debt in bad times, it cannot provide any insurance to its taxpayers. In the empirically relevant case of $\lambda>\sigma>0$, the initial $\beta_{t}^{S, C F}(1)>0$. By issuing more debt in response to an adverse shock, the government prevents the tax rate and the surplus from going up. This provides insurance to the taxpayers $\beta_{t}^{T, C F}(1)>0$. The left plot in Panel B of Figure 3 shows the positive risk premium on cumulative surplus and tax claims at horizon $h=1$. The one-period debt strip has a negative risk premium, $1-\exp \{\gamma(\lambda-\sigma)\}$, due to the counter-cyclical nature of debt issuance, as shown in the right panel. The negative risk premium is $-\gamma(\lambda-\sigma) \approx-\gamma \sigma$ is almost as large as the output risk premium in absolute value, because $\lambda$ is close to $2 \sigma$. The one-period surplus can be risky because that risk is offset by the safety of the debt 
issuance at time $t+1$.

Due to its $\mathrm{AR}(1)$ nature, the debt/output ratio starts to revert back to its mean the very next period after a shock. The risk premium on the cumulative two-period surplus depends on $\gamma\left(\phi_{1} \lambda-\right.$ $\sigma)$ which is still positive but not as large as the one-period risk premium since $\phi_{1}<1$. The risk premium on the strip that pays the annual surplus two years from now is negative, pulling down the cumulative strip risk premium. Conversely, the cumulative two-period debt strip risk premium is not as negative as the one-period debt strip risk premium.

The surplus beta $\beta_{t}^{S, C F}(h)$ inherits the dynamics of the $A R(1)$ process for the debt/output ratio. As $h$ increases, the surplus beta eventually switches signs. This occurs at the first time $h$ for which $\phi^{h-1} \lambda<\sigma$. If the rate of mean-reversion in debt is high ( $\phi_{1}$ is small), this switch occurs sooner. If the debt/output ratio is more persistent, the sign switch occurs later.

Given the counter-cyclical nature of government spending, the tax beta $\beta_{t}^{T, C F}(h)$ must cross over into negative territory sooner than the surplus beta. There is only a limited amount of taxpayer insurance that the government can provide when debt is risk-free and follows AR(1) dynamics. This insurance is further curtailed due to the counter-cyclical nature of spending.

As the right figure of Panel B shows, the risk premium on the debt strip increases with the horizon. As $h \rightarrow \infty$, it converges to the risk premium on a long-dated output strip. Again, this reflects the fact that debt is co-integrated with output. It is common in the literature to assume that this risk premium is zero at long horizons, because this allows discounting at the risk-free rate. In the presence of permanent shocks, this is incorrect. Similarly, the risk premia on the long-dated Tand G-strips also converge to risk premium on the long-dated output strip as $h \rightarrow \infty$.

When output shocks are i.i.d. and permanent, far-out surpluses are risky as they inherit the permanent output risk. Medium-term surpluses must be safe and have negative risk premia to offset both the positive risk premium of the short-run surpluses (short-run insurance provision to the taxpayer) and the positive risk premium of the long-run surpluses (output risk). Equivalently, the cash-flow betas of the tax strip must be below those of the spending strip at medium horizons. The cash-flow beta at $h=\infty$ equals the return beta, and so $\beta_{t}^{T}<\beta_{t}^{G}$ ensures that $\beta_{t}^{D}=0$. Permanent output risk rules out insurance provision to taxpayers over long horizons.

\subsection{4 $\operatorname{AR(2)~for~debt/output~}$}

In our preferred case of an $\mathrm{AR}(2)$ for debt/output, the sign of the cash flow beta of the surplus is determined by $\gamma\left(\psi_{j-1} \lambda-\sigma\right)$. If $\lambda>\sigma$, the initial surplus beta is positive. The second beta is larger since $\psi_{1}=\phi_{1}>1$. The third beta remains positive and is larger than the second beta if $\psi_{2}>\psi_{1}$ or $\phi_{1}\left(\phi_{1}-1\right)+\phi_{2}>0$. This condition is satisfied for our point estimates $\phi_{1}=1.40$ and $\phi_{2}=-0.48$. For these parameter values, the fourth beta is lower than the third, the fifth lower than the fourth, etc. Eventually the surplus cash-flow beta crosses over into negative territory. Panel C of Figure 
3 shows this occurs in year 9. The cash-flow beta for tax revenue follows a similar pattern. The cash-flow betas inherit the hump-shaped pattern from the debt/output ratio.

What allows the government to provide temporary insurance to taxpayers is debt issuance policy with more history dependence. Risk premia on debt strips, shown in the right panel, are more negative than in the AR(1) model and remain negative for longer ( 9 versus 3 years). The slow expansion and repayment of the debt in response to an adverse shock allows the government to postpone fiscal rectitude. But as $h$ increases, the expression $\gamma\left(\sigma-\psi_{j-1} \lambda\right)$ turns positive and converges to $\gamma \sigma$, the risk premium on the output strip. In sum, the cumulative surplus can be risky over a horizon $h$ (providing insurance to the tax payer) only if this risk is offset by the safety of debt issuance at time $t+h$. Insurance provision to the tax-payer is necessarily short-lived because of the long-run risk in debt.

\subsubsection{Strength of Counter-cyclical Debt Issuance}

The extent of taxpayer insurance crucially depends on the parameter $\lambda$, which measures the degree of counter-cyclicality of the debt issuance policy. To illustrate this point, Figure 4 lowers the value of $\lambda$ from $1.95 \times \sigma$ to $1.27 \times \sigma$. All other parameters remain at their benchmark values. Compared to Panel $\mathrm{C}$ of Figure 3, the short-run surplus beta is much lower and increases by less: from $1 \%$ to $3 \%$ for $h=1$ to $h=3$ compared to a change from $5 \%$ to $8 \%$ in the benchmark. In the panel on the right of Figure 4 , the risk premium on the one-year debt strip, $\gamma(\sigma-\lambda) \approx-0.27 \gamma \sigma$, is only approximately $27 \%$ of the output risk premium in absolute value. The debt issuance risk premium only decreases to $-4 \%$ in period $h=3$, compared to $-10 \%$ in the benchmark (Panel C of Figure 3).

The alternative value of $\lambda=1.27 \times \sigma$ is the value for the United Kingdom, estimated over the same sample as for the United States. Appendix G contains the estimation details for the U.K. The U.K. government does not issue debt as aggressively in bad times as the U.S. government. Arguably, strong global demand for Treasurys allows the U.S. to dramatically increase debt issuance in bad times. The high $\lambda$ is what allows the U.S. government to provide more taxpayer insurance than the U.K. government.

Consistent with the model's prediction that the U.S. provides more insurance to taxpayers at business-cycle frequencies, the actual one-year beta of tax revenue growth with respect to GDP growth is much higher in the U.S. than in the U.K. The left panels of Figure 5 show a GDP growth beta for the tax revenue of 3 for the U.S. and 0.5 for the U.K at the one-year horizon. The strong counter-cyclicality of debt issuance in the U.S. results in a much riskier tax revenue claim for the U.S. government (a safer claim for the U.S. taxpayer) than in the U.K.

The differential riskiness of the tax claims in the U.S. and the U.K. is not driven by different riskiness in the spending claims. As shown in the right panels of Figure 5, both countries' spend- 
Figure 4: Risk Premia Across Horizons: Lower $\lambda$

The figure plots the risk premium of cumulative discounted cash flows, $\beta_{t}^{i, C F}(h) \times \frac{\operatorname{var}_{t}\left[M_{t+1}\right]}{\mathbb{E}_{t}\left[M_{t+1}\right]}$, in the left panel against the horizon $h$. The right panel plots the risk premium on the debt strips: $1-\exp \left\{\gamma\left(\phi^{h-1} \lambda-\sigma\right)\right\}$. The parameters are given in Table 1 , except for $\lambda$. We choose $\lambda=1.27$, based on the U.K. data
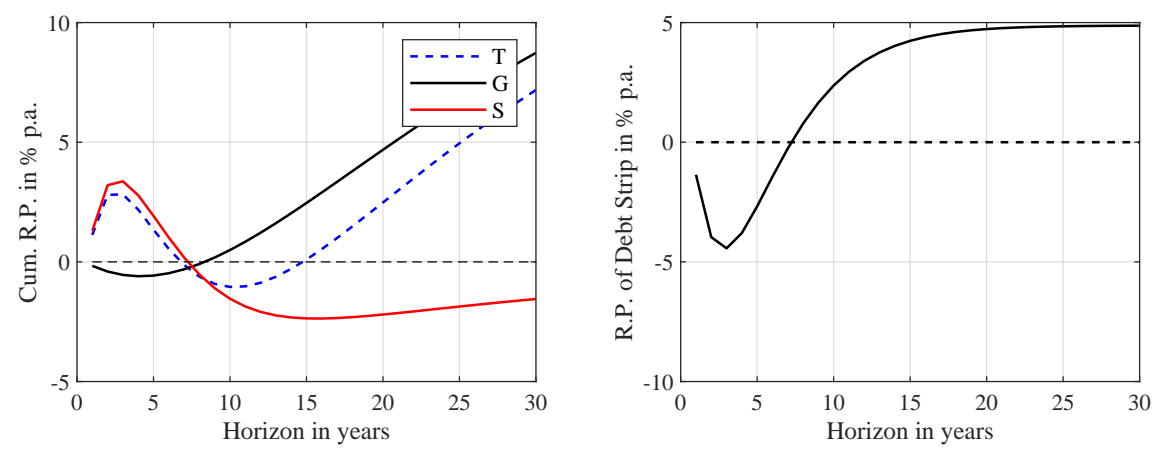

ing processes have similar covariances with GDP.

\subsubsection{Strength of Counter-cyclical Government Spending}

In Appendix $\mathrm{H}$, we analyze the effect of the counter-cyclicality of government spending on the trade-off. The more counter-cyclical government spending is (higher $b_{g}$ in Eq. (8)), the steeper the trade-off between insuring bondholders and taxpayers becomes.

\subsection{Government Savings}

Sofar, we have analyzed the case where the government borrows $(D>0)$. When, instead, the government saves $(D<0)$, it can insure taxpayers at all horizons and escape the trade-off. Appendix $C$ shows that a Ramsey planner would choose to accumulate savings in the long run. ${ }^{15}$

We consider a government which saves at the risk-free rate. We use the following stochastic AR-process in logs:

$$
\log d_{t}=\phi_{0}+\phi_{1} \log d_{t-1}+\phi_{2} \log d_{t-2}+\lambda \varepsilon_{t}-\frac{1}{2} \lambda^{2}
$$

where $\lambda$ now enters with a positive sign. Savings in levels is given by: $-D_{t}=-\exp \left(\log d_{t}\right)$. The results in Proposition 2.5 go through. Because $D<0$, the government now has a short position

\footnotetext{
${ }^{15}$ In the face of incomplete markets and risk-free debt, the Ramsey planner typically wants the government to accumulate assets in the long run (Bhandari et al., 2017). In doing so, the government can escape the trade-off between insuring bondholders and taxpayers. The U.S. and most other developed economies chose not to go down this route. This literature has not modeled the seigniorage revenue governments can only earn by manufacturing safe debt. This non-distortionary source of revenue may counteract the fiscal hedging motive for choosing risky debt in the short run and accumulating assets in the long run.
} 
Figure 5: GDP Growth Betas for Taxes and Spending

GDP Growth Betas against horizon in years computed by running regressions of tax revenue growth (in logs) and spending growth (in logs) on GDP growth (in logs). The tax betas are in the left panels. The spending betas in the right panels. Sample: $1947-2017$. Annual data.

Panel A: U.S.
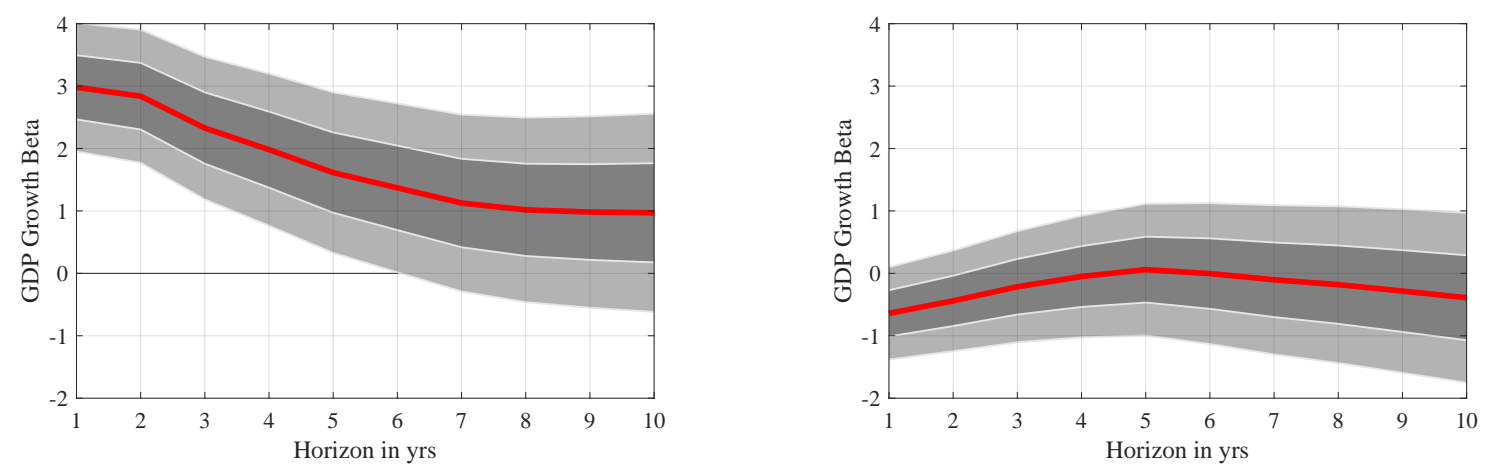

Panel B: U.K.
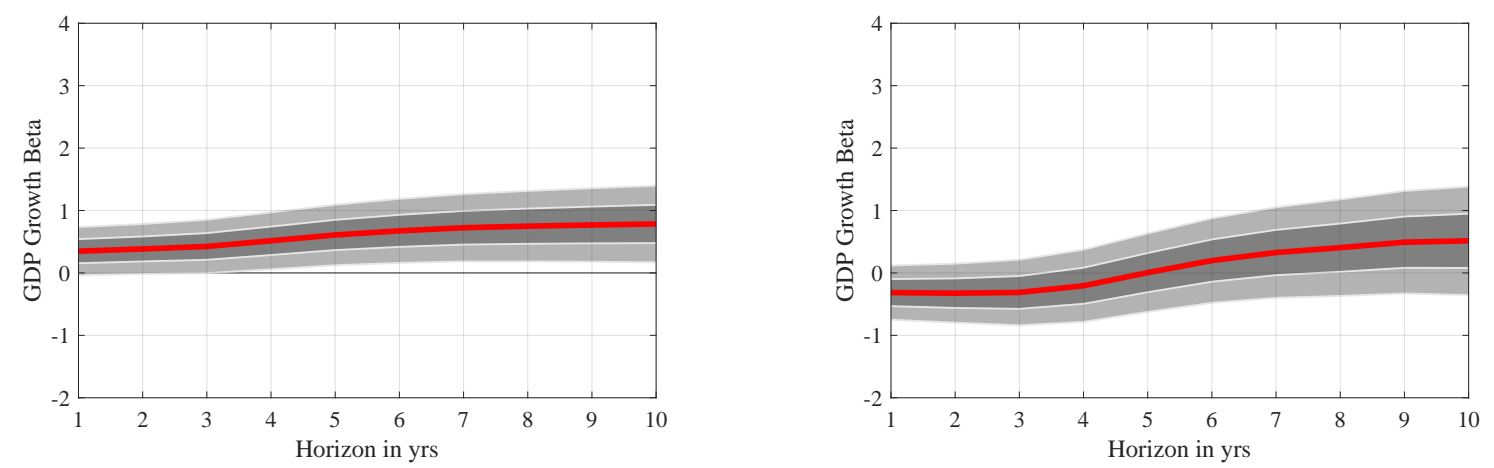

in permanent output risk because the value of taxes is smaller than the value of spending. As a result, to keep its savings risk-free, the government surpluses have to contribute enough long-run output risk.

In the simplest case in which the savings/output ratio is constant $(\lambda=0)$, Proposition 2.5 implies:

$$
\beta_{t}^{S, C F}(h)=\frac{\mathbb{E}_{t}\left[M_{t+1}\right]}{-D_{t} \operatorname{var}_{t}\left[M_{t+1}\right]} \mathbb{E}_{t}\left[M_{t+1, t+h} d Y_{t+h}\right](1-\exp \{-\gamma \sigma\})
$$

The sufficient statistic for taxpayer insurance possibilities, $\beta_{t}^{S, C F}(h)$, is positive at all horizons since $\gamma \sigma>0$. This means that, the surplus/output ratio declines in bad times. When spending/output is constant (or goes up) in bad times, tax revenues/output must also decline. The government can insure taxpayers against adverse output shocks at all horizons. In fact, it has to do so, because its savings are risk-free. 
In the benchmark case where the savings/output ratio fluctuates, with the parameters from Table 1 and a target savings/output ratio of 37\% of GDP, the short-run surplus risk premium is above $10 \%$ as shown in the left panel of Figure 6 . The cumulative surplus risk premium remains positive at every horizon, indicating that surpluses are risky over all horizons. Since taxpayers are short the surplus claim, they receive insurance at every horizon. As $h \rightarrow \infty$, the sum of discounted surpluses converges to the current value of savings $D_{t}$. Insisting on risk-free savings $\left(\beta_{t}^{D}=0\right)$ implies that $\beta_{t}^{S, C F}(h) \rightarrow 0$. The red line in the left panel converges to zero from above.

Figure 6: Risk Premia Across Horizons with Saving

The figure plots the risk premium of cumulative discounted cash flows, $\beta_{t}^{i, C F}(h) \times \frac{v^{2} r_{t}\left[M_{t+1}\right]}{\mathbb{E}_{t}\left[M_{t+1}\right]}$, in the left panel against the horizon $h$. The right panel plots minus the risk premium on the debt/savings strips: $1-\exp \left\{\gamma\left(\phi^{h-1} \lambda-\sigma\right)\right\}$. The parameters are given in Table 1.

\section{AR(2) Savings/Output}
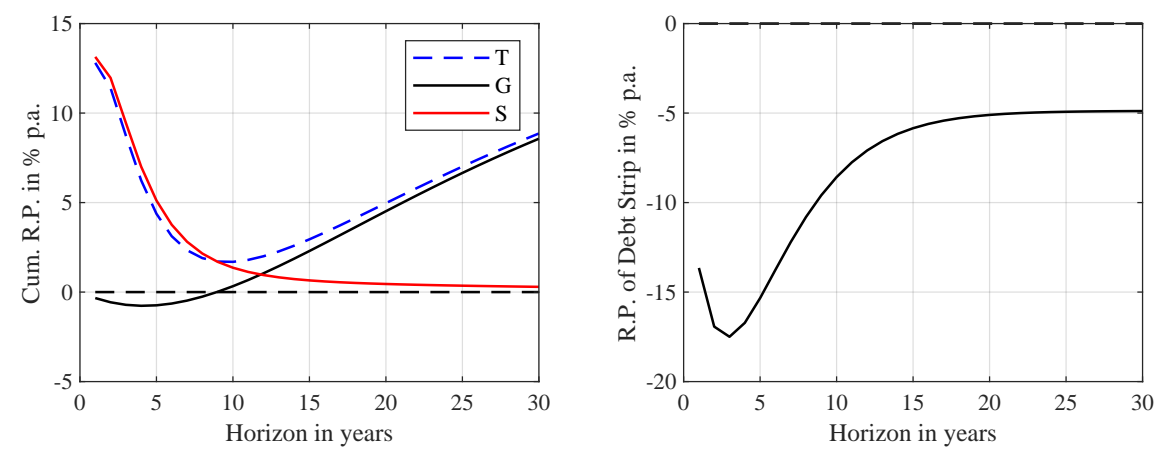

\section{Relaxing the Trade-off with Convenience Yields}

Some governments are endowed with the ability to issue safe government debt at prices that exceed their fair market value. Typically, the debt of such government serves the role of a special, safe asset for domestic or foreign investors. U.S. Treasuries currently fill the role of the world's safe asset. We investigate whether the resulting "convenience yields" relax the trade-off between insuring bondholders and taxpayers. In order to collect convenience yields, the government needs to manufacture safe debt. This justifies our emphasis on the $\beta^{D}=0$ case throughout this paper (or $\beta^{D}<0$, which makes all results stronger).

The convenience yield $\kappa_{t}$ is defined as a wedge in the investors' Euler equation for government bonds: $\mathbb{E}_{t}\left[M_{t, t+1} R_{t}^{D}\right]=\exp \left(-\kappa_{t}\right)$. Krishnamurthy and Vissing-Jorgensen (2012) estimate convenience yields on U.S. Treasuries of around 75 bps per year. Using the deviations from CIP in Treasury markets, Jiang et al. (2021); Jiang, Krishnamurthy, and Lustig (2018); Koijen and Yogo (2019) estimate convenience yields that foreign investors derive from their holdings of dollar safe 
assets that exceed 200 bps.

\subsection{The Trade-off With Return Betas Over Long Horizons}

We incorporate convenience yields in the analysis of Section 1 . Let $K_{t+j}=\left(1-e^{-\kappa_{t+j}}\right) D_{t+j}$ be the amount of interest the government does not need to pay in period $t+j$ thanks to the convenience yield. The current value of government debt reflects the present value of all convenience yields earned on future debt. We refer to this value as the Treasury's seigniorage revenue: $P_{t}^{K}=\mathbb{E}_{t}\left[\sum_{j=0}^{\infty} M_{t, t+j}\left(1-e^{-\kappa_{t+j}}\right) D_{t+j}\right]$. Jiang et al. (2019b) show that the value of the government debt equals the sum of the present value of future tax revenues plus future seigniorage revenues minus future government spending:

$$
B_{t}=\mathbb{E}_{t}\left[\sum_{j=0}^{\infty} M_{t, t+j}\left(T_{t+j}+\left(1-e^{-\kappa_{t+j}}\right) D_{t+j}-G_{t+j}\right)\right]=P_{t}^{T}+P_{t}^{K}-P_{t}^{G},
$$

provided that the transversality condition for debt holds.

Extending the Modigliani-Miller approach to the world with convenience yields, government debt is equivalent to a portfolio that goes long in the tax revenue claim and the seigniorage revenue claim and short in the spending claim. The government debt risk premium becomes:

$\mathbb{E}_{t}\left[R_{t+1}^{D}-R_{t}^{f}\right]=\frac{P_{t}^{T}-T_{t}}{B_{t}-S_{t}} \mathbb{E}_{t}\left[R_{t+1}^{T}-R_{t}^{f}\right]+\frac{P_{t}^{K}-T_{t}}{B_{t}-S_{t}} \mathbb{E}_{t}\left[R_{t+1}^{K}-R_{t}^{f}\right]-\frac{P_{t}^{G}-G_{t}}{B_{t}-S_{t}} \mathbb{E}_{t}\left[R_{t+1}^{G}-R_{t}^{f}\right]$,

where $R_{t+1}^{D}, R_{t+1}^{T}, R_{t+1}^{K}$ and $R_{t+1}^{G}$ are the holding period returns on the bond portfolio, the tax claim, the seigniorage claim, and the spending claim, respectively.

Taking the government spending and debt return process as given, we explore the implications for the properties of the tax claim. We impose that debt is risk-free because only safe debt earns convenience yields.

Proposition 3.1. In the absence of arbitrage opportunities, if the TVC holds and the debt is risk-free ( $\beta^{D}=$ $0)$, then the expected excess return on the tax claim is the unlevered expected excess return on the spending claim and the seigniorage claim:

$$
\mathbb{E}_{t}\left[R_{t+1}^{T}-R_{t}^{f}\right]=\frac{\left(P_{t}^{G}-G_{t}\right) \mathbb{E}_{t}\left[R_{t+1}^{G}-R_{t}^{f}\right]-\left(P_{t}^{K}-K_{t}\right) \mathbb{E}_{t}\left[R_{t+1}^{K}-R_{t}^{f}\right]}{D_{t}+\left(P_{t}^{G}-G_{t}\right)-\left(P_{t}^{K}-K_{t}\right)},
$$

with the beta of the tax claim given by $\beta_{t}^{T}=\frac{\left(P_{t}^{G}-G_{t}\right)}{D_{t}+\left(P_{t}^{G}-G_{t}\right)-\left(P_{t}^{K}-K_{t}\right)} \beta_{t}^{G}-\frac{\left(P_{t}^{K}-K_{t}\right)}{D_{t}+\left(P_{t}^{G}-G_{t}\right)-\left(P_{t}^{K}-K_{t}\right)} \beta_{t}^{K}$.

Consider the case where the convenience yield seigniorage process has a zero return beta $\left(\beta^{K}=\right.$ $0)$; seigniorage revenues are a-cyclical. Then the implied beta of the tax revenue process exceeds 
the beta without seigniorage revenue because $P_{t}^{K}-K_{t}>0$ :

$$
\beta_{t}^{T}=\frac{P_{t}^{G}-G_{t}}{D_{t}+\left(P_{t}^{G}-G_{t}\right)-\left(P_{t}^{K}-K_{t}\right)} \beta_{t}^{G}>\frac{P_{t}^{G}-G_{t}}{D_{t}+\left(P_{t}^{G}-G_{t}\right)} \beta_{t}^{G},
$$

A higher tax beta means that the presence of convenience yields expands insurance provision to taxpayers.

If the seigniorage revenue beta is negative $\left(\beta^{K}<0\right)$, then the proposition shows that $\beta_{t}^{T}$ is higher still so that even more taxpayer insurance is possible. Conversely, a positive $\beta^{K}$ shrinks taxpayer insurance possibilities. In sum, the extent to which convenience yields relax the trade-off depends on the properties of the seigniorage revenue stream they generate.

\subsection{The Trade-off With Cash-Flow Betas over Short Horizons}

We now explore how the trade-off over finite horizons is affected by the presence of convenience yields. We do so under the assumption that seigniorage revenue from convenience is proportional to the debt outstanding.

Assumption 4. The convenience yield $\kappa$ is constant.

We define the cash flow beta of future discounted seigniorage revenue as:

$$
\beta_{t}^{K, C F}(h) \equiv \frac{-\left(1-e^{-\kappa}\right) \cdot \operatorname{cov}_{t}\left(M_{t+1},\left(\mathbb{E}_{t+1}-\mathbb{E}_{t}\right) \sum_{j=1}^{h} M_{t+1, t+j} D_{t+j}\right)}{D_{t} \operatorname{var}_{t}\left(M_{t+1}\right)}
$$

Proposition 3.2. The return beta of debt equals the cash-flow beta of the discounted surpluses and seigniorage revenues over the next $h$ periods minus the beta of debt outstanding $h$ periods from now:

$$
\beta_{t}^{D}=\beta_{t}^{S, C F}(h)+\beta_{t}^{K, C F}(h)-\frac{\operatorname{cov}_{t}\left(M_{t+1},\left(\mathbb{E}_{t+1}-\mathbb{E}_{t}\right) M_{t+1, t+h} D_{t+h}\right)}{D_{t} \operatorname{var}_{t}\left(M_{t+1}\right)} .
$$

When debt is risk-free $\left(\beta_{t}^{D}=0\right)$, then the cash flow beta is determined by the seigniorage beta and beta of the debt outstanding $h$ periods from now:

$$
\beta_{t}^{S, C F}(h)=\frac{\operatorname{cov}_{t}\left(M_{t+1},\left(\mathbb{E}_{t+1}-\mathbb{E}_{t}\right) M_{t+1, t+h} D_{t+h}\right)}{D_{t} \operatorname{var}_{t}\left(M_{t+1}\right)}-\beta_{t}^{K, C F}(h) .
$$

When debt has negative risk premium $\left(\beta_{t}^{D}<0\right)$, then the cash flow beta is smaller than the the seigniorage beta and beta of debt outstanding $h$ periods from now:

$$
\beta_{t}^{S, C F}(h) \leq \frac{\operatorname{cov}_{t}\left(M_{t+1},\left(\mathbb{E}_{t+1}-\mathbb{E}_{t}\right) M_{t+1, t+h} D_{t+h}\right)}{D_{t} \operatorname{var}_{t}\left(M_{t+1}\right)}-\beta_{t}^{K, C F}(h)
$$

To keep the debt risk-free $\left(\beta_{t}^{D}=0\right)$ while delivering a risky surplus over short horizons 
$\left(\beta_{t}^{S, C F}(h)>0\right)$, the government can resort to issuing more debt when marginal utility growth is high $\left(\operatorname{cov}_{t}\left(M_{t+1},\left(\mathbb{E}_{t+1}-\mathbb{E}_{t}\right) M_{t+1, t+h} D_{t+h}\right)>0\right)$. When it earns seignorage revenue, this debt issuance produces a safe seigniorage revenue stream over short horizons $\left(\beta_{t}^{K, C F}(h)<0\right)$, increasing $\beta_{t}^{S, C F}(h)>0$ and expanding taxpayer insurance possibilities.

However, over long horizons, debt is co-integrated with output. Since seigniorage revenue is proportional to debt outstanding, the seigniorage claim inherits the long-run risk from output; $\beta_{t}^{K, C F}(h)$ turns positive as $h \rightarrow \infty$. The return beta of the seigniorage claim equals its cash-flow beta as the horizon becomes large: $\beta_{t}^{K}=\beta_{t}^{K, C F}(\infty)$. The cointegration argument suggests that $\beta_{t}^{K}>0$ is the relevant case in a model with permanent output risk. We explore below how convenience yields affect the trade-off quantitatively.

\subsection{Marginal Benefit of Fiscal Stabilization Policy Revisited}

With seigniorage revenue from convenience, the market value of debt becomes $D_{0}=\left(P_{0}^{T}-T_{0}\right)+$ $\left(P_{0}^{K}-K_{0}\right)-\left(P_{0}^{G}-G_{0}\right)$. The marginal benefit of net transfers to taxpayers over the infinite horizon becomes:

$$
\Omega_{n e t}^{\infty^{\prime}}(0)=\frac{\left(P_{0}^{G}-G_{0}\right)-\left(P_{0}^{T}-T_{0}\right)}{P_{0}^{C}-C_{0}}=\frac{\left(P_{0}^{K}-K_{0}\right)-D_{0}}{P_{0}^{C}-C_{0}} .
$$

Corollary 3.1. If debt $D_{0} \geq 0$, the government can provide a positive marginal insurance benefit $\Omega_{\text {net }}^{\infty^{\prime}}(0)>$ 0 to taxpayers at horizon $\infty$ with zero-average primary surpluses, provided that the (ex-dividend) value of seignorage exceeds the value of debt: $\left(P_{0}^{K}-K_{0}\right)>D_{0}$.

Providing insurance to risk averse taxpayers through a zero-average net transfer policy no longer necessarily has a positive cost to the government, because the Treasury now collects seignorage revenue. Some insurance provision to taxpayers may be possible with positive debt outstanding and zero-average surpluses. The extent of insurance provision depends on the value of the seigniorage revenue claim. This is true regardless of the risk-free rate and the growth rate in the economy.

\subsection{Quantifying the Impact of Seigniorage Revenue from Convenience}

We now introduce quantify the impact of convenience yields for the benchmark asset pricing model from the previous section with permanent risk and AR(2) dynamics for debt/output. Under the proportional convenience yields Assumption 4, the seigniorage revenue beta becomes:

$$
\beta_{t}^{K, C F}(h) \equiv-\left(1-e^{-\kappa}\right) \sum_{j=1}^{h} \frac{\mathbb{E}_{t}\left[M_{t+1}\right]}{D_{t} \operatorname{var}_{t}\left(M_{t+1}\right)} \mathbb{E}_{t}\left[M_{t+1, t+j} d_{t+j} Y_{t+j}\right]\left(\exp \left\{\gamma\left(\psi_{j-1} \lambda-\sigma\right)\right\}-1\right) \text {. }
$$

Figure 7 plots the risk premium on the cumulative seigniorage claim in the left panel. It is the product of $\beta_{t}^{K, C F}(h)$ and the market price of risk. The three lines refer to different values 
for the convenience yield $\left(1-e^{-\kappa}\right)$, ranging from $1 \%$ to $3 \%$. In the short run, the seignorage revenue claim is safe and hence earns a negative risk premium. The larger $\kappa$, the more negative the seigniorage risk premium at short horizons. As a result, the seigniorage revenue relaxes the trade-off between insuring bondholders and taxpayers over short horizons. This is shown in the right panel, which plots the risk premium on the cumulative surplus claim $\beta_{t}^{S, C F}(h) \times \frac{\operatorname{var}_{t}\left[M_{t+1}\right]}{\mathbb{E}_{t}\left[M_{t+1}\right]}$, with $\beta_{t}^{S, C F}(h)$ computed from Proposition 3.2. The cumulative surplus claim risk premium is more positive in the short run the higher the convenience yield.

Figure 7: Risk Premia on Seigniorage and Surplus Claims in Convenience Yields Model

The left panel plots the risk premium of cumulative discounted seigniorage revenue, $\beta_{t}^{K, C F}(h) \times \frac{\operatorname{var}_{t}\left[M_{t+1}\right]}{\mathbb{E}_{t}\left[M_{t+1}\right]}$, against the horizon $h$. The right panel plots the risk premium of cumulative discounted surpluses, $\beta_{t}^{S, C F}(h) \times \frac{v^{2} r_{t}\left[M_{t+1}\right]}{\mathbb{E}_{t}\left[M_{t+1}\right]}$, against the horizon $h$. The parameters are given in Table 1 with the debt/output ratio following an $\operatorname{AR}(2)$. Convenience yields $\left(1-e^{-\kappa}\right)$ range from $0 \%$ to $3 \%$.
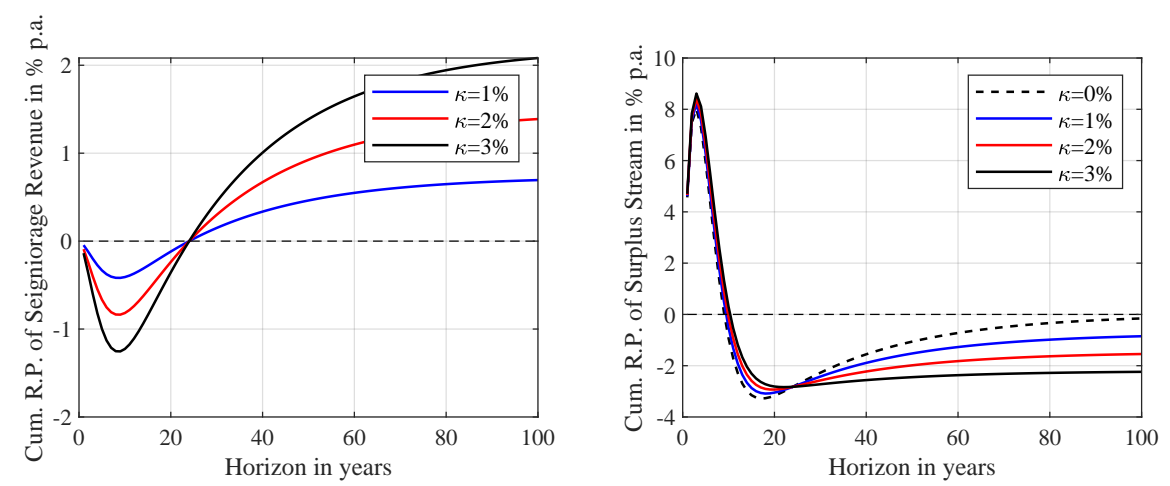

Over longer horizons, the seigniorage revenue is risky. Since seignorage revenue is proportional to debt outstanding, and debt is cointegrated with output, the long-run risk premium on the seigniorage revenue claim is dominated by long-run output risk. Seigniorage revenue inevitably adds long-run output risk to the debt. This effect is stronger the higher the convenience yield. As the right panel of Figure 7 shows, insurance provision to taxpayers worsens over horizons past 20 years.

The return beta of the seigniorage revenue stream equals its cash-flow beta at horizon $h=\infty$. Since $\beta_{t}^{K, C F}(\infty)>0$, so is $\beta_{t}^{K}>0$. As shown in Proposition 3.1, convenience yields lower the return beta of the tax claim $\beta^{T}$. In sum, convenience yields, even large ones, are no panacea. They allow for more taxpayer insurance over short horizons but less insurance in the longer-run.

\section{Quantifying the Trade-off in Model with Transitory Output Shocks}

Finally, we study the insurance trade-off in a model where output only experiences transitory shocks. This is the standard assumption in most macro-economic models, despite unappealing 
asset pricing properties. Specifically, in models with only transitory shocks and no priced aggregate risk, government debt is subject to substantial interest rate risk. Long-term bonds are the riskiest assets in the economy. ${ }^{16}$ To keep the debt risk-free in the presence of this interest rate risk, the government needs to deliver an even safer surplus process. Interest rate risk reduces the scope for insurance of taxpayers. Under natural parameter conditions, the trade-off between insuring taxpayers and bondholders is even steeper than in the model with permanent shocks.

We consider an-internally consistent-model with transitory shocks to both output and the pricing kernel. Most of the equilibrium models in the literature on optimal taxation fit into this class of models. ${ }^{17}$ Our qualitative results would go through if we used the equilibrium pricing kernels implied by these models. We adopt a flexible pricing kernel to derive closed-form solutions.

Assumption 5. (a) The shocks to output are transitory. The log output process is given by: $y_{t+1}=$ $\xi_{0}+\xi y_{t}+\sigma \varepsilon_{t+1}$ where $\varepsilon_{t+1}$ denotes the innovation to $\log$ output which is i.i.d. normally distributed. (b) The $\log$ SDF is: $m_{t, t+1}=-\rho-\frac{1}{2} \gamma^{2}-\frac{\gamma}{\sigma}\left(\sigma \varepsilon_{t+1}+(\xi-1) y_{t}\right)$.

This specific modification of the SDF is motivated by the fact that, if the agent's consumption is equal to the output and has CRRA preferences with a relative risk aversion of $\gamma / \sigma$, then the marginal utility growth is $m_{t, t+1}=-\tilde{\rho}-(\gamma / \sigma)\left(\xi_{0}+(\xi-1) y_{t}+\sigma \varepsilon_{t+1}\right)$, where $\tilde{\rho}=\rho+$ $\frac{1}{2} \gamma^{2}-(\gamma / \sigma) \xi_{0}$. The marginal utility of wealth can then be written as: $\Lambda_{t+1}=\exp (-\tilde{\rho}(t+1)-$ $\left.(\gamma / \sigma) y_{t+1}\right)$. This shows that transitory shocks in output translate into transitory shocks to the pricing kernel; there are no permanent shocks to the marginal utility of wealth. The log of the risk-free rate is given by: $r_{t}^{f}=\rho+\gamma \frac{(\xi-1)}{\sigma} y_{t}$. Output risk drives interest rate risk.

Surprisingly, even when there are no permanent shocks to output and the pricing kernel, the government cannot insure taxpayers over longer horizons. In fact, the trade-off worsens.

Proposition 4.1. Under Assumption 5 and positive debt $D_{t}>0$, the cash flow beta of the surpluses over horizon $h$ is:

$$
\beta_{t}^{S, C F}(h)=\frac{\mathbb{E}_{t}\left[M_{t+1}\right]}{D_{t} \operatorname{var}_{t}\left[M_{t+1}\right]} \mathbb{E}_{t}\left[M_{t+1, t+h} d_{t+h} Y_{t+h}\right]\left[\exp \left\{\gamma\left(\phi_{1}^{h-1} \lambda-\xi^{h-1} \sigma-\gamma\left(1-\xi^{h-1}\right)\right)\right\}-1\right]
$$

for $h \geq 1$. The sign of $\beta_{t}^{S, C F}(h)$ equals $-\operatorname{sign}\left(\gamma\left(\xi^{h-1} \sigma-\phi_{1}^{h-1} \lambda\right)+\gamma^{2}\left(1-\xi^{h-1}\right)\right)$.

As before, the cash-flow beta of the surpluses $\beta_{t}^{S, C F}(h)$ is the sufficient statistic for taxpayer insurance possibilities over horizon $h$, and its sign is pinned down by the inverse of the sign on

\footnotetext{
${ }^{16}$ Appendix I provides a formal derivation. This model implication is counter-factual. The equity risk premium in the data exceeds the yield on a long-term zero-coupon bond. Modern asset pricing research has consistently found that permanent cash-flow shocks receive a high price of risk in the market. Substantial, permanent priced risk is necessary to explain the high equity risk premium.

${ }^{17}$ For an example, see Bhandari et al. (2017, pp. 653), which features a mean-reverting process for productivity growth and government spending. See Chari et al. (1994); Debortoli et al. (2017) for other examples.
} 
the risk premium on a debt strip at horizon $t+h$. The first component of the debt strip risk premium, $\gamma\left(\xi^{h-1} \sigma-\phi_{1}^{h-1} \lambda\right)$, compensates for output risk. The second component, $\gamma^{2}\left(1-\xi^{j-1}\right)$, compensates for interest rate risk. The debt strip risk premium at horizon $h$ is positive as long as the output risk premium is not too negative. This in turn requires a high enough market price of risk. $^{18}$

Because the output innovations are temporary and the debt/output ratio is stationary $(\xi<1$ and $\phi_{1}<1$ ), the output component of the risk premium converges to zero as the horizon increases. The interest rate risk does not converge to zero, but rather to $\gamma^{2}$. Hence, in the long-run the entire debt strip risk premium of $\left(1-\exp \left(-\gamma^{2}\right)\right)$ is due to interest rate risk. It is large and positive since the long bond is the riskiest asset in an economy with only transitory risk. ${ }^{19}$ In sum, while the transitory nature of output risk broadens the scope for insurance of taxpayers in the shortrun, this is more than offset by the rising interest rate risk which accumulates with the horizon. Compared to the permanent risk case, we have replaced long-run output risk with more long-run interest rate risk. We now show that the trade-off worsens quantitatively as a result.

Figure 8 plots the trade-off for the calibrated model with transitory shocks. In Panel A, the debt/output process is equally persistent as the output process $\left(\phi_{1}=\xi=0.75\right)$. In the year of the shock $(h=1)$, the surplus beta is still positive. In the following year, the government already has to produce very safe surpluses, dragging the 2-year cumulative surplus risk premium deeply into negative territory. This implies that the 2-year surplus itself has a very negative beta. The risk premia on the cumulative surpluses remain very low (below $-15 \%$ ) for several years. The right panel shows that this arises because the risk premium on the debt strips turns positive in year two and increases rapidly in the first several years as the interest rate risk mounts. To keep the debt risk-free, the interest rate risk has to be offset by very negative surplus and tax betas. As a result, the government can only insure taxpayers over very short periods even though the shocks to the economy are fully transitory. Panel B considers a more persistent output process $(\xi=0.98)$. The initial surplus risk premium is identical, but the decline in the risk premium on the cumulative surplus over the next several years is mitigated. The government can still not insure taxpayers beyond two years.

This result does not hinge on the specific SDF we use. In the absence of arbitrage opportunities, if the SDF is not subject to permanent innovations, the zero-coupon bond with the longest maturity will always earn the highest expected log return (see Appendix I). In any model with

\footnotetext{
${ }^{18}$ The precise condition is $\gamma>\frac{\phi_{1}^{h-1} \lambda-\xi^{h-1} \sigma}{1-\xi^{h-1}}$.

${ }^{19}$ If the SDF $M$ is conditionally log-normal, the expected log excess return on a long position in the longest-maturity bond reaches the entropy bound of one half of the variance of the log SDF: $\lim _{k \rightarrow \infty} \mathbb{E}_{t} r x_{t+1}^{k}=0.5 \operatorname{Var}_{t}\left(m_{t+1}\right)$ (Backus et al., 2014). For our SDF, which is conditionally log-normal, the expected log return on the longest maturity bond equals $0.5 \gamma^{2}$. After adding a Jensen term, we recover the interest rate risk premium of $\gamma^{2}$.
} 


\section{Figure 8: Risk Premia with Transitory Shocks to Output and SDF}

The figure plots the risk premium of cumulative discounted cash flows, $\beta_{t}^{S, C F}(h) \times \frac{\operatorname{var}_{t}\left[M_{t+1}\right]}{\mathbb{E}_{t}\left[M_{t+1}\right]}$, in the left panel against the horizon $h$. The right panel plots the risk premium on the debt strips: $1-\exp \left\{\gamma\left(\phi_{1}^{h-1} \lambda-\sigma \xi^{h-1}\right)+\gamma^{2}\left(1-\xi^{h-1}\right)\right\}$. In top panel, $\phi_{1}$ is 0.75 and $\xi$ is 0.75 . In bottom panel, $\phi_{1}$ is 0.75 and $\xi$ is 0.98 . Other parameters follow benchmark calibration in Table 1.

Panel A: Output AR(1) with $\xi$ is 0.75
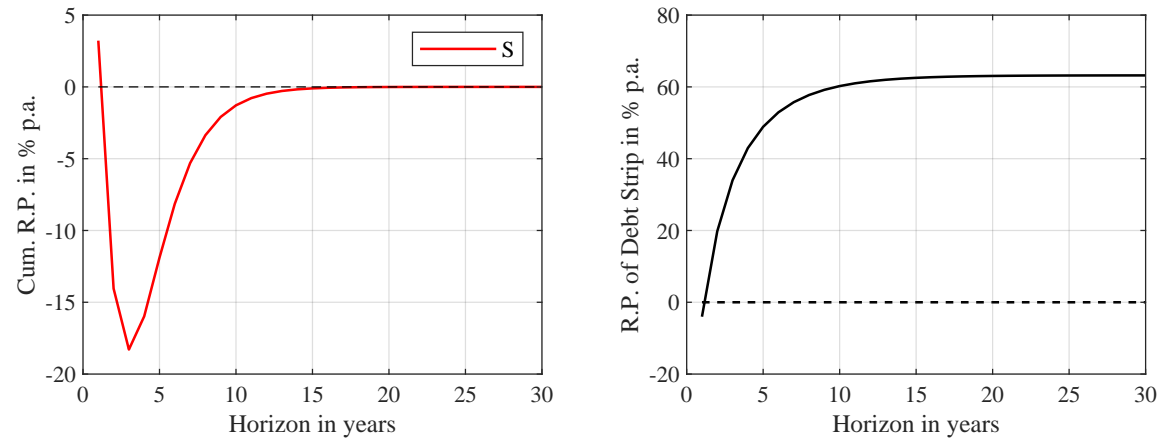

Panel B: Output AR(1) with $\xi$ is 0.98
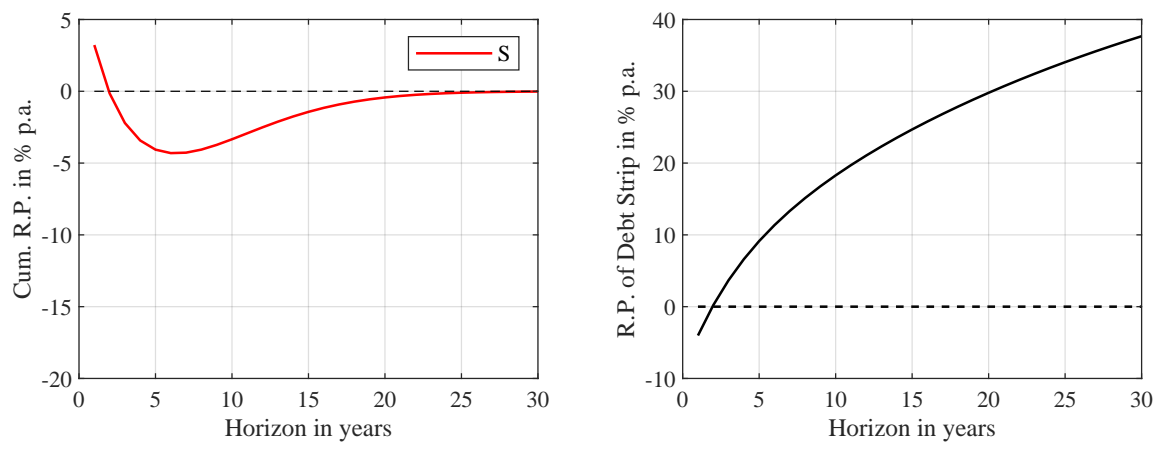
only transitory shocks, the cash flow beta of the $h$-period cumulative surplus converges to:

$$
\lim _{h \rightarrow \infty} \beta_{t}^{S, C F}(h)=\frac{\mathbb{E}_{t}\left[M_{t+1}\right]}{D_{t} \operatorname{var}_{t}\left[M_{t+1}\right]} \mathbb{E}_{t}\left[M_{t+1, t+h} d_{t+h} Y_{t+h}\right]\left[\exp \left(-\operatorname{var}_{t}\left(m_{t+1}\right)\right)-1\right],
$$

where the maximum squared Sharpe ratio $\operatorname{var}_{t}\left(m_{t+1}\right)$ governs the interest rate risk premium. To keep debt risk-free, the government has to offset the interest rate risk by generating safe surpluses, or equivalently, risky taxpayer liabilities.

\section{Conclusion}

There are limits to the government's ability to make risk-free promises. The government engineers risk-free debt by choosing the exposure of the tax claim to output risk judiciously. The more debt there is outstanding, the lower this exposure must become, and hence the more output risk must be borne by taxpayers. There is no scope for insurance of both taxpayers and debt holders over long horizons in the presence of priced shocks to output, be they permanent or transitory in nature. Over short horizons, the U.S. manages to provide its taxpayers with more insurance through more aggressive counter-cyclical debt issuance, as a result of global safe asset demand. Convenience yields on the debt alleviate the insurance trade-off temporarily but worsen it in the long run. The

only way the government can provide insurance to taxpayers over all horizons while keeping the debt risk-free is by saving.

Our approach is conservative in that we assume the risk-return trade-off is constant. However, a key tenet of modern asset pricing is that the market price of risk varies counter-cyclically. We conjecture that this would limit the government's ability to insure taxpayers even further. 


\section{References}

Aguiar, M., M. Amador, and C. Arellano (2021): “Micro risks and pareto improving policies with low interest rates," .

Aiyagari, S. R., A. Marcet, T. J. Sargent, and J. Seppälä (2002): “Optimal taxation without statecontingent debt," Journal of Political Economy, 110, 1220-1254, URL https ://doi .org/10 .1086/ 343744.

Alvarez, F. and U. Jermann (2004): "Using asset prices to measure the cost of business cycles." Journal of Political Economy, 112(6), 1223-1255.

Alvarez, F. and U. Jermann (2005): "Using asset prices to measure the measure the persistence of the marginal utility of wealth." Econometrica, 1977-2016.

Andolfatto, D. (2020): “Does the national debt matter?" https://www.stlouisfed.org/ publications/regional-economist/fourth-quarter-2020/does-national-debt-matter, accessed: 2022-1-24.

Angeletos, G.-M. (2002): "Fiscal policy with noncontingent debt and the optimal maturity structure*," The Quarterly Journal of Economics, 117, 1105-1131, URL http://dx.doi.org/10.1162/ 003355302760193977.

Angeletos, G.-M., F. Collard, and H. Dellas (2020): "Public debt as private liquidity: Optimal policy," .

Backus, D., N. Boyarchenko, and M. Chernov (2018): “Term structures of asset prices and returns," J. financ. econ., 129, 1-23.

Backus, D., M. Chernov, and S. Zin (2014): "Sources of entropy in representative agent models," J. Finance, 69, 51-99.

Baele, L., G. Bekaert, and K. Inghelbrecht (2010): "The determinants of stock and bond return comovements," Rev. Financ. Stud., 23, 2374-2428.

Ball, L. M. and G. N. Mankiw (2021): "Market power in neoclassical growth models," Technical Report w28538, National Bureau of Economic Research.

Bansal, R. and B. N. Lehmann (1997): “Growth-optimal portfolio restrictions on asset pricing models," Macroecon. Dyn., 1.

Bansal, R. and A. Yaron (2004): "Risks for the long run: A potential resolution of asset prizing puzzles," The Journal of Finance, 59, 1481-1509. 
Barro, R. J. (1979): “On the determination of the public debt,” J. Polit. Econ., 87, 940-971.

Barro, R. J. (2020): “R minus g,” NBER Working Paper No. 28002.

Bassetto, M. and W. Cui (2018): "The fiscal theory of the price level in a world of low interest rates," J. Econ. Dyn. Control, 89, 5-22.

Bhandari, A., D. Evans, M. Golosov, and T. J. Sargent (2017): “Fiscal policy and debt management with incomplete markets," Q. J. Econ., 132, 617-663.

Bianchi, J., P. Ottonello, and I. Presno (2019): “Fiscal stimulus under sovereign risk,” .

Bigio, S., G. Nuno, and J. Passadore (2019): “Debt-Maturity management with liquidity costs,” .

Blanchard, O. (2019): "Public debt and low interest rates," American Economic Review, 109, 11971229.

Bohn, H. (1995): “The sustainability of budget deficits in a stochastic economy," J. Money Credit Bank., 27, 257-271.

Borovička, J., L. P. Hansen, and J. Scheinkman (2016): “Misspecified recovery," Journal of Finance, $71,2493-2544$.

Brunnermeier, M., S. Merkel, and Y. Sannikov (2020): “The fiscal theory of price level with a bubble," .

Buera, F. and J. P. Nicolini (2004): "Optimal maturity of government debt without state contingent bonds," Journal of Monetary Economics, 51, 531 - 554.

Caballero, R. J., E. Farhi, and P.-O. Gourinchas (2008): “An equilibrium model of "global imbalances" and low interest rates," American Economic Review, 98, 358-93.

Caballero, R. J. and A. Krishnamurthy (2009): “Global imbalances and financial fragility," American Economic Review, 99, 584-88.

Campbell, J. Y., C. Pflueger, and L. M. Viceira (2020): “Macroeconomic drivers of bond and equity risks," J. Polit. Econ., 128, 3148-3185.

Chari, V. V., L. J. Christiano, and P. J. Kehoe (1994): “Optimal fiscal policy in a business cycle model," J. Polit. Econ., 102, 617-652.

Chien, Y. and Y. Wen (2019): “The determination of public debt under both aggregate and idiosyncratic uncertainty," Technical report, Federal Reserve Bank of St. Louis. 
Chien, Y. and Y. Wen (2020): “Time-inconsistent optimal quantity of debt," Technical report, Federal Reserve Bank of St. Louis.

Croce, M. M., H. Kung, T. T. Nguyen, and L. Schmid (2012): “Fiscal Policies and Asset Prices," The Review of Financial Studies, 25, 2635-2672, URL https : //doi . org/10.1093/rfs/hhs060.

Debortoli, D., R. Nunes, and P. Yared (2017): “Optimal Time-Consistent government debt maturity," Q. J. Econ., 132, 55-102.

Eggertsson, G. B., J. A. Robbins, and E. G. Wold (2018): “Kaldor and piketty's facts: The rise of monopoly power in the united states," Technical Report w24287, National Bureau of Economic Research.

Farhi, E. and F. Gourio (2018): “Accounting for macro-finance trends: Market power, intangibles, and risk premia," in BPEA Conference Draft, Fall. BPEA, volume Fall, volume Fall, accessed: 2021-5-16.

Furman, J. and L. Summers (2020): "A reconsideration of fiscal policy in the era of low interest rates," https://www.brookings.edu/wp-content/uploads/2020/11/ furman-summers-fiscal-reconsideration-discussion-draft.pdf, accessed: 2020-12-27.

Gomes, F., A. Michaelides, and V. Polkovnichenko (2012): "Fiscal Policy and Asset Prices with Incomplete Markets," The Review of Financial Studies, 26, 531-566, URL https://doi.org/10. 1093/rfs/hhs110.

Gopinath, G. and J. C. Stein (2018): "Banking, trade, and the making of a dominant currency," Technical report, Harvard University.

Gorton, G., S. Lewellen, and A. Metrick (2012): “The safe-asset share," American Economic Review, 102, 101-06, URL https: //www . aeaweb .org/articles?id=10.1257/aer.102 .3.101.

Gorton, G. and G. Ordoñez (2022): "The supply and demand for safe assets," Journal of Monetary Economics, 125, 132-147, URL https://www.sciencedirect.com/science/article/pii/ S0304393221000854.

Gourinchas, P.-O. and H. Rey (2007): "International financial adjustment," Journal of political economy, 115, 665-703.

Hall, G. and T. Sargent (2011): "Interest rate risk and other determinants of post ww-ii u.s. government debt/gdp dynamics," American Economic Journal: Macroeconomics, 3, 192-214.

Hansen, L. P. and R. Jagannathan (1991): "Implications of security market data for models of dynamic economies," Journal of Political Economy, 99, 225-262, URL http://www.jstor.org/ stable/2937680. 
Hansen, L. P. and J. Scheinkman (2009): “Long-term risk: An operator approach,” Econometrica, 77 (1), 177-234.

He, Z., A. Krishnamurthy, and K. Milbradt (2018): “A model of safe asset determination," American Economic Review.

Jiang, Z., A. Krishnamurthy, and H. Lustig (2018): "Foreign safe asset demand for US treasurys and the dollar," AEA Papers and Proceedings, 108, 537-541.

Jiang, Z., A. Krishnamurthy, and H. Lustig (2019a): "Dollar safety and the global financial cycle," Available at SSRN 3328808.

Jiang, Z., A. Krishnamurthy, and H. Lustig (2021): "Foreign safe asset demand and the dollar exchange rate," The Journal of Finance, 76, 1049-1089.

Jiang, Z., H. Lustig, S. Van Nieuwerburgh, and M. Z. Xiaolan (2019b): “The U.S. public debt valuation puzzle," NBER Working Paper 26583.

Kocherlakota, N. (2021): "Public debt bubbles in heterogeneous agent models with tail risk," University of Rochester manuscript.

Koijen, R. S. J. and M. Yogo (2019): “Exchange rates and asset prices in a global demand system," .

Krishnamurthy, A. and H. N. Lustig (2019): "Mind the gap in sovereign debt markets: The U.S. treasury basis and the dollar risk factor," .

Krishnamurthy, A. and A. Vissing-Jorgensen (2012): "The aggregate demand for treasury debt," Journal of Political Economy, 120, 233-267.

Liu, Y., L. Schmid, and A. Yaron (2019): “The risks of safe assets," in 2019 Meeting Papers.

Lucas, R. E. (1978): “Asset prices in an exchange economy,” Econometrica, 46, 1429-1445.

Lucas, R. E. (1987): Models of business cycles, volume 26, Basil Blackwell Oxford.

Lucas, R. E. and N. L. Stokey (1983): “Optimal fiscal and monetary policy in an economy without capital," Journal of Monetary Economics, 12, 55 - 93.

Lustig, H., C. Sleet, and Ş. Yeltekin (2008): “Fiscal hedging with nominal assets," Journal of Monetary Economics, 55, 710 - 727.

Maggiori, M. (2017): "Financial intermediation, international risk sharing, and reserve currencies," American Economic Review, 107, 3038-71. 
Mehrotra, N. R. and D. Sergeyev (2021): "Debt sustainability in a low interest rate world," Journal of Monetary Economics, 124, S1-S18, URL https : / www . sciencedirect.com/science/article/ $\mathrm{pii} / \mathrm{S} 0304393221000945$, the Real Interest Rate and the MarginalProduct of Capital in the XXIst CenturyOctober 15-16, 2020.

Mian, A., L. Straub, and A. Sufi (2021a): "A goldilocks theory of fiscal policy," NBER Working Paper No. 29351.

Mian, A., L. Straub, and A. Sufi (2021b): "Indebted Demand*," The Quarterly Journal of Economics, URL https://doi.org/10.1093/qje/qjab007, qjab007.

Mian, A. R., L. Straub, and A. Sufi (2020): “The saving glut of the rich," Working Paper 26941, National Bureau of Economic Research, URL http://www .nber.org/papers/w26941.

Mitchell, B. and B. Mitchell (1988): British Historical Statistics, Cambridge University Press, URL https://books . google.com/books?id=0yg9AAAAIAAJ.

Pástor, Ľ. and P. Veronesi (2013): "Political uncertainty and risk premia," Journal of Financial Economics, 110, 520-545, URL https://www.sciencedirect.com/science/article/pii/ S0304405X13002080.

Reis, R. (2021): “The constraint on public debt when $r<g$ but $g<m$," Working Paper London School of Economics.

van Wijnbergen, S., S. Olijslagers, and N. de Vette (2020): “Debt sustainability when R - G < 0: No free lunch after all," . 


\section{Appendix}

\section{A Proofs}

\section{A.1 Proof of Proposition 1.1}

Proof. Our derivation follows Alvarez and Jermann (2004) by assuming that $\left(1+\Omega_{n e t}^{h}(\alpha)\right)$ does not change the initial consumption $C_{0}$. By differentiating w.r.t. $\alpha$, we can back out the marginal benefit/cost of government intervention as follows:

$$
\Omega_{\text {net }}^{h, i^{\prime}}(0)=\frac{\mathbb{E}_{0} \sum_{t=1}^{h} U_{c, t}^{i}\left[G_{t}-T_{t}\right]}{\mathbb{E}_{0} \sum_{t=1}^{h} U_{c, t}^{i}\left[C_{t}\right]}
$$

When evaluating at $\alpha=0$, we are not actually changing the household's consumption process. When the investors can invest in Treasury markets and do not face any binding constraints, the agents agree on the valuation of aggregate payoffs from the government debt:

$$
\mathbb{E}_{0} \sum_{t=1}^{h} M_{0, t}\left[G_{t}-T_{t}\right]=\mathbb{E}_{0} \sum_{t=1}^{h} \frac{U_{c, t}^{i}}{U_{c, 0}^{i}}\left[G_{t}-T_{t}\right]
$$

For any investment horizon $h$, the following individual optimality condition has to hold, absent binding borrowing and short-sales constraints:

$$
\mathbb{E}_{0} \sum_{t=1}^{h} \frac{U_{c, t}^{i}}{U_{c, 0}^{i}}\left[G_{t}-T_{t}\right]+\mathbb{E}_{0} \frac{U_{c, h}^{i}}{U_{c, 0}^{i}}\left[D_{h}\right]-D_{0}=0=\mathbb{E}_{0} \sum_{t=1}^{h} M_{0, t}\left[G_{t}-T_{t}\right]+\mathbb{E}_{0} M_{h} D_{h}-D_{0} .
$$

In addition, the transversality condition implies that, as $h \rightarrow \infty, \mathbb{E}_{0} M_{h} D_{h} \rightarrow 0$. This implies that, for all $h$, the following equality holds:

$$
\mathbb{E}_{0} \sum_{t=1}^{h} M_{0, t}\left[G_{t}-T_{t}\right]=\mathbb{E}_{0} \sum_{t=1}^{h} \frac{U_{c, t}^{i}}{U_{c, 0}^{i}}\left[G_{t}-T_{t}\right] .
$$

By the same token, if these agents can trade claims to aggregate consumption, provided that the transversality condition holds, we know that for all $h$, the following equality holds:

$$
\mathbb{E}_{0} \sum_{t=1}^{h} M_{0, t}\left[C_{t}\right]=\mathbb{E}_{0} \sum_{t=1}^{h} \frac{U_{c, t}^{i}}{U_{c, 0}^{i}}\left[C_{t}\right]
$$

By combining these 2 equalities, we obtain the following result, for each $h$ :

$$
\Omega_{n e t}^{h^{\prime}}(0)=\frac{\mathbb{E}_{0} \sum_{t=1}^{h} M_{0, t}\left[G_{t}-T_{t}\right]}{\mathbb{E}_{0} \sum_{t=1}^{h} M_{0, t}\left[C_{t}\right]}=\frac{\mathbb{E}_{0} \sum_{t=1}^{h} U_{c, t}^{i}\left[G_{t}-T_{t}\right]}{\mathbb{E}_{0} \sum_{t=1}^{h} U_{c, t}^{i}\left[C_{t}\right]}
$$

\section{A.2 Proof of Corollary 1.1}

Proof. We start from the marginal cost at infinite horizon:

$$
\Omega_{\text {net }}^{\infty}(0)=\frac{\mathbb{E}_{0} \sum_{t=1}^{\infty} M_{0, t}\left[G_{t}-T_{t}\right]}{\mathbb{E}_{0} \sum_{t=1}^{\infty} M_{0, t}\left[C_{t}\right]}=\frac{\left(P_{0}^{G}-G_{0}\right)-\left(P_{0}^{T}-T_{0}\right)}{P_{0}^{C}-C_{0}}=-\frac{D_{0}}{P_{0}^{C}-C_{0}} .
$$

Start from the following equation:

$$
\mathbb{E}_{0} \sum_{t=1}^{\infty} M_{0, t}\left[G_{t}-T_{t}\right]=\sum_{t=1}^{\infty} \operatorname{Cov}_{0}\left(M_{0, t}, G_{t}-T_{t}\right)+\sum_{t=1}^{\infty} \mathbb{E}_{0} M_{0, t} \mathbb{E}_{0}\left[G_{t}-T_{t}\right]
$$

Since the risk premium component for debt is positive: $R P_{0}=-\sum_{t=1}^{\infty} \operatorname{Cov}_{0}\left(M_{0, t}, T_{t}-G_{t}\right)>0$, we need positive average surpluses $\mathbb{E}_{0}\left[G_{t}-T_{t}\right]<0$, to obtain $D_{0}=P_{0}^{\infty}\left[\left\{T_{t}-G_{t}\right\}\right]>0$. 


\section{A.3 Proof of Proposition 1.2}

Proof. From the investor's Euler equation $\mathbb{E}_{t}\left[M_{t+1}\left(R_{t+1}^{i}-R_{t}^{f}\right)\right]=0$, we know that the expected excess return on the tax claim, spending claim, and debt claims are given by

$$
\begin{aligned}
\mathbb{E}_{t}\left[R_{t+1}^{T}-R_{t}^{f}\right] & =\frac{-\operatorname{cov}_{t}\left(M_{t+1}, R_{t+1}^{T}\right)}{\mathbb{E}_{t}\left[M_{t+1}\right]}=\frac{-\operatorname{cov}_{t}\left(M_{t+1}, R_{t+1}^{T}\right)}{\operatorname{var}_{t}\left[M_{t+1}\right]} \frac{\operatorname{var}_{t}\left[M_{t+1}\right]}{\mathbb{E}_{t}\left[M_{t+1}\right]}=\beta_{t}^{T} \lambda_{t}, \\
\mathbb{E}_{t}\left[R_{t+1}^{G}-R_{t}^{f}\right] & =\frac{-\operatorname{cov}_{t}\left(M_{t+1}, R_{t+1}^{G}\right)}{\mathbb{E}_{t}\left[M_{t+1}\right]}=\frac{-\operatorname{cov}_{t}\left(M_{t+1}, R_{t+1}^{G}\right)}{\operatorname{var}_{t}\left[M_{t+1}\right]} \frac{\operatorname{var}_{t}\left[M_{t+1}\right]}{\mathbb{E}_{t}\left[M_{t+1}\right]}=\beta_{t}^{G} \lambda_{t}, \\
\mathbb{E}_{t}\left[R_{t+1}^{D}-R_{t}^{f}\right] & =\frac{-\operatorname{cov}_{t}\left(M_{t+1}, R_{t+1}^{D}\right)}{\mathbb{E}_{t}\left[M_{t+1}\right]}=\frac{-\operatorname{cov}_{t}\left(M_{t+1}, R_{t+1}^{D}\right)}{\operatorname{var}_{t}\left[M_{t+1}\right]} \frac{\operatorname{var}_{t}\left[M_{t+1}\right]}{\mathbb{E}_{t}\left[M_{t+1}\right]}=\beta_{t}^{D} \lambda_{t} .
\end{aligned}
$$

Proposition 1.2 follows from equation (3).

\section{A.4 Proof of Proposition 1.3}

Proof. We start from the one-period government budget constraint: $T_{t}=G_{t}-\left(D_{t}-R_{t} D_{t-1}\right)$. This implies that the return on government debt can be stated as follows:

$$
\begin{aligned}
R_{t} D_{t-1} & =S_{t}+D_{t}=S_{t}+\mathbb{E}_{t}\left[M_{t, t+1} R_{t+1} D_{t}\right],=S_{t}+\mathbb{E}_{t}\left[M_{t, t+1}\left[S_{t+1}+M_{t+1, t+2} R_{t+2} D_{t+1}\right]\right] \\
& =\mathbb{E}_{t}\left[\sum_{k=0}^{1} M_{t, t+k} S_{t+k}\right]+\mathbb{E}_{t}\left[M_{t, t+1} D_{t+1}\right]
\end{aligned}
$$

where we have used $R_{t+1} D_{t}=S_{t+1}+\mathbb{E}_{t+1}\left[M_{t+1, t+2} R_{t+2} D_{t+1}\right]$. By continued forward substitution, we obtain the following expression for the return on debt:

$$
R_{t} D_{t-1}=\mathbb{E}_{t}\left[\sum_{k=0}^{h} M_{t, t+k} S_{t+k}\right]+\mathbb{E}_{t}\left[M_{t, t+h} D_{t+h}\right]
$$

Replace the time index $t$ by $t+1$, to obtain the following expression:

$$
R_{t+1} D_{t}=\mathbb{E}_{t+1}\left[\sum_{j=1}^{h} M_{t+1, t+j} S_{t+j}\right]+\mathbb{E}_{t+1}\left[M_{t+1, t+h} D_{t+h}\right] .
$$

Next, we take the limit of $h \rightarrow \infty$, and consider the case of risk-free debt. We start again from the one-period budget constraint: $T_{t}=$ $G_{t}-\left(D_{t}-R_{t-1}^{f} D_{t-1}\right)$. When the transversality condition holds, repeated forward substitution produces the following expression:

$$
R_{t-1}^{f} D_{t-1}=S_{t}+D_{t}=S_{t}+\mathbb{E}_{t}\left[M_{t, t+1} R_{t}^{f} D_{t}\right]=S_{t}+\mathbb{E}_{t}\left[M_{t, t+1}\left(S_{t+1}+M_{t+1, t+2} R_{t+1}^{f} D_{t+1}\right)\right]=\mathbb{E}_{t}\left[\sum_{k=0}^{\infty} M_{t, t+k} S_{t+k}\right]
$$

Replace the time index $t$ by $t+1$, to obtain the following expression: $R_{t}^{f} D_{t}=\mathbb{E}_{t+1}\left[\sum_{j=1}^{\infty} M_{t+1, t+j} S_{t+j}\right]$. Since the left-hand side is known at time $t$, we obtain the result: $\left(\mathbb{E}_{t+1}-\mathbb{E}_{t}\right)\left[\sum_{j=1}^{\infty} M_{t+1, t+j} S_{t+j}\right]=0$.

\section{A.5 Proof of Proposition 1.4}

Proof. We start from eqn. A1. We take the innovations on both sides:

$$
D_{t}\left(\mathbb{E}_{t+1}-\mathbb{E}_{t}\right) R_{t+1}=\left(\mathbb{E}_{t+1}-\mathbb{E}_{t}\right)\left[\sum_{j=1}^{h} M_{t+1, t+j} S_{t+j}\right]+\left(\mathbb{E}_{t+1}-\mathbb{E}_{t}\right)\left[M_{t+1, t+h} D_{t+h}\right] .
$$

We obtain the following result:

$$
\begin{aligned}
D_{t} \operatorname{Cov}_{t}\left(M_{t+1},\left(\mathbb{E}_{t+1}-\mathbb{E}_{t}\right) R_{t+1}\right) & =\operatorname{Cov}_{t}\left(M_{t+1},\left(\mathbb{E}_{t+1}-\mathbb{E}_{t}\right)\left[\sum_{j=1}^{h} M_{t+1, t+j} S_{t+j}\right]\right) \\
& +\operatorname{Cov}_{t}\left(M_{t+1},\left(\mathbb{E}_{t+1}-\mathbb{E}_{t}\right)\left[M_{t+1, t+h} D_{t+h}\right]\right)
\end{aligned}
$$




\section{A.6 Proof of Proposition 2.1}

Proof. To verify the expression, first conjecture the pricing of the output strip is $\mathbb{E}_{t}\left[M_{t, t+k} Y_{t+k}\right]=\xi_{k} Y_{t}$, for $k \geq 0$. Then $\xi_{0}=1$ and

$$
\begin{aligned}
\xi_{k} Y_{t}=\mathbb{E}_{t}\left[M_{t, t+k} Y_{t+k}\right] & =\mathbb{E}_{t}\left[M_{t, t+1} \xi_{k-1} Y_{t+1}\right]=\exp \left(-\rho-\frac{1}{2} \gamma^{2}+\mu+\frac{1}{2}(\gamma-\sigma)^{2}\right) \xi_{k-1} Y_{t}, \\
\xi_{k} Y_{t} & =\exp \left(-\rho-\frac{1}{2} \gamma^{2}+\mu+\frac{1}{2}(\gamma-\sigma)^{2}\right) \xi_{k-1} Y_{t},
\end{aligned}
$$

which verifies the conjecture and implies $\xi_{k}=\xi_{k-1} \exp \left(-\rho-\frac{1}{2} \gamma^{2}+\mu+\frac{1}{2}(\gamma-\sigma)^{2}\right)$. Similarly, we define a $k$-period surplus strip as a claim to $S_{t+k}$, with price given by $\mathbb{E}_{t}\left[M_{t, t+k} S_{t+k}\right]=\chi_{k} Y_{t}$. The pricing of the first surplus strip is given by the following expression:

$$
\begin{aligned}
\mathbb{E}_{t}\left[M_{t, t+1} S_{t+1}\right] & =\mathbb{E}_{t}\left[M_{t, t+1}\left\{-d Y_{t+1}\left(1-R_{t}^{f} \exp \left[-\left(\mu+\varepsilon_{t+1}\right)\right]\right)\right\}\right]=-d \mathbb{E}_{t}\left[M_{t, t+1} Y_{t+1}\right]+d Y_{t} R_{t}^{f} \mathbb{E}_{t}\left[M_{t, t+1}\right], \\
& =\left[1-\exp \left(-\rho-\frac{1}{2} \gamma^{2}+\mu+\frac{1}{2}(\gamma-\sigma)^{2}\right)\right] d Y_{t}
\end{aligned}
$$

where the first equality uses the definition of the surplus and the government budget constraint.

This implies $\chi_{1}=\left[1-\exp \left(-\rho-\frac{1}{2} \gamma^{2}+\mu+\frac{1}{2}(\gamma-\sigma)^{2}\right)\right] d$. Then, similarly, the pricing of the $k$ th surplus strip is given by:

$$
\chi_{k} Y_{t}=\mathbb{E}_{t}\left[M_{t, t+k} S_{t+k}\right]=\mathbb{E}_{t}\left[M_{t, t+1} \mathbb{E}_{t+1}\left[M_{t+1, t+k} S_{t+k}\right]\right]=\mathbb{E}_{t}\left[M_{t, t+1} \chi_{k-1} Y_{t+1}\right]=\chi_{k-1} \exp \left(-\rho-\frac{1}{2} \gamma^{2}+\mu+\frac{1}{2}(\gamma-\sigma)^{2}\right) Y_{t}
$$

Note that this calculation also implies that we cannot simply price these strips off the risk-free yield curve, even though the entire debt is risk-free. The solution is given by:

$$
\chi_{1}=d\left[1-\exp \left(-\rho-\frac{1}{2} \gamma^{2}+\mu+\frac{1}{2}(\gamma-\sigma)^{2}\right)\right] ; \chi_{k}=\chi_{k-1} \exp \left(-\rho-\frac{1}{2} \gamma^{2}+\mu+\frac{1}{2}(\gamma-\sigma)^{2}\right),
$$

which implies that $\lim _{j \rightarrow \infty} \mathbb{E}_{t}\left[M_{t, t+j} S_{t+j}\right]=\sum_{k=1}^{\infty} \chi_{k} Y_{t}=\chi_{1}\left(1+\xi_{1}+\xi_{1}^{2}+\ldots\right) Y_{t}=\frac{1-\tilde{\xi}_{1}}{1-\tilde{\xi}_{1}} d Y_{t}=d Y_{t}$, where $\xi_{1}=\exp \left(-\rho-\frac{1}{2} \gamma^{2}+\mu+\right.$ $\left.\frac{1}{2}(\gamma-\sigma)^{2}\right)$

\section{A.7 Proof of Proposition 2.2}

Proof. From the gross risk-free rate expression $R_{t+1}^{f}=\exp (\rho)$ and the one-period government budget constraint, we obtain that: $\frac{T_{t}}{Y_{t}}=x-d\left(1-R_{t-1}^{f} \frac{Y_{t-1}}{Y_{t}}\right)$. The return on the tax claim can be stated as:

$$
R_{t+1}^{T}=\frac{P_{t+1}^{T}}{P_{t}^{T}-T_{t}}=\frac{\left(d+x \frac{\xi_{1}}{1-\xi_{1}}\right) Y_{t+1}+\left(x-d\left(1-R_{t}^{f} \frac{Y_{t}}{Y_{t+1}}\right)\right) Y_{t+1}}{\left(d+x \frac{\xi_{1}}{1-\tilde{\xi}_{1}}\right) Y_{t}}=\frac{x \frac{1}{1-\xi_{1}} Y_{t+1}}{\left(d+x \frac{\xi_{1}}{1-\tilde{\xi}_{1}}\right) Y_{t}}+\frac{d \exp (\rho)}{\left(d+x \frac{\xi_{1}}{1-\tilde{\xi}_{1}}\right)}
$$

Similarly, the return on the spending claim can be stated as:

$$
R_{t+1}^{G}=\frac{P_{t+1}^{G}}{P_{t}^{G}-G_{t}}=\frac{x \frac{\xi_{1}}{1-\tilde{\xi}_{1}} Y_{t+1}+x Y_{t+1}}{x \frac{\tilde{\xi}_{1}}{1-\xi_{1}} Y_{t}}=\frac{x \frac{1}{1-\tilde{\xi}_{1}} Y_{t+1}}{x \frac{\tilde{\xi}_{1}}{1-\tilde{\xi}_{1}} Y_{t}}
$$

Armed with these expressions, we get the following expression for the covariance: $\operatorname{cov}\left(R_{t+1}^{T}, M_{t, t+1}\right)=\frac{x \frac{\xi_{1}}{1-\xi_{1}}}{\left(d+x \frac{\xi_{1}}{1-\xi_{1}}\right)} \operatorname{cov}\left(R_{t+1}^{G}, M_{t, t+1}\right)$, which also translates to $\mathbb{E}_{t}\left[R_{t+1}^{T}-R_{t}^{f}\right]=\frac{x \frac{\xi_{1}}{1-\xi_{1}}}{d+x \frac{\xi_{1}}{1-\xi_{1}}} \mathbb{E}_{t}\left[R_{t+1}^{\gamma}-R_{t}^{f}\right]$.

\section{A.8 Proof of Proposition 2.3}

\section{A.8.1 Case of $A R(1)$}

Proof. We start from the government budget constraint in the case of risk-free debt: $T_{t}=G_{t}-\left(D_{t}-R_{t-1}^{f} D_{t-1}\right)$.

Hence, the surplus process is given by:

$$
\frac{S_{t}}{Y_{t}}=-\left(d_{t}-R_{t-1}^{f} d_{t-1} \frac{Y_{t-1}}{Y_{t}}\right)=d_{t-1} R_{t-1}^{f} \exp \left[-\left(\mu+\sigma \varepsilon_{t}\right)\right]-d_{t-1}^{\phi_{1}} \exp \left(\phi_{0}-\lambda \varepsilon_{t}-\frac{1}{2} \lambda^{2}\right) .
$$


We conjecture that the price of the surplus strips is given by: $\mathbb{E}_{t}\left[M_{t, t+k} S_{t+k}\right]=\left(\chi_{k, t}-\psi_{k, t}\right) Y_{t}$. The pricing of the first surplus strip is given by:

$$
\begin{aligned}
\mathbb{E}_{t}\left[M_{t, t+1} S_{t+1}\right] & =\mathbb{E}_{t}\left[M_{t, t+1}\left\{-Y_{t+1}\left(d_{t+1}-R_{t}^{f} d_{t} \exp \left[-\left(\mu+\sigma \varepsilon_{t+1}\right)\right]\right)\right\}\right], \\
& =\mathbb{E}_{t}\left[-\exp \left(\phi_{1} \log d_{t}+m_{t, t+1}+\phi_{0}-\lambda \varepsilon_{t+1}-\frac{1}{2} \lambda^{2}\right) Y_{t+1}\right]+d_{t} Y_{t}, \\
& =-\exp \left(\phi_{1} \log d_{t}+\phi_{0}-\rho-\frac{1}{2}\left(\gamma^{2}+\lambda^{2}\right)+\mu+\frac{1}{2}(\gamma+\lambda-\sigma)^{2}\right) Y_{t}+d_{t} Y_{t}, \\
\left(\chi_{1, t}-\psi_{1, t}\right) Y_{t} & =\left[d_{t}-\exp \left(\phi_{0}+\phi_{1} \log d_{t}-\rho-\frac{1}{2}\left(\gamma^{2}+\lambda^{2}\right)+\mu+\frac{1}{2}(\gamma+\lambda-\sigma)^{2}\right)\right] Y_{t} .
\end{aligned}
$$

So, we define:

$$
\left(\chi_{1, t}\right) Y_{t}=d_{t} Y_{t},\left(\psi_{1, t}\right) Y_{t}=\exp \left(\phi_{0}+\phi_{1} \log d_{t}-\rho-\frac{1}{2}\left(\gamma^{2}+\lambda^{2}\right)+\mu+\frac{1}{2}(\gamma+\lambda-\sigma)^{2}\right) Y_{t}
$$

Similarly the price of the $k$-th surplus strip is given by:

$$
\begin{aligned}
\mathbb{E}_{t}\left[M_{t, t+k} S_{t+k}\right] & =\mathbb{E}_{t}\left[M_{t, t+1} \mathbb{E}_{t+1}\left[M_{t+1, t+k} S_{t+k}\right]\right], \\
\left(\chi_{k, t}-\psi_{k, t}\right) Y_{t} & =\mathbb{E}_{t}\left[M_{t, t+1}\left(\chi_{k-1, t+1}-\psi_{k-1, t+1}\right) Y_{t+1}\right],
\end{aligned}
$$

where the $\chi^{\prime}$ s are defined by the following recursion:

$$
\begin{aligned}
\chi_{2, t} Y_{t} & =\mathbb{E}_{t}\left[M_{t, t+1} \chi_{1, t+1} Y_{t+1}\right] \\
\chi_{2, t} & =\mathbb{E}_{t}\left[\exp \left(-\rho-\frac{1}{2} \gamma^{2}-\gamma \varepsilon_{t+1}\right) \exp \left(-\lambda \varepsilon_{t+1}-\frac{1}{2} \lambda^{2}\right) \exp \left(\mu+\sigma \varepsilon_{t+1}\right)\right] \exp \left(\phi_{1} \log d_{t}+\phi_{0}\right), \\
& =\exp \left(\phi_{0}+\phi_{1} \log d_{t}-\rho-\frac{1}{2}\left(\gamma^{2}+\lambda^{2}\right)+\mu+\frac{1}{2}(\gamma+\lambda-\sigma)^{2}\right)=\psi_{1, t},
\end{aligned}
$$

and the $\psi$ 's are defined by the following recursion:

$$
\begin{aligned}
\psi_{2, t} Y_{t} & =\mathbb{E}_{t}\left[M_{t, t+1} \psi_{1, t+1} Y_{t+1}\right]=\mathbb{E}_{t}\left[\exp \left(-\rho-\frac{1}{2} \gamma^{2}-\gamma \varepsilon_{t+1}+\phi_{0}+\phi_{1} \log d_{t+1}-\rho-\frac{1}{2}\left(\gamma^{2}+\lambda^{2}\right)+\mu+\frac{1}{2}(\gamma+\lambda-\sigma)^{2}+\mu+\sigma \varepsilon_{t+1}\right)\right] \\
\psi_{2, t} & =\exp \left(-2 \rho+\phi_{0}+\phi_{1} \phi_{0}+\phi_{1}^{2} \log d_{t}-\frac{1}{2}\left(\gamma^{2}+\phi_{1} \lambda^{2}\right)-\frac{1}{2}\left(\gamma^{2}+\lambda^{2}\right)+2 \mu+\frac{1}{2}(\gamma+\lambda-\sigma)^{2}+\frac{1}{2}\left(\gamma+\lambda \phi_{1}-\sigma\right)^{2}\right), \\
& =\psi_{1, t} \exp \left(-\rho+\phi_{1} \phi_{0}+\left(\phi_{1}^{2}-\phi_{1}\right) \log d_{t}-\frac{1}{2}\left(\gamma^{2}+\phi_{1} \lambda^{2}\right)+\mu+\frac{1}{2}\left(\gamma+\lambda \phi_{1}-\sigma\right)^{2}\right) .
\end{aligned}
$$

More generally, we note that $\chi_{k+1, t}=\psi_{k, t}$, so that $\sum_{k=1}^{\infty} \mathbb{E}_{t}\left[M_{t, t+k} S_{t+k}\right]=\chi_{1, t} Y_{t}=D_{t}$. For some $0<\phi_{1}<1$, we can solve for the price of the debt strips:

$$
\begin{aligned}
\mathbb{E}_{t}\left[M_{t, t+1} D_{t+1}\right] & =\mathbb{E}_{t}\left[M_{t, t+1} Y_{t+1} d_{t+1}\right]=d_{t}^{\phi_{1}} \mathbb{E}_{t}\left[\exp \left(\phi_{0}+m_{t, t+1}-\lambda \varepsilon_{t+1}-\frac{1}{2} \lambda^{2}\right) Y_{t+1}\right], \\
& =d_{t}^{\phi_{1}} \exp \left(\phi_{0}-\rho-\frac{1}{2}\left(\gamma^{2}+\lambda^{2}\right)+\mu+\frac{1}{2}(\gamma+\lambda-\sigma)^{2}\right) Y_{t}=\exp \left(\kappa_{1}\right) \exp \left(\phi_{1} \log d_{t}\right) Y_{t}
\end{aligned}
$$

where $\kappa_{1}=\phi_{0}-\rho-\frac{1}{2}\left(\gamma^{2}+\lambda^{2}\right)+\mu+\frac{1}{2}(\gamma+\lambda-\sigma)^{2}$. Similarly, the price of the two-period ahead debt strip is given by:

$$
\begin{aligned}
\mathbb{E}_{t}\left[M_{t, t+2} D_{t+2}\right] & =\mathbb{E}_{t}\left[M_{t, t+1} \mathbb{E}_{t+1}\left[\exp \left(m_{t+1, t+2}\right) D_{t+2}\right]\right]=\mathbb{E}_{t}\left[M_{t, t+1} \exp \left(\kappa_{1}\right) \exp \left(\phi_{1} \log d_{t+1}\right) Y_{t+1}\right], \\
& =\mathbb{E}_{t}\left[M_{t, t+1} \exp \left(\kappa_{1}\right) \exp \left(\phi_{1}^{2} \log d_{t}+\phi_{1} \phi_{0}-\phi_{1} \lambda \varepsilon_{t+1}-\frac{1}{2} \phi_{1} \lambda^{2}\right) \exp \left(\mu+\sigma \varepsilon_{t+1}\right)\right] Y_{t}, \\
& =\exp \left(\kappa_{1}+\kappa_{2}\right) \exp \left(\phi_{1}^{2} \log d_{t}\right) Y_{t},
\end{aligned}
$$

where $\kappa_{2}=\phi_{1} \phi_{0}-\rho-\frac{1}{2}\left(\gamma^{2}+\phi_{1} \lambda^{2}\right)+\mu+\frac{1}{2}\left(\gamma+\phi_{1} \lambda-\sigma\right)^{2}$. Then, by induction,

$$
\begin{aligned}
\lim _{j \rightarrow \infty} \mathbb{E}_{t}\left[M_{t, t+j} D_{t+j}\right] & =\lim _{j \rightarrow \infty} \exp \left(\sum_{k=1}^{j} \kappa_{k}\right) \exp \left(\phi_{1}^{j} \log d_{t}\right) Y_{t}, \\
& =\lim _{j \rightarrow \infty} \exp \left(\frac{\phi_{0}}{1-\phi_{1}}-\rho j-\frac{1}{2}\left(\gamma^{2} j+\frac{\lambda^{2}}{1-\phi_{1}}\right)+\mu j+\sum_{k=1}^{j} \frac{1}{2}\left(\gamma+\lambda \phi_{1}^{k-1}-\sigma\right)^{2}\right) Y_{t},
\end{aligned}
$$




$$
=\lim _{j \rightarrow \infty} \exp \left(\frac{\phi_{0}}{1-\phi_{1}}-\rho j-\frac{1}{2}\left(\gamma^{2} j+\frac{\lambda^{2}}{1-\phi_{1}}\right)+\mu j+j \frac{1}{2}(\gamma-\sigma)^{2}+C\right) Y_{t}
$$

where $C=\sum_{k=1}^{j}\left[(\gamma-\sigma) \lambda \phi_{1}^{k-1}+\lambda^{2} \phi_{1}^{2(k-1)}\right]$. The above equation is 0 if and only if $-\rho+\mu+\frac{1}{2} \sigma(\sigma-2 \gamma)<0$. This condition does not depend on $\phi_{1}$ and $\lambda$.

\section{A.8.2 Case of Random Walk}

Proof. Now, assume $\phi_{1}=1$ and $\phi_{0}=0$. Then $\kappa_{j}=\phi_{0}-\rho-\frac{1}{2}\left(\gamma^{2}+\lambda^{2}\right)+\mu+\frac{1}{2}(\gamma+\lambda-\sigma)^{2}$. The TVC is $\lim _{j \rightarrow \infty} \mathbb{E}_{t}\left[M_{t, t+j} D_{t+j}\right]=$ $\lim _{j \rightarrow \infty} \exp \left(\sum_{k=1}^{j} \kappa_{k}\right) \exp \left(\log d_{t}\right) Y_{t}$, which is 0 if and only if $-\rho-\frac{1}{2}\left(\gamma^{2}+\lambda^{2}\right)+\mu+\frac{1}{2}(\gamma+\lambda-\sigma)^{2}<0$.

\section{A.8.3 Case of $A R(2)$}

Proof. From the government budget constraint in the case of risk-free debt: $T_{t}=G_{t}-\left(D_{t}-R_{t-1}^{f} D_{t-1}\right)$, it follows that the surpluses are given by:

$$
S_{t}=-\left(d_{t} Y_{t}-R_{t-1}^{f} d_{t-1} Y_{t-1}\right)=d_{t-1} R_{t-1}^{f} Y_{t-1}-\exp \left(\phi_{0}+\phi_{1} \log d_{t-1}+\phi_{2} \log d_{t-2}-\lambda \varepsilon_{t}-\frac{1}{2} \lambda^{2}\right) Y_{t}
$$

We conjecture the price of the surplus strips is given by the following expression: $\mathbb{E}_{t}\left[M_{t, t+k} S_{t+k}\right]=\left(\chi_{k, t}-\psi_{k, t}\right) Y_{t}$. The pricing of the first surplus strip then as follows:

$$
\begin{aligned}
\mathbb{E}_{t}\left[M_{t, t+1} S_{t+1}\right] & =\mathbb{E}_{t}\left[M_{t, t+1}\left\{-Y_{t+1}\left(d_{t+1}-R_{t}^{f} d_{t} \exp \left[-\left(\mu+\sigma \varepsilon_{t+1}\right)\right]\right)\right\}\right] \\
& =\mathbb{E}_{t}\left[-\exp \left(\phi_{1} \log d_{t}+\phi_{2} \log d_{t-1}+m_{t, t+1}+\phi_{0}-\lambda \varepsilon_{t+1}-\frac{1}{2} \lambda^{2}\right) Y_{t+1}\right]+d_{t} Y_{t}, \\
& =-\exp \left(\phi_{1} \log d_{t}+\phi_{2} \log d_{t-1}+\phi_{0}-\rho-\frac{1}{2}\left(\gamma^{2}+\lambda^{2}\right)+\mu+\frac{1}{2}(\gamma+\lambda-\sigma)^{2}\right) Y_{t}+d_{t} Y_{t}, \\
\left(\chi_{1, t}-\psi_{1, t}\right) Y_{t} & =\left[d_{t}-\exp \left(\phi_{0}+\phi_{1} \log d_{t}+\phi_{2} \log d_{t-1}-\rho-\frac{1}{2}\left(\gamma^{2}+\lambda^{2}\right)+\mu+\frac{1}{2}(\gamma+\lambda-\sigma)^{2}\right)\right] Y_{t} .
\end{aligned}
$$

We define the following objects:

$$
\begin{aligned}
& \left(\chi_{1, t}\right) Y_{t}=d_{t} Y_{t} \\
& \left(\psi_{1, t}\right) Y_{t}=\exp \left(\phi_{0}+\phi_{1} \log d_{t}+\phi_{2} \log d_{t-1}-\rho-\frac{1}{2}\left(\gamma^{2}+\lambda^{2}\right)+\mu+\frac{1}{2}(\gamma+\lambda-\sigma)^{2}\right) Y_{t} .
\end{aligned}
$$

Similarly the pricing of the $k$-th surplus strip is

$$
\begin{aligned}
\mathbb{E}_{t}\left[M_{t, t+k} S_{t+k}\right] & =\mathbb{E}_{t}\left[M_{t, t+1} \mathbb{E}_{t+1}\left[M_{t+1, t+k} S_{t+k}\right]\right], \\
\left(\chi_{k, t}-\psi_{k, t}\right) Y_{t} & =\mathbb{E}_{t}\left[M_{t, t+1}\left(\chi_{k-1, t+1}-\psi_{k-1, t+1}\right) Y_{t+1}\right],
\end{aligned}
$$

where the $\chi$ 's are defined by the following recursion:

$$
\begin{aligned}
\chi_{2, t} Y_{t} & =\mathbb{E}_{t}\left[M_{t, t+1} \chi_{1, t+1} Y_{t+1}\right] \\
\chi_{2, t} & =\mathbb{E}_{t}\left[\exp \left(-\rho-\frac{1}{2} \gamma^{2}-\gamma \varepsilon_{t+1}\right) \exp \left(-\lambda \varepsilon_{t+1}-\frac{1}{2} \lambda^{2}\right) \exp \left(\mu+\sigma \varepsilon_{t+1}\right)\right] \exp \left(\phi_{1} \log d_{t}+\phi_{2} \log d_{t-1}+\phi_{0}\right), \\
& =\exp \left(\phi_{0}+\phi_{1} \log d_{t}+\phi_{2} \log d_{t-1}-\rho-\frac{1}{2}\left(\gamma^{2}+\lambda^{2}\right)+\mu+\frac{1}{2}(\gamma+\lambda-\sigma)^{2}\right) .
\end{aligned}
$$

and the $\psi^{\prime}$ s are defined by the following recursion:

$$
\begin{aligned}
\psi_{2, t} Y_{t} & =\mathbb{E}_{t}\left[M_{t, t+1} \psi_{1, t+1} Y_{t+1}\right] \\
\psi_{2, t} & =\mathbb{E}_{t}\left[\exp \left(-\rho-\frac{1}{2} \gamma^{2}-\gamma \varepsilon_{t+1}+\phi_{0}+\phi_{1} \log d_{t+1}+\phi_{2} \log d_{t}-\rho-\frac{1}{2}\left(\gamma^{2}+\lambda^{2}\right)+\mu+\frac{1}{2}(\gamma+\lambda-\sigma)^{2}+\mu+\sigma \varepsilon_{t+1}\right)\right] \\
\psi_{2, t} & =\exp \left(-2 \rho+\phi_{0}+\phi_{1} \phi_{0}+\left(\phi_{1}^{2}+\phi_{2}\right) \log d_{t}+\phi_{1} \phi_{2} \log d_{t-1}-\frac{1}{2}\left(\gamma^{2}+\phi_{1} \lambda^{2}\right),\right. \\
& \left.-\frac{1}{2}\left(\gamma^{2}+\lambda^{2}\right)+2 \mu+\frac{1}{2}(\gamma+\lambda-\sigma)^{2}+\frac{1}{2}\left(\gamma+\lambda \phi_{1}-\sigma\right)^{2}\right) .
\end{aligned}
$$


We note that $\chi_{k+1, t}=\psi_{k, t}$, so this expression can be simplified as follows: $\sum_{k=1}^{\infty} \mathbb{E}_{t}\left[M_{t, t+k} S_{t+k}\right]=\chi_{1, t} Y_{t}=D_{t}$. Also note that: $d_{t}=\exp \left(\phi_{1} \log d_{t-1}+\phi_{2} \log d_{t-2}+\phi_{0}-\lambda \varepsilon_{t}-\frac{1}{2} \lambda^{2}\right)$. Using this expression, we find that:

$$
\begin{aligned}
\mathbb{E}_{t}\left[M_{t, t+1} D_{t+1}\right] & =\mathbb{E}_{t}\left[M_{t, t+1} Y_{t+1} d_{t+1}\right]=d_{t}^{\phi_{1}} d_{t-1}^{\phi_{2}} \mathbb{E}_{t}\left[\phi_{0}+\exp \left(m_{t, t+1}-\lambda \varepsilon_{t+1}-\frac{1}{2} \lambda^{2}\right) Y_{t+1}\right], \\
& =d_{t}^{\phi_{1}} d_{t-1}^{\phi_{2}} \exp \left(\phi_{0}-\rho-\frac{1}{2}\left(\gamma^{2}+\lambda^{2}\right)+\mu+\frac{1}{2}(\gamma+\lambda-\sigma)^{2}\right) Y_{t}, \\
& =\exp \left(\kappa_{1}\right) \exp \left(\phi_{1} \log d_{t}+\phi_{2} \log d_{t-1}\right) Y_{t}
\end{aligned}
$$

Define $\kappa_{1}=\phi_{0}-\rho-\frac{1}{2}\left(\gamma^{2}+\lambda^{2}\right)+\mu+\frac{1}{2}(\gamma+\lambda-\sigma)^{2}$.

$$
\begin{aligned}
\mathbb{E}_{t}\left[M_{t, t+2} D_{t+2}\right] & =\mathbb{E}_{t}\left[M_{t, t+1} \mathbb{E}_{t+1}\left[\exp \left(m_{t+1, t+2}\right) D_{t+2}\right]\right]=\mathbb{E}_{t}\left[M_{t, t+1} \exp \left(\kappa_{1}\right) \exp \left(\phi_{1} \log d_{t+1}+\phi_{2} \log d_{t}\right) Y_{t+1}\right], \\
& =\mathbb{E}_{t}\left[M_{t, t+1} \exp \left(\kappa_{1}\right) \exp \left(\left(\phi_{1}^{2}+\phi_{2}\right) \log d_{t}+\phi_{1} \phi_{2} \log d_{t-1}+\phi_{1} \phi_{0}-\phi_{1} \lambda \varepsilon_{t+1}-\frac{1}{2} \phi_{1} \lambda^{2}\right) \exp \left(\mu+\sigma \varepsilon_{t+1}\right)\right] Y_{t} \\
& =\exp \left(\kappa_{1}+\kappa_{2}\right) \exp \left(\left(\phi_{1}^{2}+\phi_{2}\right) \log d_{t}+\phi_{1} \phi_{2} \log d_{t-1}\right) Y_{t} .
\end{aligned}
$$

Define $\kappa_{2}=\phi_{1} \phi_{0}-\rho-\frac{1}{2}\left(\gamma^{2}+\phi_{1} \lambda^{2}\right)+\mu+\frac{1}{2}\left(\gamma+\phi_{1} \lambda-\sigma\right)^{2}$.

$$
\begin{aligned}
\lim _{j \rightarrow \infty} \mathbb{E}_{t}\left[M_{t, t+j} D_{t+j}\right] & =\lim _{j \rightarrow \infty} \exp \left(\sum_{k=1}^{j} \kappa_{k}\right) \exp \left(\psi_{j} \log d_{t}\right) Y_{t} \\
& =\lim _{j \rightarrow \infty} \exp \left(\frac{\phi_{0}}{1-\phi_{1}-\phi_{2}}-\rho j-\frac{1}{2}\left(\gamma^{2} j+\frac{\lambda^{2}}{1-\phi_{1}-\phi_{2}}\right)+\mu j+\sum_{k=1}^{j} \frac{1}{2}\left(\gamma+\lambda \psi_{k-1}-\sigma\right)^{2}\right) Y_{t}, \\
& =\lim _{j \rightarrow \infty} \exp \left(\frac{\phi_{0}}{1-\phi_{1}-\phi_{2}}-\rho j-\frac{1}{2}\left(\gamma^{2} j+\frac{\lambda^{2}}{1-\phi_{1}-\phi_{2}}\right)+\mu j+j \frac{1}{2}(\gamma-\sigma)^{2}+C\right) Y_{t},
\end{aligned}
$$

where $\psi_{j}=\phi_{1} \psi_{j-1}+\phi_{2} \psi_{j-2}+\phi_{3} \psi_{j-3}, j>3 ; \psi_{3}=\phi_{3}+\phi_{2} \psi_{1}+\phi_{1} \psi_{2} ; \psi_{2}=\phi_{2}+\phi_{1} \psi_{1} ; \psi_{1}=\phi_{1}$, and $C=\sum_{k=1}^{j}\left[(\gamma-\sigma) \lambda \psi_{k-1}+\lambda^{2} \psi_{k-1}^{2}\right]$. The above equation is 0 if and only if $-\rho+\mu+\frac{1}{2} \sigma(\sigma-2 \gamma)<0$. This condition does not depend on $\phi_{1}, \phi_{2}$ and $\lambda$. So this case is similar to the i.i.d. debt case $\phi=0$. More extremely, when $\lambda=0, d_{t}=\exp \left(\phi_{0}\right)$ is a constant. Now, assume $\phi=1$. Then $\kappa_{j}=\phi_{0}-\rho-\frac{1}{2}\left(\gamma^{2}+\lambda^{2}\right)+\mu+\frac{1}{2}(\gamma+\lambda-\sigma)^{2}$, and $\lim _{j \rightarrow \infty} \mathbb{E}_{t}\left[M_{t, t+j} D_{t+j}\right]=\lim _{j \rightarrow \infty} \exp \left(\sum_{k=1}^{j} \kappa_{k}\right) \exp \left(\log d_{t}\right) Y_{t}$, which is 0 if and only if $\phi_{0}-\rho-\frac{1}{2}\left(\gamma^{2}+\lambda^{2}\right)+\mu+\frac{1}{2}(\gamma+\lambda-\sigma)^{2}<0$.

\section{A.9 Proof of Proposition 2.4}

\section{A.9.1 Case of $A R(1)$}

Proof. When the log of the debt/output process follows an $A R(1)$, the surplus/output ratio is given by:

$$
\begin{aligned}
\frac{S_{t+1}}{Y_{t+1}} & =d_{t} R_{t}^{f} \exp \left[-\left(\mu+\sigma \varepsilon_{t+1}\right)\right]-d_{t}^{\phi_{1}} \exp \left(\phi_{0}-\lambda \varepsilon_{t+1}-\frac{1}{2} \lambda^{2}\right) \\
& =\exp \left(r_{t}^{f}-\mu-\sigma \varepsilon_{t+1}-\sum_{j=0}^{\infty} \phi_{1}^{j} \lambda \varepsilon_{t-j}+\frac{\phi_{0}-\frac{1}{2} \lambda^{2}}{1-\phi_{1}}\right)-\exp \left(\phi_{1}\left(-\sum_{j=0}^{\infty} \phi_{1}^{j} \lambda \varepsilon_{t-j}+\frac{\phi_{0}-\frac{1}{2} \lambda^{2}}{1-\phi_{1}}\right)+\phi_{0}-\lambda \varepsilon_{t+1}-\frac{1}{2} \lambda^{2}\right)
\end{aligned}
$$

We assume that $r_{t}^{f}=\mu$. This expression for the surplus/output ratio can be restated as:

$$
\frac{S_{t+1}}{Y_{t+1}}=\exp \left(-\sigma \varepsilon_{t+1}-\sum_{j=0}^{\infty} \phi_{1}^{j} \lambda \varepsilon_{t-j}+\frac{\phi_{0}-\frac{1}{2} \lambda^{2}}{1-\phi_{1}}\right)-\exp \left(-\sum_{j=0}^{\infty} \phi_{1}^{j} \lambda \varepsilon_{t+1-j}+\frac{\phi_{0}-\frac{1}{2} \lambda^{2}}{1-\phi_{1}}\right) .
$$

Next, we compute the derivative of the surplus/output ratio at $t+1$ :

$$
\frac{\partial \frac{S_{t+1}}{Y_{t+1}}}{\partial \varepsilon_{t+1}}=(\lambda) \exp \left(g+\sigma \varepsilon_{t+1}-\sum_{j=0}^{\infty} \phi_{1}^{j} \lambda \varepsilon_{t+1-j}+\frac{\phi_{0}-\frac{1}{2} \lambda^{2}}{1-\phi_{1}}\right)-\sigma \exp \left(-\sigma \varepsilon_{t+1}-\sum_{j=0}^{\infty} \phi_{1}^{j} \lambda \varepsilon_{t-j}+\frac{\phi_{0}-\frac{1}{2} \lambda^{2}}{1-\phi_{1}}\right) .
$$

We evaluate this derivative at $\varepsilon_{t+j}=0$ to obtain: $\frac{\partial \frac{S_{t+1}}{\partial \varepsilon_{t+1}}}{\partial \varepsilon_{t+1}}=(\lambda-\sigma) \exp \left(\frac{\phi_{0}-\frac{1}{2} \lambda^{2}}{1-\phi_{1}}\right)$. Next, we compute the derivative of the surplus/output 
ratio at $t+2$, given by the following expression:

$$
\frac{\partial \frac{S_{t+2}}{Y_{t+2}}}{\partial \varepsilon_{t+1}}=-\lambda \exp \left(-\sigma \varepsilon_{t+2}-\sum_{j=0}^{\infty} \phi_{1}^{j} \lambda \varepsilon_{t+1-j}+\frac{\phi_{0}-\frac{1}{2} \lambda^{2}}{1-\phi_{1}}\right)+\lambda \phi_{1} \exp \left(-\sum_{j=0}^{\infty} \phi_{1}^{j} \lambda \varepsilon_{t+2-j}+\frac{\phi_{0}-\frac{1}{2} \lambda^{2}}{1-\phi_{1}}\right) .
$$

We evaluate this derivative at $\varepsilon_{t+j}=0$ to obtain the following expression: $\frac{\partial \frac{S_{t+2}}{t \varepsilon_{t+1}}}{\partial \varepsilon_{t+1}}=-\lambda \exp \left(\frac{\phi_{0}-\frac{1}{2} \lambda^{2}}{1-\phi_{1}}\right)+\lambda \phi_{1} \exp \left(\frac{\phi_{0}-\frac{1}{2} \lambda^{2}}{1-\phi_{1}}\right)$. This generalizes to the following expression. For $j \geq 2$, we obtain the following expression:

$$
\frac{\partial \frac{S_{t+j}}{Y_{t+j}}}{\partial \varepsilon_{t+1}}=-\lambda \phi_{1}^{j-1} \exp \left(\frac{\phi_{0}-\frac{1}{2} \lambda^{2}}{1-\phi_{1}}\right)+\lambda \phi_{1}^{j} \exp \left(\frac{\phi_{0}-\frac{1}{2} \lambda^{2}}{1-\phi_{1}}\right) .
$$

Assume $r^{f}=\mu$. Then we obtain the impulse response function (IRF):

$$
\frac{\partial \frac{S_{t+j}}{Y_{t+j}}}{\partial \varepsilon_{t+1}}=\lambda \phi_{1}^{j-1}\left(\phi_{1}-1\right) d, j>1, \frac{\partial \frac{S_{t+1}}{Y_{t+j}}}{\partial \varepsilon_{t+1}}=(\lambda-\sigma) d, j=1 .
$$

\section{A.9.2 Case of $A R(2)$}

Proof. We use $\psi(L)$ to denote the infinite MA representation of the debt/output process. We assume that $r_{t}^{f}=\mu$. When the log of the debt/output process follows an $A R(2)$, the surplus/output ratio is given by:

$$
\frac{S_{t+1}}{Y_{t+1}}=\exp \left(-\sigma \varepsilon_{t+1}-\sum_{j=0}^{\infty} \phi_{1}^{j} \lambda \varepsilon_{t-j}+\bar{d}\right)-\exp \left(\bar{d}+\phi_{1}\left(-\sum_{j=0}^{\infty} \psi_{j} \lambda \varepsilon_{t-j}\right)+\phi_{2}\left(-\sum_{j=0}^{\infty} \psi_{j} \lambda \varepsilon_{t-1-j}\right)-\lambda \varepsilon_{t+1}-\frac{1}{2} \lambda^{2}\right) .
$$

Next, we compute the derivative of the surplus / output ratio at $t+1$, and we evaluate this derivative at $\varepsilon_{t+j}=0: \frac{\partial \frac{S_{t+1}}{\partial \varepsilon_{t+1}}}{Y_{t+1}}=-\sigma \exp (\bar{d})+$ $\lambda \exp \left(\bar{d}-\frac{1}{2} \lambda^{2}\right)$. The surplus/output ratio at $t+2$ is given by:

$$
\frac{S_{t+2}}{Y_{t+2}}=\exp \left(-\sigma \varepsilon_{t+2}-\sum_{j=0}^{\infty} \phi_{1}^{j} \lambda \varepsilon_{t+1-j}+\bar{d}\right)-\exp \left(\bar{d}+\phi_{1}\left(-\sum_{j=0}^{\infty} \psi_{j} \lambda \varepsilon_{t+1-j}\right)+\phi_{2}\left(-\sum_{j=0}^{\infty} \psi_{j} \lambda \varepsilon_{t-j}\right)-\lambda \varepsilon_{t+2}-\frac{1}{2} \lambda^{2}\right) .
$$

We evaluate this derivative at $\varepsilon_{t+j}=0$ to obtain:

$$
\frac{\partial \frac{S_{t+2}}{Y_{t+2}}}{\partial \varepsilon_{t+1}}=-\lambda \exp (\bar{d})+\lambda\left(\phi_{1}\right) \exp \left(\bar{d}-\frac{1}{2} \lambda^{2}\right)
$$

The surplus/output ratio at $t+3$ is given by:

$$
\frac{S_{t+3}}{Y_{t+3}}=\exp \left(-\sigma \varepsilon_{t+3}-\sum_{j=0}^{\infty} \psi_{j} \lambda \varepsilon_{t+2-j}+\bar{d}\right)-\exp \left(\bar{d}+\phi_{1}\left(-\sum_{j=0}^{\infty} \psi_{j} \lambda \varepsilon_{t+2-j}\right)+\phi_{2}\left(-\sum_{j=0}^{\infty} \psi_{j} \lambda \varepsilon_{t+1-j}\right)-\lambda \varepsilon_{t+3}-\frac{1}{2} \lambda^{2}\right) .
$$

We evaluate this derivative at $\varepsilon_{t+j}=0$ to obtain:

$$
\frac{\partial \frac{S_{t+3}}{Y_{t+3}}}{\partial \varepsilon_{t+1}}=-\psi_{1} \lambda \exp (\bar{d})+\lambda\left(\phi_{1} \psi_{1}+\phi_{2}\right) \exp \left(\mu+\bar{d}-\frac{1}{2} \lambda^{2}\right)
$$

This generalizes to the following expression. For $j>2$, we obtain:

$$
\frac{\partial \frac{S_{t+j}}{Y_{t+j}}}{\partial \varepsilon_{t+1}}=-\lambda \psi_{j-2} \exp (\bar{d})+\lambda \psi_{j-1} \exp \left(\bar{d}-\frac{1}{2} \lambda^{2}\right) .
$$


Assume $r^{f}=\mu$. Then we obtain the impulse response function:

$$
\begin{aligned}
\frac{\partial \frac{S_{t+j}}{\partial \varepsilon_{t+1}}}{\partial \varepsilon_{t+1}} & =-\sigma \exp (\bar{d})+\lambda \exp \left(\bar{d}-\frac{1}{2} \lambda^{2}\right), \text { for } j=1, \\
& =-\lambda \exp (\bar{d})+\lambda \phi_{1} \exp \left(\bar{d}-\frac{1}{2} \lambda^{2}\right), \text { for } j=2 \\
& =-\lambda \psi_{j-2} \exp (\bar{d})+\lambda \psi_{j-1} \exp \left(\bar{d}-\frac{1}{2} \lambda^{2}\right), \text { for } j>2 .
\end{aligned}
$$

\section{A.9.3 Case of AR(3)}

Proof. We use $\psi(L)$ to denote the infinite MA representation of the debt/output process. We assume $r^{f}=\mu$. When the log of the debt/output process follows an $\mathrm{AR}(3)$, the surplus/output ratio is given by:

$$
\frac{S_{t+1}}{Y_{t+1}}=\exp \left(-\sigma \varepsilon_{t+1}-\sum_{j=0}^{\infty} \phi_{1}^{j} \lambda \varepsilon_{t-j}+\bar{d}\right)-\exp \left(\bar{d}+\phi_{1}\left(-\sum_{j=0}^{\infty} \psi_{j} \lambda \varepsilon_{t-j}\right)+\phi_{2}\left(-\sum_{j=0}^{\infty} \psi_{j} \lambda \varepsilon_{t-1-j}+\phi_{3}\left(-\sum_{j=0}^{\infty} \psi_{j} \lambda \varepsilon_{t-2-j}\right)-\lambda \varepsilon_{t+1}-\frac{1}{2} \lambda^{2}\right)\right.
$$

Next, we compute the derivative of the surplus/output ratio at $t+1$, and we evaluate this derivative at $\varepsilon_{t+j}=0$ :

$$
\frac{\partial \frac{S_{t+1}}{Y_{t+1}}}{\partial \varepsilon_{t+1}}=-\sigma \exp (\bar{d})+\lambda \exp \left(\bar{d}-\frac{1}{2} \lambda^{2}\right)
$$

The surplus/output ratio at $t+2$ is given by:

$$
\frac{S_{t+2}}{Y_{t+2}}=\exp \left(-\sigma \varepsilon_{t+2}-\sum_{j=0}^{\infty} \phi_{1}^{j} \lambda \varepsilon_{t+1-j}+\bar{d}\right)-\exp \left(\bar{d}+\phi_{1}\left(-\sum_{j=0}^{\infty} \psi_{j} \lambda \varepsilon_{t+1-j}\right)+\phi_{2}\left(-\sum_{j=0}^{\infty} \psi_{j} \lambda \varepsilon_{t-j}\right)+\phi_{3}\left(-\sum_{j=0}^{\infty} \psi_{j} \lambda \varepsilon_{t-1-j}\right)-\lambda \varepsilon_{t+2}-\frac{1}{2} \lambda^{2}\right)
$$

We evaluate this derivative at $\varepsilon_{t+j}=0$ to obtain: $\frac{\partial \frac{S_{t+2}}{\partial \varepsilon_{t+1}}}{\varepsilon_{t+1}}=-\lambda \exp (\bar{d})+\lambda\left(\phi_{1}\right) \exp \left(\bar{d}-\frac{1}{2} \lambda^{2}\right)$. The surplus/output ratio at $t+3$ is given by:

$\frac{S_{t+3}}{Y_{t+3}}=\exp \left(-\sigma \varepsilon_{t+3}-\sum_{j=0}^{\infty} \psi_{j} \lambda \varepsilon_{t+2-j}+\bar{d}\right)-\exp \left(\bar{d}+\phi_{1}\left(-\sum_{j=0}^{\infty} \psi_{j} \lambda \varepsilon_{t+2-j}\right)+\phi_{2}\left(-\sum_{j=0}^{\infty} \psi_{j} \lambda \varepsilon_{t+1-j}+\phi_{3}\left(-\sum_{j=0}^{\infty} \psi_{j} \lambda \varepsilon_{t-j}\right)-\lambda \varepsilon_{t+3}-\frac{1}{2} \lambda^{2}\right)\right.$

We evaluate this derivative at $\varepsilon_{t+j}=0$ to obtain:

$$
\frac{\partial \frac{S_{t+3}}{Y_{t+3}}}{\partial \varepsilon_{t+1}}=-\psi_{1} \lambda \exp (\bar{d})+\lambda\left(\phi_{1} \psi_{1}+\phi_{2}\right) \exp \left(\bar{d}-\frac{1}{2} \lambda^{2}\right)
$$

We evaluate this derivative at $\varepsilon_{t+j}=0$ to obtain:

$$
\frac{\partial \frac{S_{t+4}}{Y_{t+4}}}{\partial \varepsilon_{t+1}}=-\psi_{2} \lambda \exp (\bar{d})+\lambda\left(\phi_{1} \psi_{2}+\phi_{2} \psi_{1}+\phi_{3}\right) \exp \left(\bar{d}-\frac{1}{2} \lambda^{2}\right) .
$$

This generalizes to the following expression. For $j>2$, we obtain:

$$
\frac{\partial \frac{S_{t+j}}{Y_{t+j}}}{\partial \varepsilon_{t+1}}=-\lambda \psi_{j-2} \exp (\bar{d})+\lambda \psi_{j-1} \exp \left(\bar{d}-\frac{1}{2} \lambda^{2}\right)
$$

Assume $r^{f}=\mu$. Then we obtain the IRF:

$$
\begin{aligned}
\frac{\partial \frac{S_{t+j}}{Y_{t+j}}}{\partial \varepsilon_{t+1}} & =-\sigma \exp (\bar{d})+\lambda \exp \left(\bar{d}-\frac{1}{2} \lambda^{2}\right), \text { for } j=1, \\
& =-\lambda \exp (\bar{d})+\lambda \phi_{1} \exp \left(\bar{d}-\frac{1}{2} \lambda^{2}\right), \text { for } j=2,
\end{aligned}
$$




$$
\begin{aligned}
& =-\lambda \psi_{1} \exp (\bar{d})+\lambda\left(\phi_{1} \psi_{1}+\phi_{2}\right) \exp \left(\bar{d}-\frac{1}{2} \lambda^{2}\right), \text { for } j=3, \\
& =-\lambda \psi_{j-2} \exp \bar{d}+\lambda \psi_{j-1} \exp \left(\bar{d}-\frac{1}{2} \lambda^{2}\right), \text { for } j>3 .
\end{aligned}
$$

\section{A.10 Proof of Proposition 2.5}

\section{A.10.1 Case of $A R(1)$}

Proof. As a result, we can solve for an expression of the log debt/output ratio as a function of the past shocks:

$$
\log d_{t}=-\sum_{j=0}^{\infty} \phi^{j} \lambda \varepsilon_{t-j}+\frac{\phi_{0}-\frac{1}{2} \lambda^{2}}{1-\phi}
$$

Consider a government that only issues risk-free debt. Note that the surplus at $t+1$ is given by:

$$
S_{t+1}=d_{t} Y_{t} \exp \left(r_{t}^{f}\right)-\exp \left(\phi \log d_{t}+\phi_{0}-\lambda \varepsilon_{t+1}-\frac{1}{2} \lambda^{2}\right) Y_{t+1}
$$

We get the following expression for the covariance:

$$
\begin{aligned}
\operatorname{cov}_{t}\left(M_{t+1}, S_{t+1}\right) & =\operatorname{cov}_{t}\left(M_{t+1},-d_{t+1} Y_{t+1}\right)=-\mathbb{E}_{t}\left[M_{t+1} d_{t+1} Y_{t+1}\right]+\mathbb{E}_{t}\left[M_{t+1}\right] \mathbb{E}_{t}\left[d_{t+1} Y_{t+1}\right] \\
& =-\exp \left(-\rho-\frac{1}{2} \gamma^{2}+\frac{1}{2}(\gamma+\lambda-\sigma)^{2}+\mu+y_{t}+\phi \log d_{t}+\phi_{0}-\frac{1}{2} \lambda^{2}\right) \\
& +\exp (-\rho) \exp \left(\frac{1}{2}(\lambda-\sigma)^{2}+\mu+y_{t}+\phi \log d_{t}+\phi_{0}-\frac{1}{2} \lambda^{2}\right) \\
& =-\left(\exp \left(-\frac{1}{2} \gamma^{2}+\frac{1}{2}(\gamma+\lambda-\sigma)^{2}-\frac{1}{2}(\lambda-\sigma)^{2}\right)-1\right) \mathbb{E}_{t}\left[M_{t+1}\right] \mathbb{E}_{t}\left[d_{t+1} Y_{t+1}\right] \\
& =-\mathbb{E}_{t}\left[M_{t+1}\right] \mathbb{E}_{t}\left[d_{t+1} Y_{t+1}\right](\exp (-\gamma(\sigma-\lambda))-1) .
\end{aligned}
$$

By the same token, we get the following expression for the covariance of the discounted surpluses over two periods:

$$
\operatorname{cov}_{t}\left(M_{t+1}, S_{t+1}+E_{t+1}\left[M_{t+1, t+2} S_{t+2}\right)\right]=\operatorname{cov}_{t}\left(M_{t+1},-E_{t+1}\left[M_{t+1, t+2} d_{t+2} Y_{t+2}\right]\right)=-\mathbb{E}_{t}\left[M_{t+1}\right] E_{t}\left[M_{t+1, t+2} d_{t+2} Y_{t+2}\right](\exp (-\gamma(\sigma-\phi \lambda))-1)
$$

We refer the reader to the proof of Prop. 1.3 to see why the sum of the discounted surpluses drop out and only the debt issuance term remains. We get the following expression for the covariance of the discounted surpluses over $j$ periods:

$$
\operatorname{cov}_{t}\left(M_{t+1}, \sum_{k=1}^{j} E_{t+1}\left[M_{t+1, t+j} S_{t+j}\right]\right)=\operatorname{cov}_{t}\left(M_{t+1},-E_{t+1}\left[M_{t+1, t+j} d_{t+j} Y_{t+j}\right]\right)=-\mathbb{E}_{t}\left[M_{t+1}\right] E_{t}\left[M_{t+1, t+j} d_{t+j} Y_{t+j}\right]\left(\exp \left(-\gamma\left(\sigma-\phi^{j-1} \lambda\right)\right)-1\right)
$$

\section{A.10.2 Case of $A R(2)$}

Proof. We use $\psi(L)$ to denote the infinite MA representation of the debt/output process. As a result, we can solve for an expression of the log debt/output ratio as a function of the past shocks:

$$
\log d_{t}=-\sum_{j=0}^{\infty} \psi_{j} \lambda \varepsilon_{t-j}+\frac{\phi_{0}-\frac{1}{2} \lambda^{2}}{1-\phi_{1}-\phi_{2}}
$$

where $\psi_{j}=\phi_{1} \psi_{j-1}+\phi_{2} \psi_{j-2}$. Consider a government that only issues risk-free debt. Note that the surplus at $t+1$ is given by:

$$
S_{t+1}=d_{t} Y_{t} \exp \left(r_{t}^{f}\right)-\exp \left(+\phi_{1} \log d_{t}+\phi_{2} \log d_{t-1}+\phi_{0}-\lambda \varepsilon_{t+1}-\frac{1}{2} \lambda^{2}\right) Y_{t+1}
$$


As a result, we get the following expression for the covariance:

$$
\begin{aligned}
\operatorname{cov}_{t}\left(M_{t+1}, S_{t+1}\right) & =\operatorname{cov}_{t}\left(M_{t+1},-d_{t+1} Y_{t+1}\right)=-\mathbb{E}_{t}\left[M_{t+1} d_{t+1} Y_{t+1}\right]+\mathbb{E}_{t}\left[M_{t+1}\right] \mathbb{E}_{t}\left[d_{t+1} Y_{t+1}\right] \\
& =-\exp \left(-\rho-\frac{1}{2} \gamma^{2}+\frac{1}{2}(\gamma+\lambda-\sigma)^{2}+\mu+y_{t}+\phi_{1} \log d_{t}+\phi_{2} \log d_{t-1}+\phi_{0}-\frac{1}{2} \lambda^{2}\right) \\
& +\exp (-\rho) \exp \left(\frac{1}{2}(\lambda-\sigma)^{2}+\mu+y_{t}+\phi_{1} \log d_{t}+\phi_{2} \log d_{t-1}+\phi_{0}-\frac{1}{2} \lambda^{2}\right) \\
& =-\left(\exp \left(-\frac{1}{2} \gamma^{2}+\frac{1}{2}(\gamma+\lambda-\sigma)^{2}-\frac{1}{2}(\lambda-\sigma)^{2}\right)-1\right) \mathbb{E}_{t}\left[M_{t+1}\right] \mathbb{E}_{t}\left[d_{t+1} Y_{t+1}\right] \\
& =-\mathbb{E}_{t}\left[M_{t+1}\right] \mathbb{E}_{t}\left[d_{t+1} Y_{t+1}\right](\exp (-\gamma(\sigma-\lambda))-1) .
\end{aligned}
$$

By the same token, we get the following expression for the covariance of the discounted surpluses over two periods:

$$
\operatorname{cov}_{t}\left(M_{t+1}, S_{t+1}+E_{t+1}\left[M_{t+1, t+2} S_{t+2}\right)\right]=\operatorname{cov}_{t}\left(M_{t+1},-E_{t+1}\left[M_{t+1, t+2} d_{t+2} Y_{t+2}\right]\right)=-\mathbb{E}_{t}\left[M_{t+1}\right] E_{t}\left[M_{t+1, t+2} d_{t+2} Y_{t+2}\right]\left(\exp \left(-\gamma\left(\sigma-\psi_{1} \lambda\right)\right)-1\right)
$$

Check the proof of Prop. 1.3 to see why the sum of the discounted surpluses drop out, and only the debt issuance term remains. And we get the following expression for the covariance of the discounted surpluses over $j$ periods:

$$
\operatorname{cov}_{t}\left(M_{t+1}, \sum_{k=1}^{j} E_{t+1}\left[M_{t+1, t+j} S_{t+j}\right]\right)=\operatorname{cov}_{t}\left(M_{t+1},-E_{t+1}\left[M_{t+1, t+j} d_{t+j} Y_{t+j}\right]\right)=-\mathbb{E}_{t}\left[M_{t+1}\right] E_{t}\left[M_{t+1, t+j} d_{t+j} Y_{t+j}\right]\left(\exp \left(-\gamma\left(\sigma-\psi_{j-1} \lambda\right)\right)-1\right)
$$

\section{A.11 Proof of Corollary 2.1}

\section{A.11.1 Case of $A R(1)$}

Proof. Start from the restriction:

$$
\begin{aligned}
& \operatorname{cov}_{t}\left(M_{t+1},\left(\mathbb{E}_{t+1}-\mathbb{E}_{t}\right) \sum_{k=1}^{j} M_{t+1, t+k} T_{t+k}\right) \\
= & -\mathbb{E}_{t}\left[M_{t+1}\right] \mathbb{E}_{t}\left[M_{t+1, t+j} d_{t+j} Y_{t+j}\right]\left(\exp \left(-\gamma\left(\sigma-\phi^{j-1} \lambda\right)\right)-1\right)+\operatorname{cov}_{t}\left(M_{t+1},\left(\mathbb{E}_{t+1}-\mathbb{E}_{t}\right) \sum_{k=1}^{j} M_{t+1, t+k} x_{t+k} Y_{t+k}\right), \\
= & -\mathbb{E}_{t}\left[M_{t+1}\right] \mathbb{E}_{t}\left[M_{t+1, t+j} d_{t+j} Y_{t+j}\right]\left(\exp \left(-\gamma\left(\sigma-\phi^{j-1} \lambda\right)\right)-1\right)+\sum_{k=1}^{j} \operatorname{cov}_{t}\left(M_{t+1}, \mathbb{E}_{t+1}\left[M_{t+1, t+k} x_{t+k} Y_{t+k}\right]\right),
\end{aligned}
$$

where $\log x_{t}$ follows equation (8).

Next, we compute the $\operatorname{cov}_{t}\left(M_{t+1},\left(\mathbb{E}_{t+1}-\mathbb{E}_{t}\right) \sum_{k=1}^{j} M_{t+1, t+k} x_{t+k} Y_{t+k}\right)$ :

$$
\begin{aligned}
& \operatorname{cov}_{t}\left(M_{t+1},\left(\mathbb{E}_{t+1}-\mathbb{E}_{t}\right) \sum_{k=1}^{j} M_{t+1, t+k} x_{t+k} Y_{t+k}\right)=\sum_{k=1}^{j} \operatorname{cov}_{t}\left(M_{t+1}, \mathbb{E}_{t+1}\left[M_{t+1, t+k} x_{t+k} Y_{t+k}\right]\right) \\
= & \sum_{k=1}^{j}\left[\mathbb{E}_{t}\left[M_{t+1} M_{t+1, t+k} x_{t+k} Y_{t+k}\right]-\mathbb{E}_{t}\left[M_{t+1}\right] E_{t}\left[M_{t+1, t+k} x_{t+k} Y_{t+k}\right]\right]=\sum_{k=1}^{j} \mathbb{E}_{t}\left[M_{t+1}\right] E_{t}\left[M_{t+1, t+k} x_{t+k} Y_{t+k}\right]\left(\exp \left(-\gamma\left(\sigma-\phi_{g}^{k-1} b_{g}\right)\right)-1\right) .
\end{aligned}
$$

We then obtain the cash flow beta $\beta_{t}^{G, C F}(h)$ from the definition.

\section{A.11.2 Case of $A R(2)$}

Proof. We use $\psi(L)$ to denote the infinite MA representation of the debt/output process. Start from the restriction:

$$
\begin{aligned}
& \operatorname{cov}_{t}\left(M_{t+1},\left(\mathbb{E}_{t+1}-\mathbb{E}_{t}\right) \sum_{k=1}^{j} M_{t+1, t+k} T_{t+k}\right) \\
= & -\mathbb{E}_{t}\left[M_{t+1}\right] \mathbb{E}_{t}\left[M_{t+1, t+j} d_{t+j} Y_{t+j}\right]\left(\exp \left(-\gamma\left(\sigma-\psi_{j-1} \lambda\right)\right)-1\right)+\operatorname{cov}_{t}\left(M_{t+1},\left(\mathbb{E}_{t+1}-\mathbb{E}_{t}\right) \sum_{k=1}^{j} M_{t+1, t+k} x_{t+k} Y_{t+k}\right) \\
= & -\mathbb{E}_{t}\left[M_{t+1}\right] \mathbb{E}_{t}\left[M_{t+1, t+j} d_{t+j} Y_{t+j}\right]\left(\exp \left(-\gamma\left(\sigma-\psi_{j-1} \lambda\right)\right)-1\right)+\sum_{k=1}^{j} \mathbb{E}_{t}\left[M_{t+1}\right] E_{t+1}\left[M_{t+1, t+k} x_{t+k} Y_{t+k}\right]\left(\exp \left(-\gamma\left(\sigma-\phi_{g}^{k-1} b_{g}\right)\right)-1\right) .
\end{aligned}
$$




\section{A.12 Proof of Proposition 3.1}

Proof. We start from the value of the government debt equals the sum of the expected present values of future tax revenues plus future seigniorage revenues minus future government spending:

$$
B_{t}=\mathbb{E}_{t}\left[\sum_{j=0}^{\infty} M_{t, t+j}\left(T_{t+j}+\left(1-e^{-\kappa_{t+j}}\right) D_{t+j}-G_{t+j}\right)\right]=P_{t}^{T}+P_{t}^{K}-P_{t}^{G},
$$

provided that a transversality condition holds. The government debt portfolio return equals the return on a portfolio that goes long in the tax claim and short in the spending claim:

$$
\mathbb{E}_{t}\left[R_{t+1}^{D}-R_{t}^{f}\right]=\frac{P_{t}^{T}-T_{t}}{B_{t}-S_{t}} \mathbb{E}_{t}\left[R_{t+1}^{T}-R_{t}^{f}\right]+\frac{P_{t}^{K}-K_{t}}{B_{t}-S_{t}} \mathbb{E}_{t}\left[R_{t+1}^{K}-R_{t}^{f}\right]-\frac{P_{t}^{G}-G_{t}}{B_{t}-S_{t}} \mathbb{E}_{t}\left[R_{t+1}^{G}-R_{t}^{f}\right],
$$

where $R_{t+1}^{D}, R_{t+1}^{T}, R_{t+1}^{K}$ and $R_{t+1}^{G}$ are the holding period returns on the bond portfolio, the tax claim, and the spending claim, respectively. We take government spending process, and the debt return process as exogenously given, and we explore the implications for the properties of the tax claim. In the absence of arbitrage opportunities, if the TVC holds, the expected excess return on the tax claim is the unlevered return on the spending claim and the debt claim:

$$
\mathbb{E}_{t}\left[R_{t+1}^{T}-R_{t}^{f}\right]=\frac{\left(P_{t}^{G}-G_{t}\right) \mathbb{E}_{t}\left[R_{t+1}^{G}-R_{t}^{f}\right]}{D_{t}+\left(P_{t}^{G}-G_{t}\right)-\left(P_{t}^{K}-K_{t}\right)}+\frac{D_{t} \mathbb{E}_{t}\left[R_{t+1}^{D}-R_{t}^{f}\right]}{D_{t}+\left(P_{t}^{G}-G_{t}\right)-\left(P_{t}^{K}-K_{t}\right)}-\frac{\left(P_{t}^{K}-K_{t}\right) \mathbb{E}_{t}\left[R_{t+1}^{K}-R_{t}^{f}\right]}{D_{t}+\left(P_{t}^{G}-G_{t}\right)-\left(P_{t}^{K}-K_{t}\right)}
$$

If we want the debt to be risk-free, then the following equation holds for expected returns:

$$
\mathbb{E}_{t}\left[R_{t+1}^{T}-R_{t}^{f}\right]=\frac{\left(P_{t}^{G}-G_{t}\right) \mathbb{E}_{t}\left[R_{t+1}^{G}-R_{t}^{f}\right]}{D_{t}+\left(P_{t}^{G}-G_{t}\right)-\left(P_{t}^{K}-K_{t}\right)}-\frac{\left(P_{t}^{K}-K_{t}\right) \mathbb{E}_{t}\left[R_{t+1}^{K}-R_{t}^{f}\right]}{D_{t}+\left(P_{t}^{G}-G_{t}\right)-\left(P_{t}^{K}-K_{t}\right)},
$$

and there is a similar equation for the betas:

$$
\beta_{t}^{T}=\frac{P_{t}^{G}-G_{t}}{D_{t}+\left(P_{t}^{G}-G_{t}\right)-\left(P_{t}^{K}-K_{t}\right)} \beta_{t}^{G}-\frac{P_{t}^{K}-K_{t}}{D_{t}+\left(P_{t}^{G}-G_{t}\right)-\left(P_{t}^{K}-K_{t}\right)} \beta_{t}^{K} .
$$

\section{A.13 Proof of Proposition 3.2}

Proof. This result follows directly from the proof of Proposition 1.4.

\section{A.14 Proof of Proposition 4.1}

Proof. We start from the one-period government budget constraint:

$$
S_{t+1}=d_{t} Y_{t} \exp \left(r_{t}^{f}\right)-d_{t+1} Y_{t+1}
$$

to obtain the following expression for the covariance:

$$
\begin{aligned}
\operatorname{cov}_{t}\left(M_{t+1}, S_{t+1}\right) & =\operatorname{cov}_{t}\left(M_{t+1},-d_{t+1} Y_{t+1}\right)=-\mathbb{E}_{t}\left[M_{t+1} d_{t+1} Y_{t+1}\right]+\mathbb{E}_{t}\left[M_{t+1}\right] \mathbb{E}_{t}\left[d_{t+1} Y_{t+1}\right], \\
& =-\exp \left(-\rho-\frac{\gamma}{\sigma}(\psi-1) y_{t}-\frac{1}{2} \gamma^{2}+\frac{1}{2}(\gamma+\lambda-\sigma)^{2}+\xi_{0}+(\xi-\gamma / \sigma *(\xi-1)) y_{t}+\phi \log d_{t}+\phi_{0}-\frac{1}{2} \lambda^{2}\right), \\
& +\exp \left(-\rho-\frac{\gamma}{\sigma}(\xi-1) y_{t}\right) \exp \left(\frac{1}{2}(\lambda-\sigma)^{2}+\xi_{0}+\xi y_{t}+\phi \log d_{t}+\phi_{0}-\frac{1}{2} \lambda^{2}\right) \\
& =-\left(\exp \left(-\frac{1}{2} \gamma^{2}+\frac{1}{2}(\gamma+\lambda-\sigma)^{2}-\frac{1}{2}(\lambda-\sigma)^{2}\right)-1\right) \mathbb{E}_{t}\left[M_{t+1}\right] \mathbb{E}_{t}\left[d_{t+1} Y_{t+1}\right]=-\mathbb{E}_{t}\left[M_{t+1}\right] \mathbb{E}_{t}\left[d_{t+1} Y_{t+1}\right](\exp (-\gamma(\sigma-\lambda))-1) .
\end{aligned}
$$

By the same token, we get the following expression for the covariance of the discounted surpluses over $j \geq 2$ periods:

$$
\begin{aligned}
& \operatorname{cov}_{t}\left(M_{t+1}, E_{t+1}\left[\sum_{k=1}^{j} M_{t+1, t+k} S_{t+k}\right]\right)=\operatorname{cov}_{t}\left(M_{t+1},-E_{t+1}\left[M_{t+1, t+j} d_{t+j} Y_{t+j}\right]\right)=-\mathbb{E}_{t}\left[M_{t+1} M_{t+1, t+j} d_{t+j} Y_{t+j}\right]+\mathbb{E}_{t}\left[M_{t+1}\right] \mathbb{E}_{t}\left[M_{t+1, t+j} d_{t+j} Y_{t+j}\right], \\
= & -\mathbb{E}_{t}\left[\exp \left(-\rho-\frac{\gamma}{\sigma}(\xi-1) y_{t}-\frac{1}{2} \gamma^{2}-\gamma \varepsilon_{t+1}\right) \exp \left(\ldots-\frac{\gamma(\xi-1)}{\sigma}\left(1+\xi+\ldots+\xi^{j-2}\right) y_{t+1}\right)\right.
\end{aligned}
$$




$$
\begin{aligned}
& \left.\exp \left(\phi^{j} \log d_{t}-\phi^{j-1} \lambda \varepsilon_{t+1}+\ldots\right) \exp \left(\xi^{j} y_{t}+\xi^{j-1} \sigma \varepsilon_{t+1}+\ldots\right)\right]+\mathbb{E}_{t}\left[M_{t+1}\right] \mathbb{E}_{t}\left[M_{t+1, t+j} d_{t+j} Y_{t+j}\right] \\
= & -\mathbb{E}_{t}\left[M_{t+1}\right] \mathbb{E}_{t}\left[M_{t+1, t+j} d_{t+j} Y_{t+j}\right]\left(\exp \left(-\gamma\left(\xi^{j-1} \sigma-\phi^{j-1} \lambda-\gamma(\xi-1) \frac{1-\xi^{j-1}}{1-\xi}\right)\right)-1\right), \\
= & -\mathbb{E}_{t}\left[M_{t+1}\right] \mathbb{E}_{t}\left[M_{t+1, t+j} d_{t+j} Y_{t+j}\right]\left(\exp \left(-\gamma\left(\xi^{j-1} \sigma-\phi^{j-1} \lambda+\gamma\left(1-\xi^{j-1}\right)\right)\right)-1\right) .
\end{aligned}
$$

We can also derive restrictions on the covariances with the tax process. The first equation follows from

$$
\begin{aligned}
& \operatorname{cov}_{t}\left(M_{t+1},\left(\mathbb{E}_{t+1}-\mathbb{E}_{t}\right) \sum_{k=1}^{j} M_{t+1, t+k} T_{t+k}\right)=\operatorname{cov}_{t}\left(M_{t+1},\left(\mathbb{E}_{t+1}-\mathbb{E}_{t}\right) \sum_{k=1}^{j} M_{t+1, t+k} S_{t+k}\right)+\operatorname{cov}_{t}\left(M_{t+1},\left(\mathbb{E}_{t+1}-\mathbb{E}_{t}\right) \sum_{k=1}^{j} M_{t+1, t+k} G_{t+k}\right), \\
= & -\mathbb{E}_{t}\left[M_{t+1}\right] \mathbb{E}_{t}\left[M_{t+1, t+j} d_{t+j} Y_{t+j}\right]\left(\exp \left(-\gamma\left(\xi^{j-1} \sigma-\phi^{j-1} \lambda+\gamma\left(1-\xi^{j-1}\right)\right)\right)-1\right)+x \cdot \operatorname{cov}_{t}\left(M_{t+1},\left(\mathbb{E}_{t+1}-\mathbb{E}_{t}\right) \sum_{k=1}^{j} M_{t+1, t+k} Y_{t+k}\right),
\end{aligned}
$$

where the covariance of the pricing kernel with the output strip price is given by:

$$
\begin{aligned}
& \operatorname{cov}_{t}\left(M_{t+1},\left(\mathbb{E}_{t+1}-\mathbb{E}_{t}\right) M_{t+1, t+k} Y_{t+k}\right)=\mathbb{E}_{t}\left[M_{t+1} M_{t+1, t+k} Y_{t+k}\right]-\mathbb{E}_{t}\left[M_{t+1}\right] \mathbb{E}_{t}\left[M_{t+1, t+k} Y_{t+k}\right], \\
= & \mathbb{E}_{t}\left[\exp \left(-\rho-\gamma(\xi-1) y_{t}-\frac{1}{2} \gamma^{2}-\gamma \varepsilon_{t+1}\right) M_{t+1, t+k} \exp \left(\xi^{k} y_{t}+\xi^{k-1} \sigma \varepsilon_{t+1}+\ldots\right)\right]-\mathbb{E}_{t}\left[M_{t+1}\right] \mathbb{E}_{t}\left[M_{t+1, t+k} Y_{t+k}\right], \\
= & -\mathbb{E}_{t}\left[M_{t+1}\right] \mathbb{E}_{t}\left[M_{t+1, t+k} Y_{t+k}\right]\left(\exp \left(-\gamma\left(\xi^{k-1} \sigma+\gamma\left(1-\xi^{k-1}\right)\right)\right)-1\right) .
\end{aligned}
$$

Next, we conjecture $\mathbb{E}_{t}\left[M_{t, t+j} d_{t+j} Y_{t+j}\right]=\exp \left(\sum_{k=1}^{j} \tilde{\kappa}_{k}\right) \exp \left(\phi^{j} \log d_{t}+f_{j} y_{t}\right)$. Note that:

$$
\begin{aligned}
\mathbb{E}_{t}\left[M_{t, t+j} d_{t+j} Y_{t+j}\right] & =\mathbb{E}_{t}\left[M_{t, t+1} \exp \left(\sum_{k=1}^{j-1} \kappa_{k}\right) \exp \left(\phi^{j-1} \log d_{t+1}+f_{j-1} y_{t+1}\right)\right] \\
& =\mathbb{E}_{t}\left[\exp \left(-\rho-\frac{\gamma}{\sigma}(\xi-1) y_{t}-\frac{1}{2} \gamma^{2}-\gamma \varepsilon_{t+1}\right) \exp \left(\sum_{k=1}^{j-1} \tilde{\kappa}_{k}\right) \exp \left(\phi^{j-1}\left(\phi \log d_{t}+\phi_{0}-\lambda \varepsilon_{t+1}-\frac{1}{2} \lambda^{2}\right)+f_{j-1}\left(\xi_{0}+\xi y_{t}+\sigma \varepsilon_{t+1}\right)\right)\right]
\end{aligned}
$$

So we confirm the conjecture:

$$
\begin{aligned}
\exp \left(\tilde{\kappa}_{j}\right) & =\mathbb{E}_{t}\left[\exp \left(-\rho-\frac{1}{2} \gamma^{2}-\gamma \varepsilon_{t+1}+\phi^{j-1}\left(\phi_{0}-\lambda \varepsilon_{t+1}-\frac{1}{2} \lambda^{2}\right)+f_{j-1}\left(\xi_{0}+\sigma \varepsilon_{t+1}\right)\right)\right] \\
\tilde{\kappa}_{j} & =-\rho-\frac{1}{2} \gamma^{2}+\phi^{j-1}\left(\phi_{0}-\frac{1}{2} \lambda^{2}\right)+f_{j-1} \xi_{0}+\frac{1}{2}\left(-\gamma-\phi^{j-1} \lambda+f_{j-1} \sigma\right)^{2}
\end{aligned}
$$

and $f_{j}=-\frac{\gamma}{\sigma}(\xi-1)+f_{j-1} \xi=\xi^{j}+\frac{\gamma}{\sigma}\left(1-\xi^{j}\right)=\frac{\sigma-\gamma}{\sigma} \xi^{j}+\frac{\gamma}{\sigma}$.

So, for $j>1$, we obtain:

$$
\begin{aligned}
& \mathbb{E}_{t}\left[M_{t+1, t+j} d_{t+j} Y_{t+j}\right]=\mathbb{E}_{t}\left[\exp \left(\sum_{k=1}^{j-1} \tilde{\kappa}_{k}\right) \exp \left(\phi^{j-1} \log d_{t+1}+\left(\frac{\sigma-\gamma}{\sigma} \xi^{j-1}+\frac{\gamma}{\sigma}\right) y_{t+1}\right)\right], \\
= & \exp \left(\left(-\rho-\frac{1}{2} \gamma^{2}\right)(j-1)+\frac{1-\phi^{j-1}}{1-\phi}\left(\phi_{0}-\frac{1}{2} \lambda^{2}\right)+\left(\frac{1-\xi^{j-1}}{1-\xi} \frac{\sigma-\gamma}{\sigma}+\frac{\gamma}{\sigma}(j-1)\right) \xi_{0}\right. \\
+ & \left.\sum_{k=1}^{j-1} \frac{1}{2}\left(-\gamma-\phi^{k-1} \lambda+\left((\sigma-\gamma) \xi^{k-1}+\gamma\right)\right)^{2}+\phi^{j-1}\left(\phi \log d_{t}+\phi_{0}-\frac{1}{2} \lambda^{2}\right)+\left(\frac{\sigma-\gamma}{\sigma} \xi^{j-1}+\frac{\gamma}{\sigma}\right)\left(\xi_{0}+\xi y_{t}\right)+\frac{1}{2}\left(-\phi^{j-1} \lambda+(\sigma-\gamma) \xi^{j-1}+\gamma\right)^{2}\right) .
\end{aligned}
$$

By a similar logic, we can price the output strips:

$$
\begin{gathered}
\mathbb{E}_{t+1}\left[M_{t+1, t+j} Y_{t+j}\right]=\exp \left(\left(-\rho-\frac{1}{2} \gamma^{2}\right)(j-1)+\left(\frac{1-\xi^{j-1}}{1-\xi} \frac{\sigma-\gamma}{\sigma}+\frac{\gamma}{\sigma}(j-1)\right) \xi_{0}\right. \\
\left.+\sum_{k=1}^{j-1} \frac{1}{2}\left(-\gamma+\left((\sigma-\gamma) \xi^{k-1}+\gamma\right)\right)^{2}+\left(\frac{\sigma-\gamma}{\sigma} \xi^{j-1}+\frac{\gamma}{\sigma}\right)\left(\xi_{0}+\xi y_{t}\right)+\frac{1}{2}\left(\left((\sigma-\gamma) \xi^{j-1}+\gamma\right)\right)^{2}\right) .
\end{gathered}
$$

We obtain the following result:

$$
\begin{aligned}
& \mathbb{E}_{t+1}\left[M_{t+1, t+j} d_{t+j} Y_{t+j}\right]=\mathbb{E}_{t+1}\left[M_{t+1, t+j} Y_{t+j}\right] \exp \left(\frac{1-\phi^{j}}{1-\phi}\left(\phi_{0}-\frac{1}{2} \lambda^{2}\right)+\sum_{k=1}^{j-1}\left((\gamma-\sigma) \xi^{k-1} \phi^{k-1} \lambda+\frac{1}{2}\left(\phi^{k-1} \lambda\right)^{2}\right)\right. \\
&\left.+\quad \phi^{j} \log d_{t}-\phi^{j-1} \lambda\left((\sigma-\gamma) \xi^{j-1}+\gamma\right)+\frac{1}{2}\left(\phi^{j-1} \lambda\right)^{2}\right) .
\end{aligned}
$$




\section{B Idiosyncratic Insurance}

We now consider transfers that are contingent on idiosyncratic shocks.

Proposition B.1. For households who participate in asset markets and who receive net transfers $\{G-T\}=\left\{G^{a}-T^{a}\right\}+\left\{G^{i}-T^{i}\right\}$, the marginal insurance benefit over horizon $h$ is given by:

$$
\Omega_{n e t}^{h^{\prime}}(0)>\frac{\mathbb{E}_{0} \sum_{t=1}^{\infty} M_{0, t}\left[G_{t}^{a}-T_{t}^{a}\right]}{\mathbb{E}_{0} \sum_{t=1}^{\infty} M_{0, t} C_{t}}=\frac{P_{0}^{h}\left[\left\{C_{t}\right\}\right]+\mathbb{E}_{0} \sum_{t=1}^{\infty} M_{0, t}\left[G_{t}^{a}-T_{t}^{a}\right]}{\mathbb{E}_{0} \sum_{t=1}^{\infty} M_{0, t}\left[C_{t}\right]}-1
$$

Proof. The government can provide insurance against idiosyncratic shocks without increasing the riskiness of its debt.

$$
\mathbb{E}_{0} \sum_{t=1}^{h} \frac{U_{c, t}^{i}}{U_{c, 0}^{i}}\left(\left[G_{t}^{i}-T_{t}^{i}\right]+\left[G_{t}^{a}-T_{t}^{a}\right]\right)=\mathbb{E}_{0} \sum_{t=1}^{h} \frac{U_{c, t}^{i}}{U_{c, 0}^{i}}\left[G_{t}^{i}-T_{t}^{i}\right]+\mathbb{E}_{0} \sum_{t=1}^{h} M_{0, t}\left[G_{t}^{a}-T_{t}^{a}\right] .
$$

Provided that the net transfers provide insurance against idiosyncratic risk:

$$
\sum_{t=1}^{h} \operatorname{Cov}_{0}\left(\frac{U_{c, t}^{i}}{U_{c, 0}^{i}},\left[G_{t}^{i}-T_{t}^{i}\right]\right)>0,
$$

we obtain the following inequality:

$$
\mathbb{E}_{0} \sum_{t=1}^{h} \frac{U_{c, t}^{i}}{U_{c, 0}^{i}}\left(\left[G_{t}^{i}-T_{t}^{i}\right]+\left[G_{t}^{a}-T_{t}^{a}\right]\right)>\mathbb{E}_{0} \sum_{t=1}^{h} M_{0, t}\left[G_{t}^{a}-T_{t}^{a}\right]
$$

This implies that the marginal benefit of insurance, including idiosyncratic insurance:

$$
\Omega_{n e t}^{h^{\prime}}(0)>\frac{\mathbb{E}_{0} \sum_{t=1}^{\infty} M_{0, t}\left[G_{t}^{a}-T_{t}^{a}\right]}{\mathbb{E}_{0} \sum_{t=1}^{\infty} M_{0, t}\left[C_{t}\right]}
$$

However, the cost to the government of financing these transfers is given by:

$$
\mathbb{E}_{0} \sum_{t=1}^{\infty} M_{0, t}\left[G_{t}^{i}-T_{t}^{i}\right]+\mathbb{E}_{0} \sum_{t=1}^{\infty} M_{0, t}\left[G_{t}^{a}-T_{t}^{a}\right]=\mathbb{E}_{0} \sum_{t=1}^{\infty} M_{0, t}\left[G_{t}^{a}-T_{t}^{a}\right]
$$

where we have used that idiosyncratic transfers are orthogonal to the stochastic discount factor.

This result shows that the government can provide insurance against idiosyncratic risk without making the debt riskier. Chien and Wen $(2019,2020)$ analyze the Ramsey planner's problem in environments with idiosyncratic and aggregate risk. Government debt allows households to self-insure against idiosyncratic risk. Because the interest rate is lower than the time discount factor, this self-insurance motive dominates the tax smoothing motive.

\section{Fiscal Hedging Demand in Economy with Distortionary Taxation}

In a class of dynamic models with distortionary taxation going back to Lucas and Stokey (1983), the government chooses the tax rate optimally to hedge shocks to government spending. If the government can issue state-contingent debt, the optimal tax rate inherits the serial correlation of government spending. To the extent that the government's debt securities do not span all the shocks that hit the economy, maturity choice plays an important role. In a model in which only spending shocks drive the term structure, Angeletos (2002) and Buera and Nicolini (2004) show how the government can choose the maturity of non-state-contingent government debt to mimic the complete markets allocations in Lucas and Stokey (1983), thus creating an explicit role for the maturity structure. In general, the government will not try to replicate the complete markets allocation if variation in interest rates is largely explained by non-spending shocks, as is the case in the data. When governments only issue risk-free debt, the market incompleteness imputes more persistence to the optimal tax rates, as shown by Aiyagari et al. (2002), unless the government can accumulate savings. Lustig, Sleet, and Yeltekin (2008) examine the optimal maturity structure when the government issues nominal non-state-contingent debt. A general version of the incomplete markets optimal taxation problem is analyzed by Bhandari et al. (2017).

When taxes are distortionary, the government has an additional fiscal hedging motive to issue risky debt. In a representative agent economy with distortionary taxation, Bhandari et al. (2017) show that the planner will choose the long-run target debt level to 
minimize the variance of its financing requirements:

$$
\operatorname{Var}_{0}\left[R_{1}^{D} B M_{0,1}-\sum_{j=1}^{\infty} M_{0, j} S_{j}^{\bar{\tau}}\right]=B^{2} \operatorname{Var}_{0}\left[R_{1}^{D} M_{0,1}\right]-B \operatorname{cov}_{0}\left(R_{1}^{D} M_{0,1}, \sum_{j=1}^{\infty} M_{0, j} S_{j}^{\bar{\tau}}\right)+\ldots
$$

where $S_{t+j}^{\bar{\tau}}$ denotes the surplus evaluated at a constant tax rate $\bar{\tau}$ such that $B=\mathbb{E}_{0} \sum_{j=1}^{\infty} M_{0, j} S_{j}^{\bar{\tau}}$. Given the constant tax rate, this surplus stream will be risky, and the covariance term will tend to be negative:

$$
\operatorname{cov}_{0}\left(R_{1}^{D} M_{0,1}, \sum_{j=1}^{\infty} M_{0, j} S_{j}^{\bar{\tau}}\right)<0 .
$$

With positive debt outstanding $B>0$, minimizing the variance of financing requirements is achieved by choosing a debt instrument with return $R_{1}^{D}=1 / M_{0,1}$. The optimal debt instrument is the riskiest one, the one with the maximum squared Sharpe ratio $\operatorname{Var}_{0}\left(M_{0,1}\right)$. In environments with only transitory shocks, the riskiest security is the longest-maturity debt instrument. (In environments with permanent shocks to the SDF, the riskiest asset would be more like equity.) The fiscal hedging motive would lead the government to prefer risky debt.

In general, the solution to the variance minimization problem in Bhandari et al. (see 2017, p.650) implies a long-run debt target:

$$
B^{*}=\frac{\operatorname{cov}_{0}\left(R_{1}^{D} M_{1}, \sum_{j=1}^{\infty} M_{0, j} S_{j}^{\bar{\tau}}\right)}{\operatorname{var}_{0}\left(R_{1}^{D} M_{1}\right)} .
$$

and a rate at which the debt reverts to the target given by $\frac{1}{1+e^{-2 \rho_{v a r_{0}}\left(M_{1}\right)}}$, where $\rho$ denotes the rate of time preference.

In the case of risk-free debt, the optimal target debt level is negative:

$$
B^{*}=\frac{\operatorname{cov}_{0}\left(M_{1}, \sum_{j=1}^{\infty} M_{0, j} S_{j}^{\bar{\tau}}\right)}{\operatorname{var}_{0}\left(M_{1}\right)}<0
$$

Given that the surplus evaluated at constant tax rates is exposed to short-run and long-run output risk, the planner will want to accumulate assets because debt does not provide a fiscal hedge. This rationalizing the prescription in Aiyagari et al. (2002) that the government should save. Having savings (a sovereign wealth fund) is what allows the government to choose $\beta_{t}^{T}>\beta_{t}^{G}$ and insure taxpayers against macro shocks. In the limit, by accumulating sufficient assets, the government can implement the Lucas and Stokey (1983) complete markets allocation. Even when the debt is risky, Bhandari et al. (2017) find that the planner wants to accumulate assets in the long-run because $\operatorname{cov}_{0}\left(R_{1}^{D} M_{0,1}, \sum_{j=1}^{\infty} M_{0, j} S_{j}^{\bar{\tau}}\right)<0$. Importantly, in an incomplete markets environment with idiosyncratic and aggregate risk, the Ramsey planner has an incentive to accumulate debt because the debt allows agents to self-insure (Chien and Wen, $2019,2020)$.

\section{Marginal Cost of Business Cycles}

In the spirit of Lucas (1987), the government could choose to remove all business cycle variation through fiscal policy. This would result in a deterministic consumption path $C=C+G-T$. We use $P_{0}^{h}[\{X\}]$ to denote $\mathbb{E}_{0}\left[\sum_{t=0}^{h} M_{0, t} X_{t}\right]$. We obtain the marginal cost of business cycles from Alvarez and Jermann (2004):

$$
\Omega_{\text {net }}^{h^{\prime}}(0)=\frac{P_{0}^{h}[\{C\}]}{P_{0}^{h}\left[\left\{C_{t}\right\}\right]}-1 .
$$

If we remove all aggregate consumption risk through fiscal policy, then we obtain the following marginal cost to the government:

$$
\Omega_{\text {net }}^{\infty^{\prime}}(0)=\frac{P_{0}^{\infty}[\{C\}]}{P_{0}^{\infty}\left[\left\{C_{t}\right\}\right]}-1=\frac{\frac{C_{0}}{y_{0}-g}}{\frac{C_{0}}{r^{C}-g}}=\frac{r^{C}-g}{y_{0}-g}-1=\frac{r^{C}-y_{0}}{y_{0}-g},
$$

where $y_{0}$ is the discount rate for a growing perpetuity without any cash flow risk. This is the maximum marginal benefit the government can achieve for its taxpayers. This upper bound will be higher in models with more permanent risk and/or with a larger price of permanent risk since the consumption risk premium, $r^{C}-y_{0}$, is larger in such models. Modern asset pricing has consistently found that permanent shocks to output and consumption account for most of the variance of the pricing kernel, and receive a high price of risk in securities market (e.g., Alvarez and Jermann, 2005; Hansen and Scheinkman, 2009; Bansal and Yaron, 2004; Borovička et al., 2016; Backus et al., 2018). Conversely, models without large permanent shocks produce bond risk premia that exceed equity risk premia, which is counter-factual. Hence, in models with realistic asset pricing, the marginal benefit of fiscal stabilization to taxpayers is high. Equivalently, the marginal cost to the taxpayers of keeping the debt risk-free is high. 


\section{E Return Betas and Cash Flow Betas}

What is the relationship between return betas and cash flow betas? In the simple case with constant debt/output and spending/output ratios, there is a one-to-one mapping:

Corollary E.1. The expected returns can be expressed as a function of the cash flow betas:

$$
\begin{aligned}
\mathbb{E}_{t}\left[R_{t+1}^{T}-R_{t}^{f}\right] & =\frac{x}{d\left(1-\xi_{1}\right)+x \xi_{1}} \frac{-\operatorname{cov}_{t}\left(M_{t+1}, Y_{t+1} / Y_{t}\right)}{\mathbb{E}_{t}\left(M_{t+1}\right)}=\frac{x}{d\left(1-\xi_{1}\right)+x \xi_{1}} \exp \left(\mu+\frac{1}{2} \sigma^{2}\right)(1-\exp (-\gamma \sigma)), \\
\mathbb{E}_{t}\left[R_{t+1}^{G}-R_{t}^{f}\right] & =\frac{1}{\xi_{1}} \frac{-\operatorname{cov}_{t}\left(M_{t+1}, Y_{t+1} / Y_{t}\right)}{\mathbb{E}_{t}\left(M_{t+1}\right)}=\frac{1}{\xi_{1}} \exp \left(\mu+\frac{1}{2} \sigma^{2}\right)(1-\exp (-\gamma \sigma))
\end{aligned}
$$

where $\xi_{1}=\exp \left(-\rho-\gamma \sigma+\mu+0.5 \sigma^{2}\right)$.

Proof. From $R_{t+1}^{f}=\exp (\rho)$ and $\frac{T_{t}}{Y_{t}}=x-d\left(1-R_{t-1}^{f} \frac{Y_{t-1}}{Y_{t}}\right)$, we have that the return on the tax claim can be stated as:

$$
R_{t+1}^{T}=\frac{P_{t+1}^{T}}{P_{t}^{T}-T_{t}}=\frac{\left(d+x \frac{\xi_{1}}{1-\xi_{1}}\right) Y_{t+1}+\left(x-d\left(1-R_{t}^{f} \frac{Y_{t}}{Y_{t+1}}\right)\right) Y_{t+1}}{\left(d+x \frac{\xi_{1}}{1-\xi_{1}^{2}}\right) Y_{t}}=\frac{x \frac{1}{1-\xi_{1}} Y_{t+1}}{\left(d+x \frac{\tilde{\zeta}_{1}}{1-\tilde{\xi}_{1}}\right) Y_{t}}+\frac{d \exp (\rho)}{\left(d+x \frac{\tilde{\xi}_{1}}{1-\xi_{1}}\right)} .
$$

Similarly, we have an expression for the return on the spending claim:

$$
R_{t+1}^{G}=\frac{P_{t+1}^{G}}{P_{t}^{G}-G_{t}}=\frac{x \frac{\tilde{\xi}_{1}}{1-\tilde{\xi}_{1}} Y_{t+1}+x Y_{t+1}}{x \frac{\tilde{\xi}_{1}}{1-\tilde{\xi}_{1}} Y_{t}}=\frac{x \frac{1}{1-\tilde{\xi}_{1}} Y_{t+1}}{x \frac{\tilde{\xi}_{1}}{1-\tilde{\xi}_{1}} Y_{t}}
$$

As a result, we can state the risk premium as follows:

$$
\begin{aligned}
\mathbb{E}_{t}\left[R_{t+1}^{T}-R_{t}^{f}\right] & =-\frac{\operatorname{cov}\left(M_{t+1}, R_{t+1}^{T}\right)}{\mathbb{E}_{t}\left(M_{t+1}\right)}=\frac{x}{d\left(1-\xi_{1}\right)+x \xi_{1}} \frac{-\operatorname{cov}\left(M_{t+1}, Y_{t+1} / Y_{t}\right)}{\mathbb{E}_{t}\left(M_{t+1}\right)}, \\
\mathbb{E}_{t}\left[R_{t+1}^{G}-R_{t}^{f}\right] & =-\frac{\operatorname{cov}\left(M_{t+1}, R_{t+1}^{G}\right)}{\mathbb{E}_{t}\left(M_{t+1}\right)}=\frac{1}{\xi_{1}} \frac{-\operatorname{cov}\left(M_{t+1}, Y_{t+1} / Y_{t}\right)}{\mathbb{E}_{t}\left(M_{t+1}\right)},
\end{aligned}
$$

where we have used that $\xi_{1}=\exp \left(-\rho-\frac{1}{2} \gamma^{2}+\mu+\frac{1}{2}(\gamma-\sigma)^{2}\right)=\exp \left(-\rho-\gamma \sigma+\mu+\frac{1}{2} \sigma^{2}\right)$. Then, we plug in

$$
\begin{aligned}
\frac{-\operatorname{cov}_{t}\left(M_{t+1}, Y_{t+1} / Y_{t}\right)}{\mathbb{E}_{t}\left(M_{t+1}\right)} & =\frac{-\operatorname{cov}_{t}\left(\exp \left(-\rho-\frac{1}{2} \gamma^{2}-\gamma \varepsilon_{t+1}\right), \exp \left(\mu+\sigma \varepsilon_{t+1}\right)\right)}{\mathbb{E}_{t}\left(\exp \left(-\rho-\frac{1}{2} \gamma^{2}-\gamma \varepsilon_{t+1}\right)\right)}=\frac{-\operatorname{cov}_{t}\left(\exp \left(-\gamma \varepsilon_{t+1}\right), \exp \left(\sigma \varepsilon_{t+1}\right)\right)}{\exp (-\rho)} \exp \left(-\rho-\frac{1}{2} \gamma^{2}+\mu\right), \\
& =-\left(\exp \left(\frac{1}{2}\left(\gamma^{2}+\sigma^{2}\right)\right)(\exp (-\gamma \sigma)-1)\right) \exp \left(-\frac{1}{2} \gamma^{2}+\mu\right)=\exp \left(\mu+\frac{1}{2} \sigma^{2}\right)(1-\exp (-\gamma \sigma)) .
\end{aligned}
$$




\section{F U.S. Data on Debt, Spending, Taxes}

\section{F.1 U.S. Data Sources}

We conduct our analysis at annual frequency. We focus on the post-war period from 1947 until 2018. Government spending is current expenditures (line 24) minus net interest payments (line 33 minus line 14). Tax revenue is the current government receipts (line 1). We obtain the time series of GDP from NIPA Table 1.1.5. Inflation is the change in the GDP price index from NIPA Table 1.1.4. Real GDP growth $x_{t}$ is nominal GDP growth minus inflation.

We construct the market value and the total returns of the marketable government bond portfolio using CUSIP-level data from the CRSP Treasuries Monthly Series. At the end of each period, we multiply the nominal price of each CUSIP by its total amount outstanding (normalized by the face value), and sum across all issuances (CUSIPs). We exclude non-marketable debt which is mostly held in intra-governmental accounts. Following Hall and Sargent (2011) and extending their sample to 2020, we construct zero-coupon bond (strip) positions from all coupon-bearing Treasury bonds issued in the past and outstanding in the current period. This is done separately for nominal and real bonds. Since zero-coupon bond prices are also observable, we can construct the left-hand side of eqn. (1) as the market value of outstanding marketable U.S. government debt.

\section{F.2 Persistence of Fiscal Processes in the Data and the Model}

Panel A of Figure A1 plots the sample autocorrelation function (ACF) of the log government debt/output ratio as a function of the number of annual lags. The top right panel plots the partial autocorrelation function (PACF). They are estimated on the post-war U.S. sample (1947-2017). The PACF function indicates that an AR(2) process fits the data well. Lags beyond two years in the PACF are not statistically different from zero. The point estimates for $\phi_{1}$ and $\phi_{2}$ are 1.40 and -0.48 , respectively. Both roots lie outside the unit circle (1.66 and 1.25), so that the debt/output process is stationary. While the AR(2) is our preferred specification, if we were to fit an $\operatorname{AR}(1)$, the point estimate for $\phi_{1}$ would be 0.986 .

Panel A of Figure A1 plots the sample ACF and PACF for the primary surplus/output ratio in the data. The dynamics of surplus/output are well described by an AR(1). The surplus is quite persistent, with an $A R(1)$ coefficient around 0.81 . The model cannot quite replicate the strong autocorrelation in surplus/output observed in the data. In the case of the AR(2), the ACF converges too quickly to zero, compared to the observed one plotted in Panel A of Figure A1. The ACF is no longer different from zero past two years, while in the data the ACF remains significantly positive for five years. Furthermore, the model produces a PACF(2) coefficient of -0.5 , which is larger in absolute value than the one estimated in the data. Figure A1 also plots the ACF and PACF of the debt/output and surplus/output ratios implied by the model of risk-free debt. Panel B is for the case where debt/output follows an AR(1) with the estimated persistence $\phi_{1}=0.985$. Panel $C$ is for the case where debt/output follows an AR(2) with the estimated coefficients $\phi_{1}=1.4$ and $\phi_{2}=-0.48$. The ACF and PACF for debt/output match the data by construction. As argued above, the AR(2) fits the ACF and PACF of the observed debt/output ratio the closest.

\section{G U.K. Data on Taxes, Spending and Debt}

The U.K. calibration is reported in Table A1. The main dataset we use is A millennium of macroeconomic data published by the bank of England. The dataset contains a broad set of macroeconomic and financial data for the UK. We also use other data sets as complementing the main dataset. Below we describe how we construct variables in our estimation procedure from the raw data set. The time period for all series are from 1814 to 2015. All sheets and columns refer to the excel table A millennium of macroeconomic data unless described otherwise.

Primary Surpluses The government expenditure G is the total government expenditure (Sheet A27, Column C) plus interest payments (Sheet A27, Column N). The government revenue $T$ is from Sheet A27, Column N. The raw source for the data is from Mitchell and Mitchell (1988) and UK Office of National Statistics. The primary surpluses are the government revenue $T$ minus the government spending before interest payments $G$. The market value of debt is the market value of central government liabilities ( Sheet A30b, Column W).

The U.K. debt issuance is substantially less counter-cyclical than in the U.S., and the spending is less counter-cyclical as well. The U.K. spending/output ratio $x_{t}=G_{t} / Y_{t}$ is well-described by an $\operatorname{AR}(2)$ :

$$
\log x_{t}=\varphi_{0}^{g}+\varphi_{1}^{g} \log x_{t-1}+\varphi_{2}^{g} \log x_{t-2}-\beta_{g} \varepsilon_{t}-\frac{1}{2} \beta_{g}^{2}
$$

We estimate $\left(\varphi_{0}^{g}, \varphi_{1}^{g}, \beta^{g}\right)$ from the post-war U.K. data. The parameter estimates are reported in Panel C of Table A1. Spending/output is counter-cyclical in the data. A $1 \%$ point decline in output coincides with a $0.88 \%$ point increase in the spending/output ratio.

\section{H Robustness}

\section{H.1 Counter-cyclical Spending}

The government insures transfer recipients by spending a larger fraction of GDP in recession. We now show that the more countercyclical spending becomes, the steeper the trade-off between insurance of bondholders and taxpayers. 


\section{Figure A1: Autocorrelation in Debt/Output and Surplus/Output}

Panel A plots the sample autocorrelation of the U.S. log government debt/output ratio, the U.S. government surplus/output ratio, the tax/output ratio and the spending/output ratio against GDP. Sample is annual, 1947-2017. Panel B plots the ACF and PACF of $S / Y$ and $D / Y$ for an $A R(1)$ with parameters $\phi_{1}=0.985$ and $\phi_{2}=0$. Panel C plots the ACF and PACF of $S / Y$ and $D / Y$ for an $A R(2)$. The parameters are listed in Table 1.

Panel A: Data
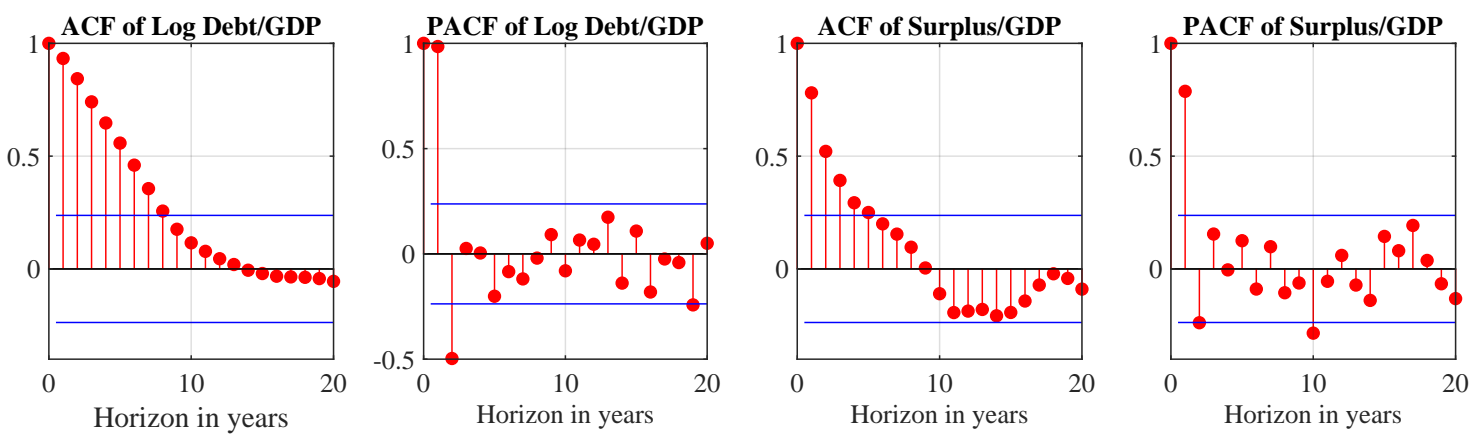

Panel B: AR(1) Model
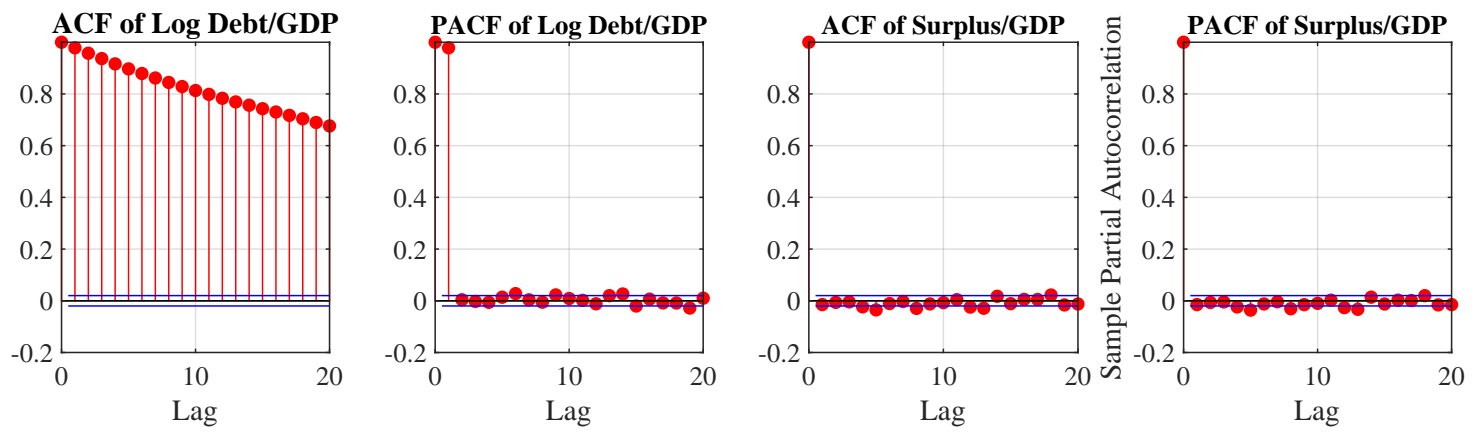

Panel C: AR(2) Model
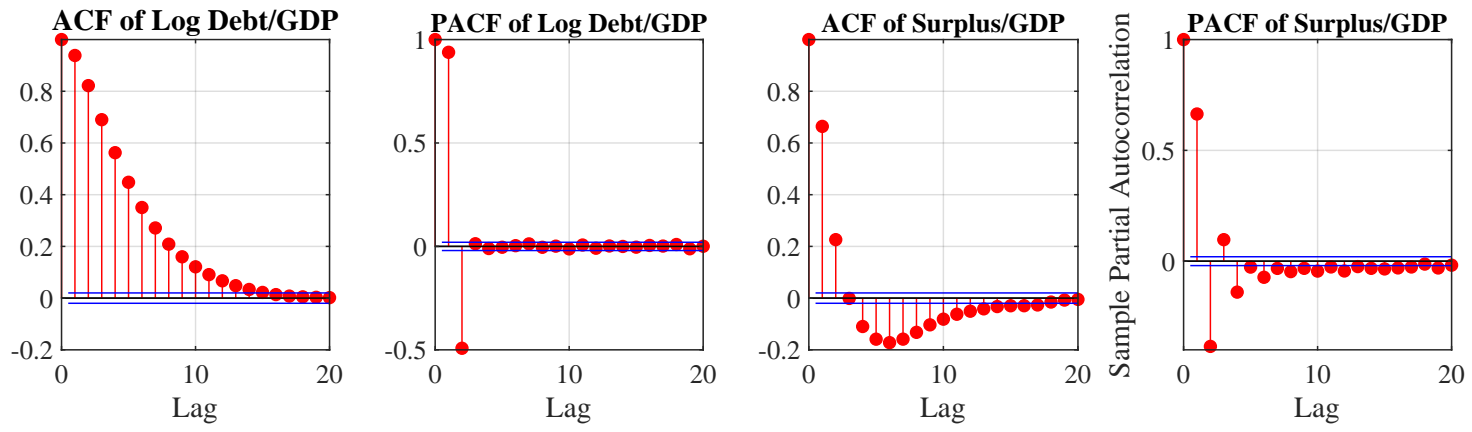


\section{Table A1: Benchmark Calibration for U.K.}

\begin{tabular}{lrl}
\hline & Panel A: Preferences and Output Dynamics \\
\hline$\gamma$ & 1 & maximum annual Sharpe ratio \\
$\rho$ & $4.16 \%$ & real rate \\
$\mu$ & $2.2 \%$ & mean of growth rate of output \\
$\sigma$ & $5.0 \%$ & std. of growth rate of output \\
& Panel B: Debt/Output Ratio Dynamics \\
\hline \multicolumn{4}{c}{$1.27 \times \sigma$} & sensitivity of debt/output to output innovations \\
$d=\exp \left\{\phi_{0} /\left(1-\phi_{1}-\phi_{2}\right)\right\}$ & 0.73 & mean of debt/output \\
$\phi_{1}$ & 1.50 & AR(1) coeff of debt/output \\
$\phi_{2}$ & -0.53 & AR(2) coeff of debt/output \\
\hline \multicolumn{4}{c}{} \\
\hline$\beta^{g}$ & $0.88 \times \sigma$ & sensitivity of spending/output to output innovations \\
$\varphi_{1}^{g}$ & 1.17 & AR(1) coeff of spending/output \\
$\varphi_{2}^{g}$ & -0.26 & AR(2) coeff of spending/output \\
$x=\exp \left\{\varphi_{0}^{g} /\left(1-\varphi_{1}^{g}-\varphi_{2}^{g}\right)\right\}$ & 0.3069 & mean of govt. spending/output \\
\hline
\end{tabular}

Figure A2 plots scaled cash-flow betas for spending, $\beta_{t}^{G, C F}(h) \times \frac{\operatorname{var}_{t}\left[M_{t+1}\right]}{\mathbb{E}_{t}\left[M_{t+1}\right]}$, in the top panel, and the implied tax revenue betas, $\beta_{t}^{T, C F}(h) \times \frac{\operatorname{var}_{t}\left[M_{t+1}\right]}{\mathbb{E}_{t}\left[M_{t+1}\right]}$, in the bottom panel, for a range of values of the cyclicality of spending $b_{g}$ in equation (8). As government spending becomes more counter-cyclical, the short-term risk premium on the spending claim declines. The short-term risk premium on the tax claim has to decline as well in order to keep the government debt risk-free. As the tax claim becomes more counter-cyclical, taxpayers face a riskier tax liability proposition. As the governments provides more insurance to transfer recipients, this reduces the scope for insurance of taxpayers.

\section{Figure A2: Varying the Counter-cyclicality of Spending}

This figure plots the scaled cash-flow beta of spending $\beta_{t}^{G, C F}(h) \times \frac{\operatorname{var}_{t}\left[M_{t+1}\right]}{\mathbb{E}_{t}\left[M_{t+1}\right]}$ in the top panel and the implied tax revenue betas, $\beta_{t}^{T, C F}(h) \times \frac{\operatorname{var}_{t}\left[M_{t+1}\right]}{\mathbb{E}_{t}\left[M_{t+1}\right]}$, in the bottom panel for a range of values of the cyclicality of spending $b_{g}$.
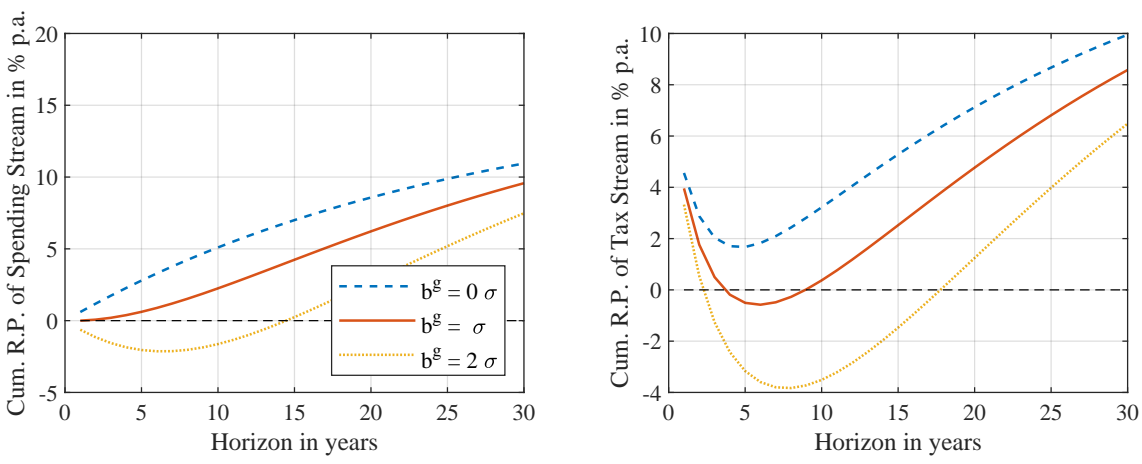


\section{Entropy Bounds}

Proposition I.1. In the absence of arbitrage, the entropy of the SDF $M_{t+1}=\frac{\Lambda_{t+1}}{\Lambda_{t}}$ puts an upper bound on the expected log excess returns:

$$
L_{t}\left(\frac{\Lambda_{t+1}}{\Lambda_{t}}\right) \geq \mathbb{E}_{t} \log R_{t+1}-\log R_{t+1,1}
$$

Proof. See Backus et al. (2014) for a comprehensive proof. We start from the definition of the conditional entropy of the SDF:

$$
L_{t}\left(\frac{\Lambda_{t+1}}{\Lambda_{t}}\right)=\log \mathbb{E}_{t} \frac{\Lambda_{t+1}}{\Lambda_{t}}-\mathbb{E}_{t} \log \frac{\Lambda_{t+1}}{\Lambda_{t}}=-\mathbb{E}_{t} \log \frac{\Lambda_{t+1}}{\Lambda_{t}}-\log R_{t+1,1} \geq \mathbb{E}_{t} \log R_{t+1}-\log R_{t+1,1}
$$

No arbitrage implies that: $\mathbb{E}_{t}\left[\frac{\Lambda_{t+1}}{\Lambda_{t}} R_{t+1}\right]=1$. Using Jensen's inequality, we obtain that: $0=\log \mathbb{E}_{t}\left[\frac{\Lambda_{t+1}}{\Lambda_{t}} R_{t+1}\right] \geq \mathbb{E}_{t} \log \left(\frac{\Lambda_{t+1}}{\Lambda_{t}} R_{t+1}\right)$. As a result, the return $1 / M_{t+1}$ the highest $\log$ return: $\mathbb{E}_{t} \log \frac{\Lambda_{t}}{\Lambda_{t+1}} \geq \mathbb{E}_{t} \log R_{t+1}$.

Proposition I.2. If the pricing kernel is not subject to permanent innovations, then the highest expected log return asset is the longest maturity zero-coupon bond.

Proof. The return on a k-period zero coupon bond is given by: $\lim _{k \rightarrow \infty} \frac{\mathbb{E}_{t+1} \Lambda_{t+k+1}}{\Lambda_{t+1}} / \frac{\mathbb{E}_{t} \Lambda_{t+k}}{\Lambda_{t}}$. The expected log bond return is given by: $\lim _{k \rightarrow \infty} \mathbb{E}_{t} \log \frac{\mathbb{E}_{t+1} \Lambda_{t+k+1}}{\Lambda_{t+1}} / \frac{\mathbb{E}_{t} \Lambda_{t+k}}{\Lambda_{t}}$. The pricing kernel has no permanent innovations if and only if: $\lim _{k \rightarrow \infty} \mathbb{E}_{t} \log \frac{\mathbb{E}_{t+1}\left[\Lambda_{t+k}\right]}{\mathbb{E}_{t}\left[\Lambda_{t+k}\right]}=0$. If there are no permanent innovations, then the expected log return on the long bond is given by: $\mathbb{E}_{t} \log \frac{\Lambda_{t}}{\Lambda_{t+1}}$.

If $M$ is conditionally log-normal, the expected log excess return on a long position in the longest maturity bonds is (Alvarez and Jermann, 2005)

$$
h_{t}(\infty)=\lim _{k \rightarrow \infty} \mathbb{E}_{t} r x_{t+1}^{k}=(1 / 2) \operatorname{Var}_{t}\left(m_{t+1}\right) .
$$

